HIAS-E-36

\title{
Long-run Consequences of Exposure to Natural Disasters
}

\author{
Krzysztof Karbownik \\ Institute for Policy Research, Northwestern University \\ Anthony Wray \\ Hitotsubashi Institute for Advanced Study, Hitotsubashi University
}

November 2016

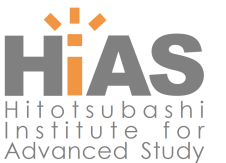

Hitotsubashi Institute for Advanced Study, Hitotsubashi University 2-1, Naka, Kunitachi, Tokyo 186-8601, Japan

tel:+81 425808604 http://hias.ad.hit-u.ac.jp/

HIAS discussion papers can be downloaded without charge from: http://hdl.handle.net/10086/27202

https://ideas.repec.org/s/hit/hiasdp.html

All rights reserved. 


\title{
Long-run Consequences of Exposure to Natural Disasters*
}

\author{
Krzysztof Karbownik ${ }^{\dagger} \quad$ Anthony Wray
}

November 5, 2016

\begin{abstract}
We utilize the individual-level World War I Draft Registration Cards matched to late-nineteenth century hurricane paths and the 1940 U.S. Census to explore whether fetal and early childhood exposure to stress caused by hurricanes affects human capital development and labor market outcomes in adulthood. Difference-in-differences estimates indicate that white males who were born in the South and experienced a hurricane either in utero or as infants had lower income at ages 42 to 53 . They are robust to alternate specifications of either the treatment or outcome variables, as well as changes in the tolerance for imperfectly matched historical data.
\end{abstract}

Keywords: Prenatal stress, natural disasters, labor market outcomes

JEL Codes: I10, J24, Q54

\footnotetext{
"We thank David Dranove, Joe Ferrie, David Figlio, Joel Mokyr, Kjell Salvanes, and numerous seminar and conference participants at Hitotsubashi University, Northwestern University, FAU Erlangen-Nurnberg, the 2014 Early Life Conference at the University of Michigan, the 2014 Canadian Economic Association Annual Meeting, the 2016 SOLE Annual Meeting, and the 2016 Early Childhood Inequality Workshop for valuable suggestions that helped to improve the paper. Karbownik and Wray acknowledge support from the Japan Society for the Promotion of Science KAKENHI Young Scientists B Grant Number J160100115 (PI: Wray) and the Hitotsubashi Institute for Advanced Study (HIAS) at Hitotsubashi University, as well as the Northwestern University Economics Department's Center for Economic History and Eisner Fund, and Wray acknowledges support from the Canadian Economic Association.

${ }^{\dagger}$ Institute for Policy Research, Northwestern University. E-mail: krzysztof.karbownik@northwestern.edu

${ }^{\ddagger}$ Hitotsubashi Institute for Advanced Study, Hitotsubashi University. E-mail: anthony.wray@r.hit-u.ac.jp
} 


\section{Introduction}

There is a growing consensus that healthy fetal development has a positive relationship with the level of subsequent health, educational, and labor market outcomes (Barker 1995; Black et al. 2007; Almond and Currie 2011; Figlio et al. 2014; Bharadwaj et al. 2016). Furthermore, a large body of evidence has documented that sizable and severe in utero health insults, such as a global flu epidemic (Almond 2006; Lin and Liu 2014) and nuclear fallout (Almond et al. 2009), can affect exposed individuals over a long time horizon. However, with the exception of recent studies that examine airborne pollution (Isen et al. 2016) and seasonal influenza (Schwandt 2016), much less is known about the broad economic consequences of milder shocks caused by more typical events, such as low intensity hurricanes.

Yet, a number of factors make the long-run consequences of hurricanes a concern for policymakers. First, the rise in the number of storms and storm-days in the North Atlantic basin over the past few decades (Webster et al. 2005) suggests that the individual probability of exposure to storms has increased. Second, a large fraction of children around the world now face the risk of prenatal exposure to these recurring events. In the U.S. context, 9 to 14 percent of births from 1992 to 2010 occurred in coastal shoreline or watershed counties along the southern Atlantic coast, which is vulnerable to hurricaneforce winds. ${ }^{1}$ Third, exposure to tropical cyclones has been shown to lower a country's growth and productivity in the long run (Hsiang and Jina 2014).

This paper investigates the short- and long-run effects of in utero and early childhood exposure to low intensity (Category 1 and 2) hurricanes that affected the U.S. South during the late-nineteenth century. Our primary contribution to the literature is to provide evidence that prolonged maternal stress, caused by relatively commonplace events that may occur during pregnancy, leads to long-term effects on individual productivity. Maternal stress during pregnancy can have harmful consequences for the neurodevelopment of a child, as several biology studies have hypothesized, based on evidence of raised levels of the stress hormone, cortisol (Glover et al. 2010). Evidence from siblings indicates that in utero exposure to elevated cortisol is associated with a reduction in years of schooling through its effect on a child's IQ and health (Aizer et al. 2016). Hurricanes are stressful events not only for pregnant women, but also for the population at large. Psychology studies document experiences of post traumatic stress disorder (PTSD) and psychological distress (PD) among individuals affected by natural disasters (Galea et al. 2007; Paxson et al. 2012), and show that these conditions persist anywhere from 30 days to at least 2 years following the event, depending on the intensity (Galea et al. 2005; 2007).

When it comes to low intensity hurricanes, the quasi-experimental treatment will operate primarily through prolonged stress induced by uncertainty, loss of normalcy, or temporary displacement from unanticipated and potentially life-threatening natural phenomena (Badakhsh et al. 2010), rather than major destruction to property and infrastructure, or long-lasting disruption to economic activity. Prenatal stress induced by hurricanes (Currie and Rossin-Slater 2013) is distinct from environmental toxins (Isen

\footnotetext{
${ }^{1} \mathrm{~A}$ coastal shoreline county is defined as a county directly adjacent to the open ocean or major estuaries, while a county is considered a coastal watershed county if at least 15 percent of the county overlaps a coastal watershed, or at least 15 percent of a coastal watershed is contained within the county (Ache et al. 2015). Alternatively, if we consider hurricane-prone areas of the eastern U.S. as defined by the American Society of Civil Engineers (ASCE) based on the occurrence of winds in excess of 90 mph, then 15 to 17 percent of children were at risk of fetal exposure to hurricanes among births between 1992 and 2010.
} 
et al. 2016) and infectious disease (Schwandt 2016) as a pathway linking the mild shock of recurring events to fetal programming and neonatal health. ${ }^{2}$ Existing evidence on the persistent effects of prenatal stress is mixed, with Black et al. (2016) documenting no long-run consequences, and Persson and RossinSlater (2016) finding adverse effects on mental health. However, since these studies are based on the acute trauma of family bereavement, it is not clear whether the consequences of prolonged prenatal stress for fetal programming translate into influences on adult well-being.

This paper links newly collected population-level war registry data to spatial data on hurricane tracks and complete-count census data to study the long-run educational and labor market effects of in utero and early-life exposure to hurricanes. We follow individuals born between January 1887 and August 1897, and exposed to hurricanes between June 1885 and October 1899, until they were aged 42 to 53 at the time of the 1940 U.S. Census. We use a difference-in-differences identification strategy in which the first difference is a comparison of individuals exposed to a hurricane in utero to those born before or after a storm, and the second is a comparison between those born in exposed and surrounding locations.

We find evidence that exposure to hurricanes while in utero and during infancy had negative effects on the labor market outcomes of white Southern males. In the preferred specification, we estimate a decrease in income of 7.5 percent for those exposed to hurricanes while in utero, and 5.1 percent for those exposed during infancy before the age of 6 months. The magnitude of the in utero exposure effect on income is larger than Black et al. (2013) and Isen et al. (2016), comparable to Almond (2006), and smaller than Schwandt (2016). The labor market deficiencies, albeit smaller, remain even after accounting for educational attainment. When we examine hurricane exposure by trimester of pregnancy, we find an effect of first trimester exposure on educational attainment and income, while third trimester exposure affects income and full time employment. We find little evidence that the long-run effects were mediated by migration in response to the disasters. While data and institutional concerns necessitate the focus on the white population for the long-run outcomes, we expect hurricanes to also have a negative effect on the underprivileged black population. We document that in utero and age 0 to 6 month exposure to hurricanes were associated with increased mortality for blacks but not for whites, when we use the male-to-female gender ratio in 1900 as a proxy for mortality from hurricane exposure.

This project also contributes to a growing literature that examines the consequences of in utero and early life exposure to natural disasters for socioeconomic and health outcomes. Recent work has shown the effects of hurricanes on birth outcomes (Simeonova 2011; Currie and Rossin-Slater 2013; de Oliveira and Quintana-Domeque 2016), infant mortality (Antilla-Hughes and Hsiang 2013), early schooling outcomes (Fuller 2014; Deuchert and Felfe 2015), and health (Sotomayor 2013; Tseng 2016). Similarly, earthquakes have been found to affect infant mortality and birth outcomes (Torche 2011; Liu et al. 2015), in addition to completed education (Caruso and Miller 2015). ${ }^{3}$ Several of these studies have pointed to prenatal stress as a potential mechanism, but we are the first to provide evidence of persistent

\footnotetext{
${ }^{2}$ Almond et al. (2015) also study a moderate and relatively common distruption to fetal health - nutritional deficiency due to maternal fasting during the month of Ramadan — and examine effects on academic performance at age 7.

${ }^{3}$ Other environmental shocks experienced during pregnancy include rainfall that led to positive changes in income through improved agricultural output (Maccini and Yang 2009), Dust Bowl erosion that resulted in poor economic conditions (Cutler et al. 2007; Arthi 2015), and wildfires that caused a deterioration in air quality (Jayachandran 2009). A parallel stream of the literature focuses on the role of fetal exposure to famine (Lindeboom et al. 2010) and alcohol (Nilsson, 2016).
} 
effects on later-life labor market outcomes. Importantly, our data identify birth location at a much finer level of geography than some of the aforementioned papers, reducing measurement error in the assignment of exposure to a disaster. Finally, given that our data contain information on the exact date of birth, our results provide a cleaner distinction between the effects of shocks to fetal and infant health.

Our analysis also provides a counterpoint to studies that find short-run benefits for survivors of natural disasters and affected communities when examining the contemporaneous implications of positive mortality selection (Ho et al. 2016) and labor market responses to natural disasters (Deryugina et al. 2014; Groen et al. 2016). Similarly, potential medium-run gains can arise due to induced migration (Nakamura et al. 2016), and the transfer of wealth that occurs when disaster relief flows into affected regions (Deryugina 2016). These immediate effects ignore the potential negative and long-lasting consequences of exposure to natural disasters for vulnerable populations such as developing fetuses and young children. Evidence that prenatal stress induced by hurricanes is linked to adverse labor market outcomes may explain in part the macroeconomic consequences of environmental disasters documented by Hsiang and Jina (2014). Thus, by failing to account for in utero and early childhood insults that persist into adulthood, assessments of the overall consequences of environmental shocks may be misleading.

\section{Data and descriptive statistics}

In the absence of radar and satellite technology at the end of the nineteenth century, the hurricane forecasting and warning system was largely ineffective. Large cities had limited advanced notice of an incoming storm, while hurricanes often hit rural areas with no warning. Beginning in 1870, the U.S. Army Signal Corps developed a network of meteorological reporting stations linked by telegraph in order to collect meteorological information and provide storm warnings. However, the reliability of the hurricane warning system was compromised by the frequent breakdown of telegraph lines when a storm made landfall (Barnes 1998, pp. 34, 37, 66-67). Moreover, ships recorded the position of storms at sea, but without ship-to-shore telegraph technology, warnings usually could not be communicated to the weather stations until ships docked at a port. Even though the forecasting and advanced warning of storms was often ineffective, the meteorological data was collected ex-post and preserved, allowing for the reconstruction of storm paths over one hundred years later.

\subsection{Principal data sources}

Our paper brings together data on historical hurricane paths, the date and place of birth for the near universe of males born in the U.S. during the late-nineteenth century from World War I draft records, in addition to education and labor market outcomes from the complete-count records of the 1940 U.S. Census of Population.

We reconstruct the paths of all Atlantic-basin hurricanes that made continental U.S. landfall between June 1885 and October 1899 from the HURDAT2 database of "best track" estimates. Table O1 lists the twenty-six hurricanes that occurred during this period, along with the landfall date, the maximum category of strength and the maximum wind speed recorded over land, as well as the states exposed to 
each storm. It also lists the four hurricanes that passed within 30 kilometers of the continental U.S. during the sample period, which were close enough to affect coastal areas. The HURDAT2 database contains a standardized set of latitude and longitude coordinates for the location of a storm every six hours, in addition to the wind speed, direction, and speed of the storm at each coordinate, which are estimated from storm observations in historical sources (Fernández-Partagás and Diaz 1996; Landsea and Franklin 2013). Although the database contains coordinates for all storms that matched or exceeded the intensity of tropical depressions, we restrict attention to coordinates with a recorded wind speed of at least 120 kilometers per hour, which is the minimum threshold for a hurricane. ${ }^{4}$ It is important to note that our sample consists almost entirely of Category 1 and 2 hurricanes (approximately 60 and 40 percent of the sample, respectively), which are typically not strong enough to cause long-lasting destruction of property and infrastructure. However, these storms are powerful enough to cause damage to rooftops, and can lead to fatalities from flooding and collapsed trees.

We obtain the date of birth and detailed place of birth from the database of U.S. World War I Draft Registration Cards. ${ }^{5}$ When the U.S. entered World War I in May 1917, all male residents between the ages of 18 and 45 were required to register for the draft regardless of citizenship status. The First and Second Registration waves contain the draft cards for the near universe of the June 1886 through August 1897 male birth cohorts. We are unable to make use of the Third Registration, which covered males born between 11 September 1897 and 12 September 1900 as well as those born between 11 September 1872 and 5 June 1886, because it did not request individuals to report place of birth. We extract the records of approximately two million individuals born between January 1887 and August 1897 in one of nine Southern states: Alabama, Florida, Georgia, Louisiana, Mississippi, North Carolina, South Carolina, Texas, and Virginia. None of the hurricanes in our sample passed over any other state as hurricanestrength storms, although some of them continued inland as tropical storms or depressions. ${ }^{6}$

We assign latitude and longitude coordinates to the places of birth in the WWI records by matching place name strings to the universe of U.S. physical and cultural geographic features in the Geographic Names Information System (GNIS), a database developed by the U.S. Geological Survey (2014). Since the GNIS database contains many non-unique feature names, some of which did not exist during the nineteenth century, we use residential locations from a sample linking WWI records to the 1900 census to identify matches to features in the correct counties. We account for changes in county boundaries over time by assigning all coordinates to the county in which they were located in 1880 , the most recent census year prior to the sample period. ' The main analysis sample restricts attention to individuals in the WWI records with non-missing city or town of birth, and excludes those who reported only the county

\footnotetext{
${ }^{4}$ See Appendix A.1 for more details on the construction of the hurricane tracks.

${ }^{5}$ Historical population census records typically asked respondents to report their age in years on the day of the census, and thus are not useful in determining an individual's in utero period. We are not aware of any other data source that reports the exact date of birth and within-state place of birth for the cohorts of interest.

${ }^{6}$ Specifically, the records only include individuals born up to 24 August 1897 since younger individuals were not recorded until later registrations. The Second Registration also covered individuals born in 1886 after 6 June, but we exclude the 1886 birth cohort due to under-registration. See Appendix A.2 for more details on the timing and coverage of the registration waves for the World War I draft.

${ }^{7}$ See Table $\mathrm{O} 2$ for a summary of match rates and Appendix A.2 for more details on the procedure used to match the birth locations reported in the WWI records to the GNIS file.
} 
of birth. We also geocode birth locations with the coordinates of the county centroid, which allows for a larger sample at the cost of precision in the assignment of exposure. Our results remain significant when hurricane exposure is defined at the county level, though they are smaller in magnitude (Table A1).

A map shown in Figure 1 displays the locations surrounding the paths of hurricanes that hit the Gulf Coast and Eastern seaboard of the U.S. (from Texas to Florida and as far north as Virginia) between 1885 and 1899. The green circles denote individuals born in locations ever within 30 kilometers of any point along a hurricane path during our sample period, and red circles denote birth locations ever within 30 to 100 kilometers of a sample period storm path, while the diameter of the circles represents the sample size at each location. We follow the previous literature (Weatherford and Gray 1988; Currie and RossinSlater 2013) in choosing a 30-kilometer-radii band to represent the "eyewall," which is the area, 30 to 60 kilometer in diameter around the eye of the storm, with the strongest winds and heaviest rainfall. Given that many hurricane tracks overlap or pass in close proximity to a previous storm, 57 percent of individuals in the main estimation sample were born in locations within 100 kilometers of multiple hurricane paths during the sample period. Thus, a subset of individuals in the sample will be treated by one storm and form part of the control group for individuals exposed to another storm.

We extract long run outcomes from the 1940 U.S. Census of Population complete count file for individuals in our sample, who were ages 42 to 53 on the day of enumeration, 1 April. The 1940 census is valuable since it is the first, and only publicly available, U.S. census to report (annual) individual wage and salary income (for 1939), and years of completed education, but it also has limitations. The census reveals very little about an individual's business, farm, or self-employment income, given that respondents were only asked to indicate "yes" or "no" in response to whether they had at least $\$ 50$ in non-wage income. This limitation is of particular concern for our sample, in which 76 percent of individuals employed in agriculture and 36 percent of those in the labor force do not report any wage income.

We take a number of approaches to remedy the missing data problem. In our primary analysis, we construct a measure of total income that combines reported wage and salary income with a predicted value for self-employment (business and farm) income based on estimating 1950 self-employment income as a function of age, completed years of education, as well as state, county, industry code, and occupation code fixed effects for white males aged 39 to 56. We use the IPUMS 1-percent sample of the 1950 U.S. Census (Ruggles et al. 2015) and follow the procedure implemented by Feigenbaum (2015b), which we describe in more detail in Appendix A.3. While our baseline sample from the WWI draft records contains individuals who would be ages 42 to 53 when enumerated in the 1940 census, we extend the age range for imputing income to account for misreporting of age in the 1940 census. In Section 4.1, we show that the results are robust to alternative specifications of the dependent variable, such as restricting attention to only the wage and salary income reported in the 1940 census, using occupational earnings and education scores, and trimming the tails of the income distribution. We also take the number of weeks worked in 1939 and construct an indicator for working at least fifty weeks, which represents a proxy for full-time employment, to study effects on the extensive margin of labor supply.

From the 1940 census we also use the years of completed education and an indicator for middle school graduation as measures of educational attainment. The census question on education asked enumerators 
to report the highest grade successfully completed by an individual, but they were also directed to report the number of years in school when the highest grade was unknown. Margo (1986) provides evidence that blacks and whites interpreted the question differently, particularly older blacks educated in ungraded schools. Since we study older cohorts we cannot escape this measurement issue, and choose to drop blacks from the main analysis to minimize this and other potentially problematic factors outlined in Section 1.3.

\subsection{Data linkage}

We begin with the population of records from the January 1887 through August 1897 birth cohorts in the WWI Draft Registration Cards database with non-missing first name, last name, state of birth, and date of birth, excluding records that only report a first or last initial. We also extract all males aged 39 to 56 with non-missing first name, last name and state of birth from the 1940 U.S. Census of Population complete count file. We follow the procedure in Parman (2015) and construct the Phonex codes for the first and last names in each data set, which enables us to allow for differences in the spelling of phonetically similar names across data sets that might arise from typographical errors and changes in the spelling of names. ${ }^{8}$ Prior to the implementation of the matching algorithm, we perform a "blocking" step in which the two data sets are joined using four blocking variables: the Phonex code of the first and last names, age in years when enumerated in the 1940 census, and state of birth (Christen 2012). The matching algorithm draws on elements of the procedures pioneered by Ferrie (1996) and utilized by Abramitzky et al. (2012), Feigenbaum (2015a), and Mill and Stein (2016). It proceeds as follows:

1. Drop all pairs of WWI-1940 observations that do not have matching Phonex codes or state of birth, while allowing discrepancies in the reported age of up to 3 years.

2. Compute the Jaro-Winkler score between the first names and last names in each pair of observations. Discard all pairs with a Jaro-Winkler score less than 0.7 for either the first or last name. ${ }^{9}$

3. For each record in the WWI data set, determine the maximum Jaro-Winkler score averaged over the first and last names, and the minimum discrepancy in age among all 1940 records identified in Step 2. Count the number of records in the 1940 census with a Jaro-Winkler score $\left(J_{s}\right)$ satisfying $(1+0.1) J_{s} \geq \bar{J}$, where $\bar{J}$ is the Jaro-Winkler score of the best match, and having a reported age within one year of the closest match.

4. Drop all pairs of WWI-1940 observations with a discrepancy in reported age greater than the minimum discrepancy across all 1940 records matched to a given WWI record.

5. Drop any remaining pairs of WWI-1940 records with a Jaro-Winkler score $\left(J_{s}\right)$ satisfying $(1+$ 0.1) $J_{s}<\bar{J}$, where $\bar{J}$ is the Jaro-Winkler score of the best match.

\footnotetext{
${ }^{8}$ See Nix and Qian (2015) and the supplemental materials to Parman (2015) for discussions of the Phonex algorithm.

${ }^{9}$ The Jaro-Winkler score has become the preferred string distance measure among economic historians linking names across census databases because it places greater weight on characters that match at the beginning of a string (Feigenbaum 2015a; Mill and Stein 2016). Jaro-Winkler scores range from 0 to 1, where a score of 0 indicates no common letters, while a score of 1 indicates a perfect match. For more details on the Jaro-Winkler method, and other string comparison algorithms, see Christen (2012).
} 
6. Keep all pairs of WWI-1940 records with a Jaro-Winkler score greater than 0.9 averaged across the first and last name, that satisfy the following conditions: each WWI record has a unique match in the 1940 census, and each 1940 census record has a unique match in the WWI records.

We perform similar analysis for matching the WWI records to the 1900 census to examine short-run migration patterns in response to hurricanes, and other robustness exercises.

Table 1 presents the linkage rates from the WWI draft records to the 1900 and 1940 censuses (in panels A and B, respectively) for all U.S.-born males, and separately for Southern and non-Southern states, ever-treated locations (within 0 to 30 kilometer-radii bands around the storm tracks) and control areas (30 to 100 kilometers away), and finally individuals exposed in utero to hurricanes. The overall match rate to the 1940 census is about 33 percent, which is similar to rates that have been documented by previous studies and are considered standard in the literature. ${ }^{10}$ When matching the WWI records to the 1900 census, we observe a lower rate of multiple matches ( 10 percent in comparison to 28 percent for the 1940 census), and a higher rate of failing to find any potential match (53 percent compared to 39 percent), which are consistent with the use of additional and more precise information on date of birth in the 1900 census. ${ }^{11}$

The match rate to the 1940 census is also higher outside the South than in the South (36 percent versus 24 percent), but match rates are similar across Southern states in our sample, ranging from about 21 percent (Georgia and South Carolina) to about 28 percent (Florida). The match rates for individuals exposed in utero to the hurricanes are very similar to individuals born in the same locations before or after the storms, while those born in surrounding counties (30 to 100 kilometers away) are matched at slightly higher rates. The match rates are based on samples that pool together blacks and whites, because the race variable has not been transcribed in the electronic version of the WWI records (National Archives and Records Administration, n.d.). The overall regional differences in the likelihood of matching individuals across censuses likely overstates differences in the white population that is the focus of our analysis.

As shown in Figures A1a and A1b, the match rate exhibits seasonality, though the variation is small compared to the difference between the South and non-South. More crucially, we do not observe any trend in the match rates by year of birth. Figures A1c and A1d indicate that the match rate has an inverse U-shape relationship with commonness of name, as we are less likely to match the least common names - many of which will be typographical errors - and the most common names.

\footnotetext{
${ }^{10}$ The linkage rates found by Abramitzky et al. (2012), Collins and Wanamaker (2014), Long and Ferrie (2013), and Mill and Stein (2016) using similar matching algorithms are approximately 30 percent, 21 percent, 22 percent, and 11 to 34 percent, respectively. Other studies have found considerably higher match rates by manually linking data sets or by including multiple matches. Feigenbaum (2015b) uses training data and a machine learning algorithm to achieve a match rate of 56 percent, while Nix and Qian (2015) obtain match rates ranging from 61 to 67 percent by randomly selecting a record among multiple potential matches to augment samples of unique matches. We are unable to apply the matching method of Feigenbaum (2015b) due to a lack of the training data. While others have developed methods for incorporating multiple matches into the estimation sample in cases where there are multiple potential outcome variables (Bugni et al. 2014; Nix and Qian 2015), or multiple potential explanatory variables (Poirier and Ziebarth 2016), neither approach is suitable for the present application, in which the sample of matches from the WWI records to the 1940 census contains non-uniqueness for both outcome and explanatory variables.

${ }^{11}$ The 1900 census reports month and year of birth, whereas the 1940 census only reports the age in years on the day of the census. Give that the WWI records were created in 1917 and 1918, the database is linked back in time to the 1900 census, and matched forward in time to the 1940 census.
} 


\subsection{Sample selection}

Our main analysis deals exclusively with white males, given the presence of a racially segregated labor market in the U.S. in 1940 and concerns that census questions about educational attainment and labor market outcomes may have been interpreted and enumerated differently by race. ${ }^{12}$ Carruthers and Wanamaker (2016) attribute the majority of racial wage inequality during this period to lower human capital and the inferior quality of separate but unequal schools for blacks, which can be traced back to public sector discrimination and local control of schools. Regardless of the underlying cause of the differences, the data on education and income are ultimately not consistent between races.

After restricting attention to white males matched from the WWI records to the 1940 census, we exclude a subset of observations for which we are unable to identify the latitude and longitude coordinates of the birth city or town. In 7.9 percent of cases in the baseline matched sample, the birth place is only known at the county level, while 14.7 percent of the baseline sample is excluded when a county has the same name as a city or town in a different county of the same state. We also exclude an additional 13.7 percent of the sample when the place of birth cannot be distinguished between the name of a city and the county in which it is located. ${ }^{13}$ After we restrict attention to individuals with geocoded birth locations, we are left with 82,024 observations. We exclude a small set of individuals born in Dade and Monroe counties, at the southern tip of Florida, because there are no suitable control locations in the surrounding area that were not exposed to storms.

The next set of sample restrictions relate to the characteristics observed in the 1940 census. After excluding individuals with missing outcome variables (total income and weeks worked) and years of education, about 27.6 percent of the remaining sample, we are left with 58,979 observations. We also drop 128 individuals who were working in non-standard occupational categories (military and religious orders), incarcerated or residing in institutional care, engaged in housework, or enrolled in school, leaving us with 58,851 observations in the main analysis sample. We impute zero income for individuals who were out of the labor force with zero wage and salary income, non-wage income below $\$ 50$, and no reported occupational or industry category. All in all, due to missing data and sample restrictions, we utilize 45.7 percent of the 128,821 white males linked from the WWI records to the 1940 census who were born within 100 kilometers of a hurricane path during the sample period.

Table A2 examines, in a regression framework, whether exposure to hurricanes affects the probability of successfully matching a WWI draft record to U.S. census records. In column 1 the dependent variable is an indicator for a unique match from the WWI draft records to the 1900 census, in column 2 it is an indicator for more than one match, and in column 3 it takes the value one for the subset of unique matches used in the estimation of migration outcomes (Table 7). Columns 4 and 5 show results for unique and multiple matches of the WWI records to the 1940 census, while column 6 shows estimates for

\footnotetext{
${ }^{12}$ As we discussed in Section 1.1, data quality with respect to the highest grade completed variable is more of an issue for blacks, especially among the cohorts in our sample (ages 42 to 53). We are unable to study outcomes for women since the WWI draft only registered men.

${ }^{13}$ Table O2 reports match rates of birth locations separately for locations ever within 0 to 30 kilometers of the sample period hurricane tracks, and locations 30 to 100 kilometers away (but never within 30 kilometers). For ease of exposition, we discuss overall match rates for the hurricane exposure zone.
} 
the probability of appearing in the main estimation sample (Table 4). In comparison to the descriptive match rates presented in Table 1, the regression results are based on the sample of WWI draft records for which the birth location is known. In general, pre-conception, in utero, and early-childhood exposure to hurricanes have small and statistically insignificant associations with the probability of a unique match, or multiple matches, to either census. Coefficient sizes are at most 0.8 percentage points and are only significant (at the 5 percent level) in two cases for early-childhood exposure when matched to the 1900 census: the probability of multiple matches and the probability of a unique match that appears in the analysis sample. In combination with the descriptive match rates shown in Table 1, this finding suggests that the difference in the match rates for individuals exposed to hurricanes, if any, is small enough that it should not bias the main results.

\subsection{Descriptive statistics}

Table 2 provides some baseline characteristics at the time of the 1880 U.S. Census, the closest preperiod census available, for the population of interest in the nine Southern U.S. states that represent the focus of the analysis. The first column presents averages based on the entire population of U.S.-born males, while the subsequent two columns compare the nine Southern states to the remainder of the U.S. Columns 4 and 5 separate the counties in these nine states into those that were within 30 to 100 kilometers of a storm at some point during the sample period, but never within 30 kilometers (column 4), and those that were ever within 30 kilometers of a storm (column 5). Southern states in 1880 had a larger black population, were slightly more rural, and were poorer that the reminder of the U.S. ${ }^{14}$ Further comparison between column 3, on one hand, and columns 4 and 5, on the other, reveals that the "hurricane zone" sample has, on average, an even higher share of blacks, while the mean occupational status of the white population - the principal focus of this paper - is higher than in the South as a whole.

Although we do not observe much of a difference in terms of occupational status or the urbanization rate between counties in our sample that were ever treated and those that constitute a control group, there is a difference in average farm value and farm size between the two regions. ${ }^{15}$ In particular, the counties that were ever within 30 kilometers of a hurricane between 1885 and 1899 had larger and less valuable farms, on average. Overall, we view the populations of counties that constitute part of the treatment and control groups as comparable in terms of observable characteristics in 1880, six years prior to the beginning of our study period. Since we use a difference-in-differences strategy, level differences across treated and control counties will not bias our results as long as these are constant over time.

Table 3 presents summary statistics for the full population of U.S-born white males, who were aged 42 to 53 in the 1940 census (column 1), as well as for Southern and non-Southern states separately (columns 2 and 3 ). For the purposes of this table, we adopt a definition of Southern states limited to the nine states

\footnotetext{
${ }^{14}$ Individuals are considered urban residents if they resided in cities or incorporated places with at least 2,500 inhabitants (Ruggles et al. 2015).

${ }^{15}$ Average farm value represents the per acre fair market value of farms, including land, fences, and buildings, while average farm size is measured in acres. Both statistics are obtained from the 1880 Census of Agriculture (Walker and Seaton 1880). The census schedules define a farm to include "all considerable nurseries, orchards, and market gardens, which are owned by separate parties, which are cultivated for pecuniary profit, and employ as much as the labor of 1 able-bodied workman during the year." Farms smaller than three acres were not reported unless they sold more than $\$ 500$ in produce.
} 
ever exposed to hurricanes in our sample. Based on these three samples, it is clear that the population in the states that we investigate is different from the rest of the country, and that this pattern is in line with evidence based on the 1880 census provided in Table $2 .{ }^{16}$ In particular, even among whites, individuals in the Southern states included in the analysis are less educated, poorer, and work in occupations with lower status. The subsequent two columns focus on the characteristics of the South and non-South samples that are successfully matched to the database of World War I Draft Registration Cards. As shown in Table 1, we are about 11 percentage points less likely to match individuals residing in the Southern states, but in both sub-samples we match relatively better off individuals. Consequently, our working sample is positively selected from the population, in part due to differential survival rates of individuals with lower socioeconomic status (Ferrie and Rolf 2011).

Columns 6 to 8 focus on the estimation sample, which includes individuals in one of the nine Southern states who were born in locations that were within 100 kilometers of a hurricane path during the sample period. Column 6 presents characteristics of individuals born within a 30 kilometers band of a hurricane path (our preferred distance threshold for exposure), while column 7 describes individuals born in surrounding areas 30 to 100 kilometers away from the storm paths. In column 8, we present descriptive statistics for a subset of individuals, drawn from the sample in column 6, who were exposed to the storm while in utero. The final estimation sample appears to be modestly positively selected in comparison to all counties within the Southern states. The comparison of columns 6 and 7 with column 8, as well as the kernel density plot of total income shown in Figure O1, preview the main results documenting worse labor market outcomes among the individuals exposed in utero.

\section{Empirical framework}

We use a difference-in-differences framework to estimate the effects of in utero and early childhood exposure to hurricanes on long-run outcomes. The first difference compares individuals exposed in utero to those born before and after a hurricane struck a given location, while the second difference compares locations ever exposed to the hurricane path to the surrounding counties. In Figure 1 each circle represents a geographic location in the World War I Draft Registration Cards database, with green circles denoting locations within 30 kilometers of the path of a hurricane-strength storm that occurred during the sample period, and red circles denoting locations 30 to 100 kilometers away. The size of the circles represents the number of observations at each location in the final estimation sample. ${ }^{17}$

Our baseline estimates are obtained from the following regression:

$$
Y_{i b y w}=\alpha_{0}+\alpha_{1}\left(\text { In-utero }_{i b y w}\right)+\beta \mathbf{X}_{\text {ibyw }}+\gamma_{\mathbf{c}}+\delta_{\mathrm{y}}+\pi_{\mathrm{w}}+\varepsilon_{\mathrm{ibyw}}
$$

where $i$ indexes individuals, $b$ indexes birth location, $c$ indexes birth county, $y$ indexes conception years,

\footnotetext{
${ }^{16}$ Note that there is overall improvement in affluence of the "hurricane zone" counties over the 60 years between censuses. For example, the occupational income score improves by about 40 percent.

${ }^{17}$ These locations are overlayed on a map of 1880 U.S. county boundaries. The sum of individuals represented by the green circles corresponds to the sample size reported in column 6 of Table 3, while the sum of individuals represented by the red circles corresponds to the sample size of column 7 in the same table. Figure O2 plots the birth locations and sample sizes of only the individuals exposed in utero (column 8 of Table 3 ).
} 
and $w$ indexes conception weeks. The vector $\mathbf{X}_{\mathbf{i}}$ includes linkage quality measures, an indicator for birth locations ever within 30 kilometers of a hurricane during the sample period, and state specific linear trends. We also include a set of birth county $(\gamma)$, as well as year $(\delta)$ and week $(\pi)$ of conception fixed effects. ${ }^{18}$ In this regression model, the coefficient $\alpha_{1}$ measures the effect of an in utero shock from hurricane exposure on later-life outcomes. The treatment takes on a value of one for individuals who were in utero when a hurricane passed within 30 kilometers of their birth location. We assume that pregnant mothers do not move between exposure and birth, and thus, in our setting, county of conception is equivalent to county of birth. ${ }^{19}$ In all specifications we cluster standard errors by county of birth.

In a second specification, we refine this model by adding indicators for post-storm conception and exposure during post-birth periods, and estimate the following regression:

$$
Y_{i b y w}=\alpha_{0}+\alpha_{k} \sum_{k=-1}^{3}\left(\operatorname{Period}_{i b y w}^{k}\right)+\beta \mathbf{X}_{\mathbf{i b y w}}+\gamma_{\mathbf{c}}+\delta_{\mathrm{y}}+\pi_{\mathbf{w}}+\varepsilon_{\mathrm{ibyw}}
$$

where Period ${ }^{k}$ consists of five indicator variables for exposure to storms: up to one year pre-conception, in utero, between birth and six months, between six and twelve months after birth, and between ages one and two. We divide the first year of life into two six-month periods in order to understand whether the biological effect operates through the mother, child or both. Arguably, the in utero shock affects the fetus only through the mother's experience, while exposure at ages six to twelve months (and age one to two) operates directly through the child's experience. Treatment in the first six months of life can operate both indirectly through the mother (e.g. breastfeeding) and directly through the child's experience.

The identifying assumption underlying the interpretation of the in utero and post-birth exposure coefficients in these equations is that pregnant women, or mothers raising young children, with lower unobserved human capital or propensity to earn income do not differentially relocate to, or away from, areas struck by hurricanes. In other words, the natural disasters are as good as randomly assigned. Although the absence of any baseline characteristics in the WWI records prevents us from providing direct evidence for the exogenous timing of hurricanes, previous research that has used high resolution data has supported this assumption, even in settings with advanced warning and forecasting systems (Currie and Rossin-Slater 2013; Fuller 2014; Deuchert and Felfe 2015). The case for the exogenous timing of hurricanes at end of the nineteenth century is arguably even stronger, given the limited communications and forecasting technology available at the time.

Since we do not observe place of residence, we proxy for it with place of birth when assigning post-birth hurricane exposure status. While this assumption is reasonable during infancy, it becomes increasingly untenable as children age, and thus we refrain from estimating effects of hurricane exposure at older ages. Finally, we interpret the post-storm conception coefficient as a reduced form effect that combines fetal exposure to the potentially depressed economic conditions in the aftermath of a hurricane,

\footnotetext{
${ }^{18}$ The results remain unchanged if we include conception year-by-week fixed effects.

${ }^{19}$ While our baseline estimates utilize county fixed effects, the results are qualitatively similar if we use location of birth fixed effects. These results remain significant, but are less precise, due to the fact that the WWI draft records do not contain a sufficient number of births at relatively small locations to generate meaningful variation. Nonetheless, in all regressions the exposure is defined based on location of birth. We relax this assumption in Table A1 and show results for larger samples that include individuals with birth locations defined at the county level.
} 
and selection due to a differential fertility response of parents or differential migration into and out of areas struck by hurricanes. Since the selection effect could go in either direction, we remain agnostic about the sign of the post-storm conception coefficient.

\section{Main results}

We begin with the main analysis of the causal effect of in utero exposure to natural disasters, for white males, on years of completed education, income, and employment. Then, we extend the analysis to include controls for post-birth exposure and post-storm conception, and differentiate the effects by trimesters of pregnancy and category of the hurricane, before turning to the heterogeneity in the estimates. Next, we estimate the effects on the gender ratio, separately by race, for individuals enumerated in the 1900 U.S. Census, which we view as a proxy for survival to 1900 . We also study potential mediators of the main estimates and report effects on the probability of migrating to different destinations by 1900 or 1940.

Panel A of Table 4 presents estimates of equation 1 for the effects of in utero exposure to hurricanes on long-run outcomes. The first two columns report effects on years of completed education and the probability of middle school graduation. The conditioning variables for these models include birth county fixed effects, conception year and week fixed effects, an indicator for individuals born in locations that were within 30 kilometers of a hurricane during the sample period, linkage quality measures, and state-specific linear trends. ${ }^{20}$ We include these controls in all our main estimates. The first column indicates that average years of completed education decreased by 0.13 years, while the second column shows a 2.3 percentage point ( $\mathrm{pp}$ ) reduction in the probability of graduating from middle school (9th grade). Both are statistically insignificant at conventional levels, but the effect size for middle school graduation suggests a decline in the probability of completion by 6.1 percent.

The third column presents our main result for the effects of in utero exposure on the natural logarithm of total income. The estimate indicates that individuals born in locations within 30 kilometers of a hurricane that occurred during the fetal period earn income in 1939 that is 7.3 percent lower, on average, in comparison to individuals born within 100 kilometers of the hurricane with no fetal exposure to a storm. ${ }^{21}$ This effect size is comparable to the 5 to 9 percent effect of in utero exposure to the $1918 \mathrm{flu}$ pandemic on wages for men (Almond 2006), smaller than the 10 percent reduction in earnings from in utero exposure to seasonal influenza (Schwandt 2016), and larger than the penalties for exposure to radiation (Black et al. 2013) and airborne pollution (Isen et al. 2016). The fourth column documents a statistically insignificant $1.6 \mathrm{pp}$ ( 2.2 percent $)$ decline in the probability of working at least 50 weeks during the year, a proxy for full-time employment. ${ }^{22}$ In columns 5 and 6 we show that the income and employment effects

\footnotetext{
${ }^{20}$ The linkage quality measures include flexible controls for the absolute deviation in the ages reported in the WWI records and the 1940 census, as well as indicators for exact string matches of the first and last names between the two sources. We also flag individuals for whom we impute self-employment income, and individuals whose self-reported wage or imputed selfemployment income are truncated at $\$ 5000$ (1939 USD).

${ }^{21}$ The average age of individuals in the estimation sample when enumerated in the 1940 census is 47.1 years, with ages ranging from 42 to 53 years, based on the birth date reported in the WWI records.

${ }^{22}$ We have also estimated the regression with total income per weeks worked as the dependent variable (Carruthers and
} 
decrease only modestly after we condition on completed years of education. This is likely due to the relatively small and imprecise estimates for the effects on human capital accumulation, and suggests that the decrease in long-run labor market outcomes operates primarily through productivity rather than the accumulation of cognitive skills. ${ }^{23}$

In panel B of Table 4 we extend the analysis to include separate effects of exposure during the first two years after birth, and for individuals conceived up to one year post-storm. We do not find any statistically significant effects on the post-storm conception indicator variable, and the coefficient in the specification with income as the dependent variable is small and positive. On the other hand, we find negative estimates for in utero and early childhood exposure, with the largest effects on income stemming from the fetal period. In the case where the dependent variable is the log of total income, we can reject the null hypothesis of equality of the coefficients across periods. The finding that effects are larger for exposure in utero and at ages 0 to 6 months also supports the hypothesis that mothers potentially play a crucial role in the transmission process. Similar to the results in panel A, we also find negative, but statistically insignificant, coefficients on educational attainment.

Table 5 further expands the analysis with two extensions of the model from panel B of Table 4. First, panel A documents that the effects on income are primarily driven by exposure during the first and third trimesters. ${ }^{24}$ In the regressions with employment as the dependent variable, the third trimester coefficient is the largest, while for education, the first trimester matters the most. Although we cannot reject the equality of the estimates across trimesters, the observed pattern of results is consistent with the fact that neurons in the brain develop rapidly during first trimester, while the fetus grows the most during the third trimester. Thus, if early brain development is more important for educational achievements and cognition, while overall health matters more for labor market productivity (Cunningham et al. 2010; Black et al. 2007), then we would expect to observe such a pattern of results. Similarly, when we control for years of completed education in the income regression, the first trimester coefficient decreases while the third trimester coefficient increases in magnitude, which is also consistent with the first trimester effect operating through cognition and schooling more so than through productivity.

Second, Panel B examines whether the negative effects of in utero exposure are stronger when the fetus is exposed to a more severe storm, where severity is proxied by hurricanes that reach Category 2 intensity or above. ${ }^{25}$ We do not find any statistically significant differences in effects by storm intensity, which may be the case because wind speed is poorly measured, or that Category 1 and 2 hurricanes do not differ substantially in their impact. On the other hand, Figure A4 shows evidence of heterogeneity

\footnotetext{
Wanamaker 2016), and find statistically significant results that are qualitatively similar to our preferred measures.

${ }^{23}$ Since we find much larger effects of hurricane exposure on the probability of middle school completion, we also included the latter as a conditioning variable in place of the flexible years of education controls. We find that the estimated coefficient for income is almost identical to the estimates from the specification with flexible education controls $(-0.058$ compared to -0.060$)$.

${ }^{24}$ The table does not show coefficients on the controls for post-storm conception, exposure at 0 to 6 months, 6 to 12 months, and 1 to 2 years.

${ }^{25}$ We group together Category 2 and 3 hurricanes since the sample only includes one Category 3 hurricane and no hurricanes of greater intensity. The regression also includes interactions of the indicator for hurricanes, that reach Category 2 intensity or above, with each of the remaining hurricane exposure controls: post-storm conception, exposure at 0 to 6 months, 6 to 12 months, and 1 to 2 years. The effects of exposure at ages 0 to 6 months are similar to those found in the main specifications (panel B of Table 4).
} 
in severity of exposure within storms, and suggests that mothers living further away from the storm path experienced a milder shock. The figure plots coefficients on separate indicators for in utero exposure 0 to 10 kilometers, 10 to 20 kilometers, 20 to 30 kilometers, 30 to 40 kilometers, and 40 to 50 kilometers away from the storm path, each from the same regression with log income as the dependent variable. ${ }^{26}$ The indicator for exposure 10 to 20 kilometers away from the hurricane path has the largest negative point estimate, which corresponds to a 10.8 percent reduction in income, while the point estimate is slightly smaller (-9.4 percent) in the 20 to 30 kilometer band further away from the storm path. The coefficient on exposure in the 0 to 10 kilometer band is smaller and statistically insignificant, which reflects the fact that the eye of the storm is relatively calm. The coefficients on in utero exposure decrease monotonically beyond the 30 kilometer-radii band, which is consistent with finding the strongest winds in the "eyewall" of the storm.

Due to data limitations, we cannot perform standard heterogeneity analysis that has typically been explored in similar contexts, such as splitting results by gender, parental education, or race. However, we are able to examine the heterogeneity in the effects of in utero exposure to hurricanes by baseline countylevel urbanization rates and farm values measured in 1880 . We estimate a variant of the specification in panel B of Table 4, in which we include interactions of the birth county urbanization rate with each of the hurricane exposure indicators. For parsimony, panel A of Table A3 only presents the level effect of in utero exposure and the interaction of the in utero exposure coefficient with the urbanization rate. The effect of in utero exposure on log income does not differ substantially across urban and rural counties, which provides suggestive evidence that the main results are not driven by rural counties dependent on agriculture. ${ }^{27}$ Panel B of Table A3 shows results from interacting the effect of in utero exposure to hurricanes with an indicator for whether the average farm value in the birth county was below the median. ${ }^{28}$ We do not find any statistically significant interaction terms. While we cannot definitively conclude that the main results for log income are driven by poorer or wealthier counties, the results are consistent with poorer and more vulnerable populations fairing worse in the long-run.

Thus far, we have examined effects of hurricane exposure on educational attainment and long-run labor market outcomes for white Southern males. In Section 1.3 we pointed out the data quality issues and institutional differences in the labor market by race that preclude the analysis of long-run outcomes for the black population, but for completeness, we show parallel results for the main specifications in Table O3. With the exception of effects on the probability of full-time employment, we do not estimate any significant or sizable effects of exposure to hurricanes for blacks. However, it would be unexpected if the black population did not suffer the consequences of exposure to hurricanes, given that it is characterized

\footnotetext{
${ }^{26}$ The specification also includes indicators for whether a storm passed within each of the distance bands around a birth location during the sample periods, as well as interactions of the distance bands with each of the exposure dummies: conception up to one year post-storm, in utero, age 0 to 6 months, age 6 to 12 months, and age 1 to 2 years.

${ }^{27}$ The mean urbanization rate is 17.9 percent and the median is 0 , indicating that more than half of the individuals in the sample were born in counties that did not have any settlements with a population exceeding 2,500 in 1880 . The interaction of the urbanization rate with in utero exposure is positive and significant in the middle school completion and weeks worked regressions, with the effect sizes for a one standard deviation change in the urbanization rate being 4.1 and $4.9 \mathrm{pp}$, respectively.

${ }^{28}$ The specification also includes interactions of the indicator for below median farm values with each of the remaining hurricane exposure indicators. In most cases, these interaction terms are generally imprecise and are not substantially different across the two groups of farm values.
} 
by a higher rate of poverty compared to the white population.

We examine effects on mortality selection using the male-to-female gender ratio, which has been used to test the hypothesis that male fetuses are more sensitive to external shocks (Trivers and Willard 1973; Norberg 2004; Almond and Edlund 2007). We turn to the 1900 U.S. Census for data on population counts by gender and race, but in the absence of data on birth county we use county of residence as a proxy. Although it is probable that some individuals migrated across county boundaries during the ten-year span, perhaps selectively in response to disasters, if we assume that parents did not have strong gender-specific preferences, then it is likely that the gender ratio is unrelated to storm exposure except through the fetal shock channel.

For the purposes of the gender ratio analysis, we collapse data on the 1886 to 1896 conception cohorts, by race, at the county of residence-by-month of conception level and define the dependent variable as the ratio of males to females. ${ }^{29}$ The regression includes county of birth fixed effects, year and month of conception fixed effects, state-specific linear trends, along with the standard set of exposure controls in equation 2. An observation in the regression is a county of birth-by-conception month cell. We assume that, for all individuals, the conception month is nine months prior to the birth month reported in the 1900 census, and that the county of conception, county of birth, and county of residence are equivalent. We estimate the regression on the set of counties within 100 kilometers of storm paths in our main analysis sample.

Table 6 presents the results beginning with estimates that pool births for blacks and whites in columns 1 and 2. In line with the hypothesized effect, we find fewer males than females surviving until 1900, among those exposed to stress from hurricanes while in utero, with estimates in column 1 and panel B of Table 6 suggesting a $2.7 \mathrm{pp}$ reduction in the gender ratio compared to the mean of 1.074. This effect corresponds to a 1.2 percent decrease in the probability that a child surviving until 1900 was a boy, and is six times the size of the difference between married and unmarried mothers, and twice as large as the difference between mothers with a high school degree and mothers with some college education, estimated by Almond and Edlund (2007). ${ }^{30}$ We also find evidence for a reduction in the gender ratio of $2.6 \mathrm{pp}$ for those exposed up to 6 months of age.

In the second column, we estimate the same specification using individuals conceived in the latter half of the sample period, between 1892 and 1896, to take advantage of the younger cohorts who were less likely to have moved at the time of enumeration in the 1900 census. For the effect of in utero exposure we find a 3.2 pp reduction in the gender ratio in comparison to a mean of 1.063 , which corresponds to a 1.5 percent decrease in the probability that a male child survived until 1900.

In the subsequent columns of the table we present estimates separately by race and show that the

\footnotetext{
${ }^{29}$ More specifically, we include individuals born between January 1887 and August 1897 to match the cohorts used in the analysis of long-run labor market outcomes.

${ }^{30} \mathrm{Almond}$ and Edlund (2007) find that married mothers are 0.2 percent more likely to give birth to sons than unmarried mothers, while mothers who did not graduate high school were 0.6 percent less likely to have a boy than mothers with some college education. At the mean gender ratio of 1.074 , our sample contains 517.9 boys per 1,000 individuals surviving to 1900 . If in utero exposure reduces gender ratio by $2.7 \mathrm{pp}$ to 1.047 , then there will be 511.7 boys per 1,000 individuals alive in 1900 . That corresponds to a 1.2 percent $\left(\frac{517.9-511.7}{517.9} \cdot 100\right)$ reduction in the probability of having a surviving boy. The effect of in utero exposure to hurricanes on the gender ratio in 1900 also corresponds to 55 percent (2.75/4.84) of the effect of the $9 / 11$ terrorist attacks on the gender ratio for children born in New York City (Catalano et al. 2006).
} 
results for exposure in utero and up to 6 months in age are driven by the black population, reflecting higher mortality risk for a more vulnerable individuals with lower socioeconomic status. For blacks, in utero exposure is associated with a $4.8 \mathrm{pp}$ reduction in the gender ratio in 1900 relative to a mean of 1.087, which corresponds to a 2.1 percent decrease in the male survival probability. The corresponding estimates for whites are very small and statistically insignificant, suggesting that the estimates for long-run outcomes are not biased by mortality selection. ${ }^{31}$

In Table 7, we examine whether migration in the aftermath of a hurricane represents a potential mediator of the long-run effects on income (Boustan et al. 2012). In columns 1 to 3, our analysis documents residential location decisions of parents whose children were exposed to hurricanes, with the caveat that we do not observe instances when parents give birth to children after migrating in response to experiencing a hurricane. Furthermore, one channel through which the negative effects on income and employment may arise is a decrease in geographic mobility, and in particular restricted possibilities to migrate out of the South (Collins and Wanamaker 2014; Eichenlaub et al. 2010). Thus, in columns 4 to 6, we investigate migration decisions in adulthood. We consider three migration destinations outside the county of birth: counties within the same state, different states, and states outside the South. ${ }^{32}$

We find small and statistically insignificant effects on the probability of migration by 1900 , which indicates that short-run mobility in response to the disasters is not a significant mediator for the analysis of the long-run outcomes. Similarly, we generally do not find much evidence for effects of exposure to hurricanes on changes in long-run migration patterns. ${ }^{33}$ The only significant coefficients suggest that individuals exposed in utero were about $2.8 \mathrm{pp}$ (10.8 percent) less likely to move outside the state of birth, and that individuals exposed at age 1 to 2 were $1.5 \mathrm{pp}$ ( 15.5 percent) more likely to move outside the South. The remaining estimates are not only insignificant, but also much smaller in magnitude. Overall, the results in Table 7 suggest that in utero exposure to hurricanes was unlikely to have restricted the opportunities of individuals to migrate to locations with better employment and earnings opportunities. ${ }^{34}$

To further examine the potential influence of post-storm selective mortality and fertility, Table O5 shows results based on a sample that excludes individuals conceived after a hurricane, and restricts the control group to individuals born before the storm. The advantage of this specification is that the composition of the control group is not affected by selection due to a migration response or differential fertility in the aftermath of the hurricane. The results are very similar to the main specification in Table 4 with in utero exposure estimated to reduce income by 7.8 percent in the full model of panel B, which indicates that the baseline results are not biased by comparisons to a selective group of individuals conceived in the

\footnotetext{
${ }^{31}$ We find a weakly significant negative effect of post-storm conception and positive effect of exposure at ages 7 to 12 months on the gender ratio, but these estimates are not robust to different specifications of the range of conception years in the sample.

${ }^{32}$ Given that we match the WWI draft records backwards in time to the 1900 census, appearing in the sample is conditional on survival to 1917/18 and registering for the WWI draft. We assume that longevity and registration for the draft are not correlated with the decision to migrate by 1900 . Elsewhere in the paper we have referred to the nine states exposed to hurricanes as the "South," but here we utilize a more standard definition of Southern states. In addition to the nine hurricane states, they include Arkansas, Delaware, Kentucky, Maryland, Oklahoma, Tennessee, and West Virginia.

${ }^{33}$ The results are virtually unchanged when we include flexible controls for years of completed education.

${ }^{34}$ Individuals in our sample who migrated outside their county of birth by 1940 have higher levels of education and income than those who stayed behind. Those who migrated outside their state of birth and those who migrated outside the South have even higher educational attainment and income. When we control for migration status by including indicators for the three migration categories, our results for in utero and age 0 to 6 month exposure are attenuated slightly, but remain significant.
} 
year after a storm.

We have argued that prenatal stress is an important pathway through which in utero exposure to hurricanes can have long-term labor market consequences (Currie and Rossin-Slater 2013). Galea et al. (2005) and Paxson et al. (2012) document increased PTSD and PD prevalence, in the aftermath of natural disasters, that can persist for extended periods of time, while Badakhsh et al. (2010) provide qualitative evidence on the psychological struggles that pregnant women faced in areas affected by hurricane Katrina. The hurricanes observed in our historical sample are not as extreme as the recent Category 4 and 5 hurricanes examined in the stress literature, but in comparison to today, people living in the late-nineteenth century lacked the technology and relief aid to cope with a disaster. Importantly, the stress interpretation does not preclude immediate but temporary disruptions to resource access and everyday routines, in addition to repairable damage to residential structures. However, an alternative channel to rule out, might be poor nutrition and the loss of income due to more extensive destruction of property and infrastructure in the aftermath of the storm.

While we lack systematic data on the damage caused by hurricanes during the late-nineteenth century, we are able to proxy for the potential short-run impact on local economic activity using average county-level farm values available every ten years from the U.S. Census of Agriculture. We present estimates for the relationship between hurricane exposure and farm values in Table O4. The coefficients compare farm values in 1880 (column 1) and 1890 (column 2) to values in 1890 and 1900, respectively, in addition to a comparison of counties within 30 kilometers of a hurricane, during a two-year exposure window, to counties 30 to 100 kilometers away. Although the coefficient of interest is similar to the difference-in-differences estimator that we utilize in the main specification, we give it a more descriptive interpretation because of measurement error in the farm value data and the strong assumption of timeinvariant unobservables across the 10-year spans. Nonetheless, hurricane exposure does not appear to correlate significantly with farm values. The estimates are relatively small in magnitude in comparison to average farm values and inconsistently signed. We thus view this result as suggestive of the fact that the damage caused by relatively mild, Category 1 and 2 hurricanes, did not lead to severe declines in economic activity. It also corroborates our assumption that the primary channel for the long-run effects is the PTSD-type experience of pregnant mothers exposed to hurricanes.

\section{Testing the robustness of the results}

Our empirical objective is to isolate the causal effects of in utero and early childhood exposure to hurricanes on long-run outcomes such as completed education and income. In Section 3 we have documented that selective mortality and migration are unlikely to have had a major confounding effect on the main outcomes of interest. We now consider a series of approaches to test the robustness of the labor market results, which are the primary focus of the paper. ${ }^{35}$

In the following subsections we address concerns that a particular state or hurricane may have undue influence on the income results (Figures A2 and A3). We then explore the influence of measurement error

\footnotetext{
${ }^{35}$ For parsimony, we suppress the output for the educational attainment outcomes. Nonetheless, we perform the robustness checks and find that the estimates are qualitatively similar.
} 
in self-reported wage and salary income, and the imputation of self-employment income from historical census records, and show that our results are robust to alternative specifications of the outcome variable. In particular, we show that similar results are found when we restrict attention to self-reported wage and salary income (Table A4) or consider effects on occupational income scores (Table O6), and that our results are not driven by the tails of the income distribution (Table O7). We also supplement our main sample with individuals for whom we only observe the county of birth, or define exposure based on distance from the hurricane path to the centroid of the birth county (Table A1), and test different definitions of the treatment variable by modifying the radii of exposure (Table A6 and Figure A4). Next, we perform sensitivity checks for match quality and accuracy that are standard when using historical data sources (Figures A5, A6a, and A6b). Finally, we place restrictions on the range of conception years in the sample (O8), and collapse data at the birth-county-by-conception month level (Table A7).

Before turning to exercises that test the robustness of the income results to alternate specifications of the dependent variable and the treatment, we check whether any particular state or hurricane is driving the results. Figure A2 plots point estimates and 95-percent confidence intervals for the coefficient on in utero exposure from equation 2 and the specification shown in column 3 and panel B of Table 4, with each line representing separate estimates based on samples that exclude each state one at a time. The point estimates and confidence intervals are very stable, ranging from -5.7 to $-8.4 \mathrm{pp}$ compared to $-7.5 \mathrm{pp}$ in the main specification, which indicates that the income results are not driven by any particular state. ${ }^{36}$

Next, Figure A3 plots the results of performing the same exercise, but dropping individual storms from the sample one by one. Given that 57.3 percent of individuals in our main estimation sample were born in locations that were within 100 kilometers of multiple storm paths during the sample period, we take two approaches to dropping a single storm from the analysis. In both cases, only individuals who were born within 100 kilometers of the excluded storm, but not within 100 kilometers of any other storm during the sample period are dropped from the sample. For individuals born within 100 kilometers of multiple storms we assign exposure in two different ways. First, we ignore exposure to the dropped storm when coding an individual's exposure to the remaining storms in the sample (Figure A3a). Next, we define exposure to hurricanes based on all storms in the sample, including exposure to the excluded storm (Figure A3b). Regardless of the approach taken, we find that no particular storm drives the result that in utero exposure leads to reduced income in adulthood, as the coefficients remain stable and statistically significant across all samples. ${ }^{37}$

\subsection{Alternate specifications of income}

In Table A4 we present estimates from specifications that do not add predicted values for non-wage income to total income, but rather define the dependent variable as the natural logarithm of self-reported

\footnotetext{
${ }^{36}$ The coefficients on exposure at ages 0 to 6 months, when dropping states one by one, are similar in magnitude to the preferred estimate of $-5.1 \mathrm{pp}$, ranging from -2.7 to $-6.2 \mathrm{pp}$, but are less precisely estimated in some cases. The point estimate is only significant at the 10 percent level when North Carolina is dropped from the sample, and is no longer significant at conventional levels when Florida, Louisiana and South Carolina are (separately) dropped from the sample.

${ }^{37}$ The coefficient on exposure at ages 0 to 6 months is also stable (ranging from -2.9 to $-6.4 \mathrm{pp}$ ) and remains significant at the 10-percent level in 56 out of 60 samples across the two approaches (Figure O3).
} 
wage and salary income from the 1940 census, and show results for three samples. First, we consider a "restricted sample" (columns 1 and 2), which only includes individuals who reported having between $\$ 0$ and $\$ 50$ of self-employment income. In these cases, wage and salary income provides a reasonably good approximation of total income. Second, in a "relaxed sample" (columns 3 and 4), we add individuals with more than $\$ 50$ of self-employment income, but ignore the estimates of predicted non-wage income. In both cases, we impute zero income only when other contextual variables make it clear that the individual was out of the labor force. Specifically, we restrict attention to individuals out of the labor force, with zero reported wage and salary income, non-wage income less than $\$ 50$, no reported occupation or industry, and not in school or engaged in housework. And third, in the "full sample" we add all individuals with no reported wage income, regardless of whether other variables suggest that the respondent earned unreported wage income. ${ }^{38}$

The estimates based on the "restricted" and "relaxed" samples in panel A indicate that in utero exposure is associated with a 5.5 to 6.1 percent reduction in log wages, which is modestly smaller than the 7.3 percent effect on total income in our preferred specification. Larger effect sizes around 7 percent are found in the "full sample" which presumably includes poorer individuals reporting zero income, but the estimates are insignificant, which reflects the noise from imputing zero incomes when wages are not reported. These estimates are generally larger when we expand the treatment to include early childhood exposure, which is also in line with results in Table $4 .{ }^{39}$

In Table O6 we abstract from the actual income reported in the 1940 census, and instead focus on a variety of occupation and education based income and earnings scores (Ruggles et al. 2015). In particular, we use the occupational income score, occupational earnings score, occupational education score, and the Nam-Powers-Boyd occupational status score as alternative measures of income, which are described in detail in the Online Appendix. For each outcome, the effects are negative, but in one out of four specifications we lose statistical significance for estimates of in utero exposure. Nonetheless, the in utero effect sizes suggest reductions in the outcome variables ranging from 1.8 to 6.5 percent, as compared to the preferred estimate of negative 7.3 percent for the effect on income.

A drawback of the IPUMS occupational score variables is that they are computed using data on income for blacks and whites, whereas our sample includes only whites. Thus, we compute an alternative measure of average income using data on only whites in the IPUMS 1-percent sample of the 1950 census. Specifically, we calculate average 1950 income by occupational code, based on wages and salaries, as well as business, farm, and self-employment income. This measure is similar to the occupational income score computed by Carruthers and Wanamaker (2016), though we deviate by restricting the data to the age range in our sample (ages 42 to 53 years old) when calculating average income by occupation code. The results are reported in column 5 and indicate that in utero exposure to hurricanes is associated with a 2.5 percent decline in average occupational income. While the estimate is smaller in magnitude than the preferred specification, it only captures effects on sorting into different occupations and not productivity

\footnotetext{
${ }^{38}$ In specifications where we perform a log transformation of wage and salary income, we assign a small value (\$1) to observations with zero income.

${ }^{39}$ Measurement error in earnings is of particular concern for farmers, many of whom do not report any wage income. Table O9 shows that the main results for total income hold when individuals employed in agriculture are dropped from the sample.
} 
differences within an occupation.

Table $\mathrm{O} 7$ explores the extent to which our results are driven by the tails of the income distribution. In columns 1 to 4 we trim the top or bottom 5 to 10 percent of the income distribution, while in columns 5 and 6 we simultaneously trim both tails. The results are generally smaller in magnitude, especially when we exclude relatively poorer people, but they remain statistically significant. This finding is in line with differential sensitivity of already impoverished people to negative shocks, and with the finding that the coefficient for the effect of in utero exposure on log wages increases in magnitude when estimated on the "full sample" that includes more individuals with zero income (columns 5 and 6 in Table A4).

\subsection{Definition of exposure}

In Table A1, we test whether the selection of birth cities and towns that are matched to geographic coordinates impacts our results, by adding to the sample individuals for whom we only observe birth place at the county level (columns 1 and 2). The downside of this approach is that the coordinates of the county centroid provide a much noisier measure of distance to the storm, and it follows that the estimated effects of in utero exposure on income are smaller than our preferred estimates. The coefficients are further attenuated when exposure is defined relative to the county centroid for all observations, but they remain statistically significant.

Next, we examine two sources of measurement error in the determination of hurricane exposure status, which may bias our results. First, a limitation of historical data is that, unlike in contemporary studies, gestational length is not observable, forcing us to assume that all pregnancies had a uniform 39-week gestational period, which may generate misassignment of fetal exposure status. Consequently, some early-term infants will be coded as exposed in utero, when in fact they were conceived after the storm, and vice versa. We address this issue in Table A5 by presenting a range of specifications that vary the uniform gestational length of the sample between 37 and 41 weeks. In panel A, the estimates for the effects of in utero exposure on total income range between negative 6.7 and 7.3 percent, which are similar in magnitude to our preferred estimates. That the point estimates change minimally when we vary the assumed gestational age is also consistent with the absence of substantial effects of in utero stress on gestational length (Currie and Rossin-Slater 2013).

Second, the 30 kilometers band around the storm paths may not accurately capture areas exposed to the storms. Table A6 and Figure A4 explore the sensitivity of the main results to different assumptions about the diameter of the area exposed to the storm, and different ways of specifying how the treatment effect varies by distance from the storm. The first three columns of Table A6 change the indicator variable for exposure to include individuals living within 20 kilometers, 40 kilometers, or 50 kilometers of the hurricane path, respectively. Our results are fundamentally unchanged for the first two distance bands, but they become smaller when exposure is defined to include a 50 kilometers band around the storm. The observed attenuation is consistent with introducing false positives into the treatment group, as mothers living further away from the storm would have experienced a milder dosage of the treatment or were not affected at all. In columns 4 to 6 we replicate this exercise, but drop a 20 kilometers band between the treated and control groups from the sample. For example, in column 4 , treated individuals 
are those exposed at birth locations within 20 kilometers of the hurricane path, while the control group includes individuals born 40 to 100 kilometers away from the storm path. This specification, in particular, excludes individuals in the control group most likely to have been exposed to the treatment. The results in the "donut hole" regressions are broadly similar to the specifications without these sample restrictions.

\subsection{Match quality and accuracy}

A consequence of using imperfectly linked historical data sources is that biased estimates can arise from the fact that the analysis is conducted on a sample of uniquely matched individuals accounting for only about 24 percent of the population (Column 3 in Table 1). One method of relaxing the restrictiveness of a sample that consists of uniquely matched records is to vary the threshold for the minimum match quality required to enter the sample. Our results for total income are robust to decreasing the minimum Jaro-Winkler string similarity score by increments of 0.02 from 1.0 to 0.8 (Figure A5).

In the presence of misreported ages in the census, the probability of a false match is increasing in the number of records with similar names in neighboring birth cohorts. Figure A6 shows that the results are robust to restricting the number of census records similar to the matched observation. In comparison to the main specification, which places no restriction on the number of similar census records, the effects on working fifty or more weeks are more precisely estimated and significant at the 10 percent level.

\subsection{Restrictions on range of conception years}

An important concern with the WWI records is the extent to which the registration process was complete. Figure 2 shows estimated completeness rates by birth cohort for the Southern "hurricane zone" states and the rest of the country, computed by comparing the number of individuals who registered for the WWI draft to the number of individuals enumerated in the 1910 U.S. Census. Since mortality between 1910 and 1918 would have reduced the surviving cohort sizes, the estimated completeness rates should be considered as lower bounds. The near universe of draft-age males were registered outside the South, but there is some indication of under-registration in the South, and among the earlier cohorts in our sample. Part of the difference between the South and non-South could be due to differential mortality, especially for the earlier cohorts. Individuals had to survive until at least June 1917, seven years after the 1910 census, in order to be registered. ${ }^{40}$ The registration rate in the South ranged between 64 and 82 percent for the 1887 to 1889 birth cohorts, but rose above 90 percent for all subsequent cohorts, except in 1892 when it fell to 82 percent. ${ }^{41}$ Under the assumption that the rate of under-registration did not differ

\footnotetext{
${ }^{40}$ The estimated under-registration can also partly be attributed to the fact that individuals already serving in the military did not register for the draft. However, with only 100,000 men serving in the U.S. Army in 1914, the size of the active military accounted for less than 1 percent of the population eligible for the draft, and an even smaller percentage of the draft eligible population in the U.S. South, since Southerns volunteered for the military at a lower rate than the rest of the country.

${ }^{41}$ The birth cohort for year $t$ includes births between 16 April in year $t-1$ and 15 April in year $t$. We adopt this convention since the 1910 census took place on 15 April and asked respondents to report their age in years on the day of the census. While the WWI records are only 64 percent complete for births between 16 April 1886 and 15 April 1887, the 1886 births are not included in the main estimation sample. In 3 percent of state-by-birth year groups, we find more individuals registered in the WWI draft records than enumerated in the 1910 census. Although we assign a weight of 0.5 to observations with missing gender and a weight of $\frac{1}{N}$ to observations for which the birth place may be located in one of $N$ states, we may still under count the cohort sizes in the 1910 census due to missing data.
} 
based on exposure to hurricanes, our results should not be affected by the incomplete registration.

Table O8 shows that the main results for effects on log income hold when restricting attention to the later cohorts, for whom registration was effectively complete (column 3). The estimates for the 1889 to 1891 conception year cohorts (column 2), when there were few cases of in utero exposure to hurricanes, are statistically insignificant, but the magnitudes are within the same ballpark as the main estimates. The results are also robust to dropping the 1889 to 1891 conception year cohorts (column 4), as well as the 1892 and 1896 to 1897 birth cohorts (columns 5 and 6, respectively), which were years subject to a greater degree of under-registration in the WWI records.

\subsection{Collapsed data}

With many birth locations in the WWI draft records having few individuals in the estimation sample, outlier observations may have undue influence on the regression results. Table A7 presents results from collapsing the individual-level data at the birth county-by-conception month level. The interpretation of these results is different from the main specification given that the dependent variable is the mean educational or labor market outcome in the birth county-by-conception month cell, while the treatment is an indicator variable equal to one if at least one individual in the cell was exposed in utero to a hurricane within 30 kilometers of the birth location.

In comparison to the main results in panel $\mathrm{A}$ of Table 4, the effects on educational outcomes are slightly larger and statistically significant, with in utero hurricane exposure leading to reductions in the highest grade completed and the probability of middle school graduation of 3.3 and 9.4 percent (compared to 1.6 and 6.1 percent), respectively. When it comes to the labor market outcomes, the effect on $\log$ income is slightly larger without educational controls (8.1 versus 7.3 percent), and slightly smaller once educational controls are added (5.3 versus 6.0 percent). The effects on working fifty or more weeks are now also statistically significant, and larger than the main estimates ( 3.7 vs 2.2 percent without educational controls). Overall, the results based on birth county-by-conception month averages are very similar to the main results. Generally, the standard errors are larger in the main specification based on the individual-level sample, which reflects the presence of measurement error from having a small number of observations at some birth locations.

\section{Conclusions}

A growing literature has documented negative effects of exposure to natural disasters on fetal development, but due to data limitations, the majority of this research has focused on either health at birth or intermediate schooling outcomes. If these shocks operate, at least in part, through prenatal maternal stress and elevated levels of cortisol, then these mechanisms may explain the link between exposure to natural disasters, child development, and long-lasting consequences. In addition to examining short-run effects on mortality, which is proxied by the gender ratio in childhood, this study extends the horizon by analyzing the effects of prenatal maternal stress on long-run outcomes: completed years of education, income, full time employment, and migration. The analysis is based on a data set constructed by linking 
the World War I Draft Registration Cards, which contain the near universe of males born between January 1887 and August 1897, to the 1940 U.S. Census. The exogenous variation in stress is derived from hurricanes that struck the U.S. South between June 1885 and October 1899.

The main results, which are based on a sample of white males born in the U.S. South, reveal negative effects of in utero exposure on income, as well as smaller and less precisely estimated effects on educational attainment. The effects on income are also present for individuals exposed during the first six months of life, but otherwise not for exposure before the age of two. They are unlikely to be driven by selective migration, mortality, measurement error in the dependent variable, or differences in the likelihood of matching an individual across data sources. The concentration of the effects during the prenatal and neonatal periods, in combination with the nature of the shock, provides support for the interpretation that maternal stress during pregnancy represents the primary mechanism leading to long-term consequences (Galea et al. 2005; Paxson et al. 2012; Currie and Rossin-Slater 2013).

Our preferred estimates suggest that the decrease in income cannot be fully explained by lower human capital accumulation, but the absence of medical records precludes us from quantifying the contribution of poor health to the estimated long-run effect. Nonetheless, Currie and Rossin-Slater (2013) present limited evidence that in utero stress affects a newborn's overall health, a result that is corroborated by Fuller (2014). Although we do not assess whether the effects on income can be explained by poorer overall health, and mental health especially, in adulthood, the intensive margin income estimates are consistent with productivity representing an important factor that drives the results.

We also consider the short-run consequences of hurricane exposure for the poorer and more vulnerable black population. We provide evidence of increased mortality among black males exposed in utero and during the neonatal period, which is consistent with previously documented findings that stress affects the gender ratio and results in a smaller number of surviving male fetuses. Concerns about labor market segregation and data quality prevent us from analyzing long-run outcomes for blacks.

We view these results as particularly relevant given the macroeconomic evidence that exposure to tropical cyclones can dampen a country's growth and productivity over a twenty-year time horizon (Hsiang and Jina 2014). Our findings suggest that the consequences of hurricanes, and potentially other natural disasters, can include costs such as reduced individual-level productivity, that do not manifest themselves until long after the immediate aftermath of the disaster. Our results also contrast some of the estimates of the short- and medium-run effects of hurricane exposure on the adult population, such as Deryugina et al. (2014), Groen et al. (2016) and Ho et al. (2016), who document positive effects of exposure and associate the results with positive mortality selection, increased labor demand during the reconstruction, and the inflow of relief to the affected locations. In the context of this study, where the subject of the "experiment" is a relatively fragile population, storms were unanticipated, and relief efforts were minimal, we find unambiguously negative long-term consequences. These costs to child development and productivity remain relevant to policymakers as the ongoing growth of coastal populations has brought more people to locations at risk of extreme weather events, and add to the growing concern within both the scientific community and governments about the impact of climate change (Dell et al. 2012; Burke et al. 2015; McNutt 2015; Burke et al. 2016). 


\section{References}

Abramitzky, Ran, Leah Platt Boustan, and Katherine Eriksson, "Europe's Tired, Poor, Huddled Masses: Self-Selection and Economic Outcomes in the Age of Mass Migration," American Economic Review, 2012, 102 (5), 1832-56.

Ache, Brent W., Kristen M. Crossett, Percy A. Pacheco, Jeffery E. Adkins, and Peter C. Wiley, “"'The Coast” is Complicated: A Model to Consistently Describe the Nation's Coastal Population," Estuaries and Coasts, 2015, 38 (1), 151-155.

Aizer, Anna, Laura Stroud, and Stephen Buka, "Maternal Stress and Child Well-Being: Evidence from Siblings," Journal of Human Resources, 2016, forthcoming.

Almond, Douglas, "Is the 1918 Influenza Pandemic Over? Long-Term Effects of In Utero Influenza Exposure in the Post-1940 U.S. Population," Journal of Political Economy, 2006, 114 (4), 672-712.

- and Janet Currie, "Human Capital Development Before Age Five," in "Handbook of Labor Economics,” Vol. 4, Elsevier, 2011, pp. 1315-1486.

- and Lena Edlund, "Trivers-Willard at Birth and One Year: Evidence from US Natality Data 19832001,” Proceedings of the Royal Society B: Biological Sciences, 2007, 274 (1624), 2491-2496.

_ , Bhashkar Mazumder, and Reyn van Ewijk, "In Utero Ramadan Exposure and Children's Academic Performance,” Economic Journal, 2015, 125 (589), 1501-1533.

_ , Lena Edlund, and Mårten Palme, "Chernobyl's Subclinical Legacy: Prenatal Exposure to Radioactive Fallout and School Outcomes in Sweden," Quarterly Journal of Economics, 2009, 124 (4), 1729_ 1772.

Ancestry.com, U.S. World War I Draft Registration Cards, 1917-1918 [database on-line], Ancestry.com Operations Inc, 2005.

Antilla-Hughes, Jesse K. and Solomon M. Hsiang, "Destruction, Disinvestment, and Death: Economic and Human Losses Following Environmental Disaster," Working Paper, 2013.

Arthi, Vellore, ““The Dust was Long in Settling”: Human Capital and the Lasting Impact of the American Dust Bowl," Working Paper, 2015.

Badakhsh, Roshan, Emily Harville, and Baishakhi Banerjee, "The Childbearing Experience During a Natural Disaster," Journal of Obstetric, Gtnecologic and Neonata Nursing, 2010, 39 (4), 489-497.

Barker, David, “The Fetal Origins of Coronary Heart Disease,” BMJ, 1995, 311, 171-174.

Barnes, Jay, Florida's hurricane history, Chapel Hill: University of North Carolina Press, 1998.

Bharadwaj, Prashant, Petter Lundborg, and Dan-Olof Rooth, "Birth Weight in the Long-Run," Journal of Human Resources, 2016, forthcoming.

Black, Sandra E., Aline Bütikofer, Paul J. Devereux, and Kjell G. Salvanes, "This Is Only a Test? Long-Run Impacts of Prenatal Exposure to Radioactive Fallout," National Burean of Economic Research Working Paper Series, 2013, No. 18987.

_, Paul J. Devereux, and Kjell G. Salvanes, "From the Cradle to the Labor Market? The Effects of Birth Weight on Adult Outcomes," Quarterly Journal of Economics, 2007, 122 (1), 409-439. 
Black, Sandra, Paul Devereux, and Kjell Salvanes, "Does Grief Transfer Acorss Generations? Bereavements During Pregnancy and Child Outcomes," American Economic Journal: Applied Economics, 2016, $8(1), 193-223$.

Boustan, Leah Platt, Matthew Kahn, and Paul Rhode, "Moving to Higher Ground: Migration Response to Natural Disasters in the Early Twentieth Century," American Economic Review, 2012, 102 (3), 238-244.

Bugni, Federico, Bo Honoré, and Adriana Lleras-Muney, "Estimation and Inference with Imperfectly Matched Data," Working Paper, 2014.

Burke, M., M. Craxton, C. D. Kolstad, C. Onda, H. Allcott, E. Baker, L. Barrage, R. Carson, K. Gillingham, J. Graff-Zivin, M. Greenstone, S. Hallegatte, W. M. Hanemann, G. Heal, S. Hsiang, B. Jones, D. L. Kelly, R. Kopp, M. Kotchen, R. Mendelsohn, K. Meng, G. Metcalf, J. Moreno-Cruz, R. Pindyck, S. Rose, I. Rudik, J. Stock, and R. S. J. Tol, "Opportunities for advances in climate change economics," Science, 2016, 352 (6283), 292-293.

Burke, Marshall, Solomon M. Hsiang, and Edward Miguel, "Climate and Conflict," Annual Review of Economics, 2015, 7, 577-617.

Carruthers, Celeste K. and Marianne H. Wanamaker, "Separate and Unequal in the Labor Market: Human Capital and the Jim Crow Wage Gap," National Bureau of Economic Research Working Paper Series, 2016, No. 21947.

Caruso, Germán and Sebastian Miller, "Long run effects and intergenerational transmission of natural disasters: A case study on the 1970 Ancash Earthquake," Journal of Development Economics, 2015, 117, $134-150$.

Catalano, R., T. Bruckner, A.R. Marks, and B. Eskenazi, "Exogenous shocks to the human sex ratio: the case of September 11, 2001 in New York City," Human Reproduction, 2006, 21 (12), 3127-3131.

Chambers, John Whiteclay, To raise an army: The draft comes to modern America, New York: Free Press, 1987.

Christen, Peter, Data Matching: Concepts and Techniques for Record Linkage, Entity Resolution, and Duplicate Detection, Berlin, Heidelberg: Springer, 2012.

Collins, William J. and Marianne H. Wanamaker, "Selection and Economic Gains in the Great Migration of African Americans: New Evidence from Linked Census Data," American Economic Journal: Applied Economics, 2014, 6 (1), 220-52.

Cunningham, Gary, Kenneth Leveno, Steven Bloom, John Hauth, Dwight Rouse, and Catherine Spong, Williams Obstetrics, McGraw-Hill, 2010.

Currie, Janet and Maya Rossin-Slater, "Weathering the Storm: Hurricanes and Birth Outcomes," Journal of Health Economics, 2013, 32 (3), 487-503.

Cutler, David M., Grant Miller, and Douglas M. Norton, "Evidence on Early-Life Income and LateLife Health from America's Dust Bowl Era," Proceedings of the National Academy of Sciences, 2007, 104 (33), 13244-13249.

de Oliveira, Victor Hugo and Climent Quintana-Domeque, "Natural Disasters and Human Development: Hurricane Catarina and Birth Outcomes in Brazil," Working Paper, 2016. 
Dell, Melissa, Benjamin Jones, and Benjamin Olken, "Temperature Shocks and Economic Growth: Evidence from the Last Half Century," American Economic Journal: Macroeconomics, 2012, 4 (3), 6695.

Deryugina, Tatyana, “The Fiscal Cost of Hurricanes: Disaster Aid Versus Social Insurance,” 2016.

_, Laura Kawano, and Steven Levitt, "The Economic Impacts of Hurricane Katrina on Its Victims: Evidence from Individual Tax Returns," 2014.

Deuchert, Eva and Christina Felfe, "The Tempest: Short- and Long-term Consequences of a Natural Disaster for Children's Development," European Economic Review, 2015, 80, 280-294.

Eichenlaub, Suzanne, Stewart Tolnay, and Alexander Trent, "Moving out but not up: Economic outcomes in the Great Migration," American Sociological Review, 2010, 75 (1), 101-225.

Feigenbaum, James, "Automated Census Record Linking: A Machine Learning Approach," 2015a. Working Paper.

_ , "Intergenerational Mobility During the Great Depression," 2015b. Working Paper.

Fernández-Partagás, José and Henry F. Diaz, "Atlantic Hurricanes in the Second Half of the Nineteenth Century," Bulletin of the American Meteorological Society, 1996, 77 (12), 2899-2906.

Ferrie, Joseph and Karen Rolf, "Socioeconomic Status in Childhood and Health After Age 70: A New Longitudinal Analysis for the U.S., 1895-2005," Explorations in Economic History, 2011, 48 (4), 445460.

Ferrie, Joseph P., "A New Sample of Males Linked from the Public Use Micro Sample of the 1850 U.S. Federal Census of Population to the 1860 U.S. Federal Census Manuscript Schedules," Historical Methods, 1996, 29, 141-56.

Figlio, David, Jonathan Guryan, Krzysztof Karbownik, and Jeffrey Roth, "The Effects of Poor Neonatal Health on Children's Cognitive Development," American Economic Review, 2014, 104 (12), 3921-3955.

Fuller, Sarah C., "The Effects of Prenatal Natural Disaster Exposure on School Outcomes," Demography, 2014, 51, 1501-1525.

Galea, S., C. R. Brewin, M. Gruber, and et al., "Exposure to hurricane-related stressors and mental illness after hurricane katrina," Archives of General Psychiatry, 2007, 64 (12), 1427-1434.

Galea, Sandro, Arijit Nandi, and David Vlahov, "The Epidemiology of Post-traumatic Stress Disorder after Disasters," Epidemiologic Reviews, 2005, 27, 78-91.

Glover, Vivette, T. G. O'Connor, and Kieran O'Donnell, "Prenatal stress and the programming of the HPA axis," Neuroscience E Biobehavioral Reviews, 2010, 35 (1), 17-22.

Groen, Jeffrey A., Mark J. Kutzbach, and Anne E. Polivka, "Storms and Jobs: The Effect of Hurricanes on Individuals' Employment and Earnings over the Long Term," US Census Burean Center for Economic Studies Paper No. CES-WP-15-21R, 2016.

Hill, Jennifer and Andrew Gelman, Data Analysis Using Regression and Multi-level/Hierarchical Models, Cambridge, England: Cambridge University Press, 2007. 
Ho, Jessica Y., Elizabeth Frankenbeg, Cecep Sumantri, and Duncan Thomas, "Adult Mortality Five Years after a Natural Disaster: Evidence from the Indian Ocean Tsunami,” 2016.

Hsiang, Solomon M. and Amir S. Jina, "The Causal Effect of Environmental Catastrophe on Long-Run Economic Growth: Evidence From 6,700 Cyclones," National Burean of Economic Research Working Paper Series, 2014, No. 20352.

Isen, Adam, Maya Rossin-Slater, and W. Reed Walker, "Every Breath You Take - Every Dollar You'll Make: The Long-Term Consequences of the Clean Air Act of 1970," Journal of Political Economy, 2016, forthcoming.

Jayachandran, Seema, "Air Quality and Early-Life Mortality: Evidence from Indonesia's Wildfires," Journal of Human Resources, 2009, 44 (4), 916-954.

Keith, Jeanette, "The Politics of Southern Draft Resistance, 1917-1918: Class, Race, and Conscription in the Rural South," The Journal of American History, 2001, 87 (4), 1335-1361.

Landsea, Christopher W. and James L. Franklin, "Atlantic Hurricane Database Uncertainty and Presentation of a New Database Format," Monthly Weather Review, 2013, 141 (10), 3576-3592.

Lin, Ming-Jen and Elaine M. Liu, "Does in utero exposure to Illness matter? The 1918 influenza epidemic in Taiwan as a natural experiment," Journal of Health Economics, 2014, 37, 152-163.

Lindeboom, Maarten, France Portrait, and Gerard van den Berg, "Long-Run Effects on Longevity of a Nutritional Shock Early in Life: The Dutch Potato Famine of 1846-1847," Journal of Health Economics, 2010, 29 (5), 617-629.

Liu, Elaine M., Jin-Tan Liu, and Tzu-Yin Hazel Tseng, "The Impact of a Natural Disaster on the Incidence of Fetal Losses and Pregnancy Outcomes,” Working Paper, 2015.

Long, Jason and Joseph Ferrie, "Intergenerational Occupational Mobility in Great Britain and the United States since 1850," American Economic Review, 2013, 103 (4), 1109-37.

Maccini, Sharon and Dean Yang, "Under the Weather: Health, Schooling, and Economic Consequences of Early-Life Rainfall," American Economic Review, 2009, 99 (3), 1006-1026.

Margo, Robert A., "Race, Educational Attainment, and the 1940 Census," The Journal of Economic History, 1986, 46 (01), 189-198.

McNutt, Marcia, “Climate Warning, 50 Years Later," Science, 2015, 350, 721.

Mill, Roy and Luke C.D. Stein, "Race, Skin Color, and Economic Outcomes in Early TwentiethCentury America,” Working Paper, 2016.

Minnesota Population Center, National Historical Geographic Information System: Version 2.0, Minneapolis, MN: University of Minnesota, 2011.

Nakamura, Emi, Jósef Sigurdsson, and Jón Steinsson, "The Gift of Moving: Intergenerational Consequences of a Mobility Shock," National Bureau of Economic Research Working Paper Series, 2016, No. 22392.

National Archives and Records Administration, United States World War I Draft Registration Cards, 1917-1918, Washington D.C.: FamilySearch, n.d. 
Nilsson, J Peter, "Alcohol Availability, Prenatal Conditions, and Long-term Economic Outcomes," Journal of Political Economy, 2016, forthcoming.

Nix, Emily and Nancy Qian, “The Fluidity of Race: "Passing" in the United States, 1880-1940," 2015. NBER Working Paper 20828.

Norberg, Karen, "Partnership Status and the Human Sex Ratio at Birth," Proceedings of the Royal Society B: Biological Sciences, 2004, 271 (1555), 2403-2410.

Nudd, Jean, “U.S. World War I Draft Registrations," Middlesex Genealogical Society, 2005, 21 (1).

Parman, John, "Childhood Health and Sibling Outcomes: Nurture Reinforcing Nature During the 1918 Influenza Pandemic," Explorations in Economic History, 2015, 58, $22-43$.

Paxson, Christina, Elizabeth Fussell, Jean Rhodes, and Mary Waters, "Five Years Later: Recovery from Post Traumatic Stress and Psychological Distress Among Low-Income Mothers Affected by Hurricane Katrina," Social Science and Medicine, 2012, 74, 150-157.

Persson, Petra and Maya Rossin-Slater, "Family Ruptures, Stress, and the Mental Health of the Next Generation," American Economic Review, 2016, forthcoming.

Poirier, Alexandre and Nicolas L. Ziebarth, "Estimation of Models with Multiple-Valued Explanatory Variables," Working Paper, 2016.

Ruggles, Steven, Katie Genadek, Ronald Goeken, Josiah Grover, and Matthew Sobek, Integrated Public Use Microdata Series: Version 6.0, Minnesota: University of Minnesota, 2015.

Schwandt, Hannes, "The Lasting Legacy of Seasonal Influenza: In-utero Exposure and Human Capital Development," Working Paper, 2016.

Simeonova, Emilia, "Out of Sight, Out of Mind? Natural Disasters and Pregnancy Outcomes in the USA,” CESifo Economic Studies, 2011, 57 (3), 403-431.

Sotomayor, Orlando, "Fetal and Infant Origins of Diabetes and Ill Health: Evidence from Puerto Rico's 1928 and 1932 Hurricanes," Economics and Human Biology, 2013, 11 (3), 281-293.

Torche, Florencia, "The Effect of Maternal Stress on Birth Outcomes: Exploiting a Natural Experiment," Demography, 2011, 48 (4), 1473-1491.

Trivers, Robert and Dan Willard, "Natural Selection of Parental Ability to Vary the Sex Ratio of Offspring,” Science, 1973, 179 (4068), 90-92.

Tseng, Tzu-Yin Hazel, "The Hidden Costs of Natural Disasters: In Utero Environment and Mental Health in Adulthood," Working Paper, 2016.

U.S. Geological Survey, U.S. Geographic Names Information System (GNIS), Reston VA: U.S. Geological Survey, 2014.

Walker, Francis A. and Charles W. Seaton, "Report on the Productions of Agricuture," 1880.

Weatherford, Candis and William Gray, "Typhoon Structure as Revealed by Aircraft Reconnaissance. Part II: Structural Variability,” Monthly Weather Review, 1988, 116, 1044-1056.

Webster, Peter, Gregory Holland, Judith Curry, and Hai-Ru Chang, "Changes in Tropical Cyclone Number, Duration, and Intensity in a Warming Environment," Science, 2005, 309 (5742), 1844-1846. 


\section{Tables}

Table 1: Linkage Rates from the WWI Draft Registration Cards to U.S. Censuses

\begin{tabular}{|c|c|c|c|c|c|c|}
\hline & \multirow{3}{*}{$\begin{array}{c}(1) \\
\text { U.S.-Born }\end{array}$} & \multicolumn{2}{|c|}{ U.S. birth region } & \multirow{3}{*}{$\begin{array}{c}\frac{30-100 \mathrm{~km}}{(4)} \\
\text { All }\end{array}$} & \multicolumn{2}{|c|}{$0-30 \mathrm{~km}$} \\
\hline & & (2) & $(3)$ & & (5) & $(6)$ \\
\hline & & Non-South & South & & All & In utero \\
\hline \multicolumn{7}{|c|}{ Panel A: Linking WWI records to the 1900 U.S. Census } \\
\hline No match & 0.532 & 0.494 & 0.657 & 0.654 & 0.701 & 0.708 \\
\hline Multiple matches & 0.099 & 0.100 & 0.095 & 0.091 & 0.083 & 0.084 \\
\hline Unique match & 0.369 & 0.406 & 0.248 & 0.255 & 0.216 & 0.207 \\
\hline Baseline sample & 7656005 & 5845398 & 1810607 & 464208 & 255570 & 15774 \\
\hline \multicolumn{7}{|c|}{ Panel B: Linking WWI records to the 1940 U.S. Census } \\
\hline No match & 0.391 & 0.370 & 0.455 & 0.453 & 0.475 & 0.476 \\
\hline Multiple matches & 0.280 & 0.273 & 0.303 & 0.291 & 0.290 & 0.286 \\
\hline Unique match & 0.329 & 0.357 & 0.242 & 0.255 & 0.234 & 0.238 \\
\hline Baseline sample & 7755491 & 5867503 & 1887988 & 480895 & 271143 & 15740 \\
\hline
\end{tabular}

Note: Panel A presents match rates from the WWI draft records to the 1900 U.S. Census. The linking variables are first and last name, birth year and birth month, and state of birth. Panel B presents match rates from the WWI draft records to the 1940 U.S. Census. The linking variables are first and last name, age in years at the time of the census (birth year \pm 3 years), and state of birth. The baseline population, shown in columns 3 to 6, consists of all individuals in the data set of WWI Draft Registration Cards who were born between January 1887 and August 1897 in one of nine Southern U.S. states exposed to hurricanes during the sample period (Alabama, Florida, Georgia, Louisiana, Mississippi, North Carolina, South Carolina, Texas, and Virginia). Both panels exclude records with missing first or last name, and cases reporting only a first or last initial. Panel A also excludes observations with missing birth month, since it is one of the matching variables, and thus the baseline population is slightly lower. Each column shows match failure, multiple match, and unique match rates for different samples, beginning with all U.S.-born males, excluding Alaska and Hawaii, in the WWI records (column 1). Next, match rates are presented separately for the non-South and South regions (columns 2 and 3 ), where the South is restricted to the nine Southern states exposed to hurricanes. Columns 4 and 5 show match rates for locations 30 to 100 kilometers away and 0 to 30 kilometers away, respectively, from hurricane paths that hit the continental U.S. between 1885 and 1899. Finally, separate match rates are shown for individuals exposed in utero to hurricanes (column 6), a subset of individuals in column 5. 
Table 2: Baseline Characteristics from the 1880 U.S. Census

\begin{tabular}{|c|c|c|c|c|c|}
\hline & & \multicolumn{2}{|c|}{ U.S. birth region } & \multicolumn{2}{|c|}{ Hurricane zone } \\
\hline & $\begin{array}{c}(1) \\
\text { U.S.-Born }\end{array}$ & $\begin{array}{c}(2) \\
\text { Non-South }\end{array}$ & $\begin{array}{c}(3) \\
\text { South }\end{array}$ & $\begin{array}{c}(4) \\
30-100 \mathrm{~km}\end{array}$ & $\begin{array}{c}(5) \\
0-30 \mathrm{~km}\end{array}$ \\
\hline \multicolumn{6}{|c|}{ Panel A: County averages (Full population) } \\
\hline Black & 0.146 & 0.047 & 0.360 & 0.438 & 0.444 \\
\hline Rural & 0.928 & 0.910 & 0.968 & 0.956 & 0.960 \\
\hline On farm & 0.565 & 0.558 & 0.579 & 0.550 & 0.507 \\
\hline Average farm value & 18.9 & 25.2 & 6.4 & 7.0 & 6.1 \\
\hline Average farm size & 229.8 & 150.8 & 387.5 & 281.9 & 326.1 \\
\hline \multicolumn{6}{|c|}{ Panel B: Individual characteristics (White males age 20 to 40 ) } \\
\hline Labor force participation rate & 0.934 & 0.933 & 0.940 & 0.937 & 0.933 \\
\hline Employed in agriculture & 0.450 & 0.412 & 0.658 & 0.576 & 0.591 \\
\hline Occupational income score & 20.3 & 20.8 & 17.5 & 18.6 & 18.1 \\
\hline Occupational earnings score & 33.8 & 35.6 & 23.4 & 27.5 & 25.9 \\
\hline Occupational education score & 9.3 & 9.5 & 8.3 & 8.9 & 8.4 \\
\hline Average age & 28.3 & 28.3 & 28.2 & 28.2 & 28.3 \\
\hline Married & 0.535 & 0.524 & 0.595 & 0.564 & 0.580 \\
\hline Family size & 2.6 & 2.6 & 3.0 & 3.0 & 3.0 \\
\hline Has children in household & 0.416 & 0.402 & 0.492 & 0.459 & 0.478 \\
\hline $\mathrm{N}$ & 5682214 & 4806489 & 875725 & 236353 & 191201 \\
\hline
\end{tabular}

Note: This table reports summary statistics from the 1880 U.S. Census of Population. Panel A presents county averages computed by collapsing individual-level data for U.S.-born black and white males, age 20 and up, at the county level, while Panel B shows individual means for U.S.-born white males, age 20 to 40. Sources: Ruggles et al. (2015) for the 1880 census. We thank Hoyt Bleakley for kindly sharing data on farm size and farm value obtained from the U.S. Censuses of Agriculture. 
Table 3: Population Statistics from the 1940 U.S. Census

\begin{tabular}{|c|c|c|c|c|c|c|c|c|}
\hline & \multirow[b]{2}{*}{$\begin{array}{c}(1) \\
\text { U.S.-Born }\end{array}$} & \multicolumn{2}{|c|}{ U.S. birth region } & \multicolumn{2}{|c|}{ Match to WWI } & \multicolumn{3}{|c|}{ Final sample (exposure) } \\
\hline & & $\begin{array}{c}\text { (2) } \\
\text { Non-South }\end{array}$ & $\begin{array}{c}\text { (3) } \\
\text { South }\end{array}$ & $\begin{array}{c}\text { (4) } \\
\text { Non-South }\end{array}$ & $\begin{array}{c}(5) \\
\text { South }\end{array}$ & $\begin{array}{c}(6) \\
0-30 \mathrm{~km}\end{array}$ & $\begin{array}{c}(7) \\
30-100 \mathrm{~km}\end{array}$ & $\begin{array}{c}(8) \\
\text { In utero }\end{array}$ \\
\hline Reported any wage income & 0.642 & 0.657 & 0.564 & 0.651 & 0.570 & 0.734 & 0.734 & 0.733 \\
\hline $50+$ USD non-wage income & 0.398 & 0.386 & 0.458 & 0.406 & 0.466 & 0.370 & 0.369 & 0.358 \\
\hline Wage and salary income & 1467.1 & 1503.8 & 1255.8 & 1529.1 & 1324.9 & 1359.0 & 1362.2 & 1294.9 \\
\hline Predicted business income & 1006.9 & 1064.2 & 756.6 & 1075.3 & 783.3 & 814.6 & 848.5 & 772.2 \\
\hline Occupational income score & 26.2 & 26.6 & 24.4 & 26.6 & 24.9 & 26.2 & 26.1 & 25.9 \\
\hline Occupational earnings score & 52.3 & 53.6 & 45.9 & 53.3 & 47.3 & 51.7 & 52.0 & 50.9 \\
\hline Occupational education score & 14.1 & 14.4 & 12.7 & 14.4 & 13.2 & 13.9 & 13.7 & 13.3 \\
\hline Worked 50+ weeks & 0.702 & 0.700 & 0.708 & 0.711 & 0.721 & 0.724 & 0.731 & 0.710 \\
\hline Employed in agriculture & 0.189 & 0.167 & 0.295 & 0.183 & 0.285 & 0.240 & 0.232 & 0.239 \\
\hline Married & 0.845 & 0.839 & 0.879 & 0.860 & 0.892 & 0.896 & 0.897 & 0.893 \\
\hline Highest grade completed & 8.7 & 8.9 & 7.8 & 8.9 & 8.0 & 8.1 & 8.0 & 8.0 \\
\hline Primary school graduate & 0.471 & 0.495 & 0.353 & 0.507 & 0.362 & 0.355 & 0.381 & 0.356 \\
\hline Middle school graduate & 0.148 & 0.145 & 0.159 & 0.150 & 0.164 & 0.158 & 0.153 & 0.157 \\
\hline High school graduate & 0.167 & 0.170 & 0.154 & 0.167 & 0.158 & 0.175 & 0.164 & 0.168 \\
\hline College completion & 0.054 & 0.056 & 0.044 & 0.056 & 0.046 & 0.057 & 0.049 & 0.055 \\
\hline $\mathrm{N}$ & 7003368 & 5825991 & 1177377 & 2115346 & 340661 & 19226 & 39625 & 1392 \\
\hline
\end{tabular}

Note: This table reports summary statistics from the 1940 U.S. Census by region, for the population and for the linked WWI-1940 sample, and by distance from hurricane paths for the final analysis sample. All columns restrict attention to U.S.-born white males with non-missing values of the main outcome variables: wages and imputed self-employment income, hours of work, and years of completed education. They also exclude individuals who were incarcerated, serving in the military, working for religious orders, or enrolled in school in 1940. Columns 1 to 3 report means for individuals aged 42 to 53 in 1940, while the remaining columns also include some individuals aged 39 to 41 , or 54 to 56 , due to inexact matches on age to WWI records. Source: authors' calculations based on the restricted-use version of 1940 U.S. Census complete count file. See Appendix A.3 for details on how predicted business income is computed. 
Table 4: Effects on Education and Labor Market Outcomes

\begin{tabular}{|c|c|c|c|c|c|c|}
\hline & $\begin{array}{c}\text { (1) } \\
\text { Years of } \\
\text { education }\end{array}$ & $\begin{array}{c}(2) \\
\text { Middle school } \\
\text { graduation }\end{array}$ & $\begin{array}{c}(3) \\
\text { Log income } \\
\text { (1939 USD) }\end{array}$ & $\begin{array}{c}(4) \\
\text { Worked } \\
50+\text { weeks }\end{array}$ & $\begin{array}{c}(5) \\
\text { Log income } \\
\text { (1939 USD) }\end{array}$ & $\begin{array}{c}(6) \\
\text { Worked } \\
50+\text { weeks }\end{array}$ \\
\hline \multicolumn{7}{|c|}{ Panel A: Effects of in utero exposure to hurricanes } \\
\hline Hurricane in utero & $\begin{array}{c}-0.131 \\
(0.100)\end{array}$ & $\begin{array}{c}-0.023 \\
(0.015)\end{array}$ & $\begin{array}{c}-0.073^{* * *} \\
(0.021)\end{array}$ & $\begin{array}{c}-0.016 \\
(0.014)\end{array}$ & $\begin{array}{c}-0.060^{* * *} \\
(0.019)\end{array}$ & $\begin{array}{c}-0.013 \\
(0.014)\end{array}$ \\
\hline \multicolumn{7}{|c|}{ Panel B: Post-storm conception, in utero, or age 0 to 2 exposure to hurricanes } \\
\hline Post-storm conception & $\begin{array}{c}0.030 \\
(0.092)\end{array}$ & $\begin{array}{c}0.013 \\
(0.011)\end{array}$ & $\begin{array}{c}0.024 \\
(0.019)\end{array}$ & $\begin{array}{c}-0.002 \\
(0.012)\end{array}$ & $\begin{array}{c}0.021 \\
(0.016)\end{array}$ & $\begin{array}{c}-0.003 \\
(0.011)\end{array}$ \\
\hline Hurricane in utero & $\begin{array}{c}-0.132 \\
(0.105)\end{array}$ & $\begin{array}{c}-0.022 \\
(0.015)\end{array}$ & $\begin{array}{c}-0.075^{* * *} \\
(0.022)\end{array}$ & $\begin{array}{c}-0.018 \\
(0.014)\end{array}$ & $\begin{array}{c}-0.062^{* * *} \\
(0.019)\end{array}$ & $\begin{array}{c}-0.015 \\
(0.013)\end{array}$ \\
\hline Hurricane age $[0,6]$ months & $\begin{array}{c}0.001 \\
(0.135)\end{array}$ & $\begin{array}{c}-0.011 \\
(0.021)\end{array}$ & $\begin{array}{r}-0.051^{*} \\
(0.027)\end{array}$ & $\begin{array}{c}-0.012 \\
(0.015)\end{array}$ & $\begin{array}{c}-0.049^{* *} \\
(0.023)\end{array}$ & $\begin{array}{c}-0.013 \\
(0.015)\end{array}$ \\
\hline Hurricane age $[7,12]$ months & $\begin{array}{c}-0.183 \\
(0.134)\end{array}$ & $\begin{array}{c}-0.016 \\
(0.018)\end{array}$ & $\begin{array}{c}-0.010 \\
(0.028)\end{array}$ & $\begin{array}{c}-0.008 \\
(0.015)\end{array}$ & $\begin{array}{c}0.008 \\
(0.026)\end{array}$ & $\begin{array}{c}-0.004 \\
(0.015)\end{array}$ \\
\hline Hurricane age $[1,2]$ & $\begin{array}{c}0.069 \\
(0.106)\end{array}$ & $\begin{array}{c}0.010 \\
(0.014)\end{array}$ & $\begin{array}{c}-0.015 \\
(0.021)\end{array}$ & $\begin{array}{c}-0.008 \\
(0.013)\end{array}$ & $\begin{array}{c}-0.022 \\
(0.020)\end{array}$ & $\begin{array}{c}-0.009 \\
(0.012)\end{array}$ \\
\hline Education controls & No & No & No & No & Yes & Yes \\
\hline Mean of $Y$ & 8.001 & 0.374 & 6.907 & 0.729 & 6.907 & 0.729 \\
\hline P-value (Equality of coefficients) & 0.440 & 0.145 & 0.008 & 0.938 & 0.008 & 0.958 \\
\hline $\mathrm{N}$ & \multicolumn{6}{|c|}{58851} \\
\hline
\end{tabular}

Notes: Each column and panel displays coefficients from a separate regression of an educational or labor market outcome in 1940 on a measure of hurricane exposure: an indicator variable equal to one if a hurricane track passed within 30 kilometers of the individual's location of birth during the in utero period (Panel A), or separate indicators for exposure in utero, age 0 to 6 months, age 7 to 12 months, age 1 to 2 years, and conception up to 1 year after the storm (Panel B). In columns 3 and 5, income is the sum of wage income reported in the 1940 census, and business or farm income imputed using data from the 1950 census (See Appendix A.3 for details). Each specification controls for linkage quality measures, an indicator for individuals born in locations within 30 kilometers of a hurricane during the sample period, state-specific linear time trends, as well as county of birth, conception year, and conception week fixed effects. The samples restrict attention to individuals with non-missing occupational outcomes, incomes, and years of education in 1940. Standard errors are clustered by county of birth. Point estimates marked $* * ; *$, and $*$ are statistically significant at the 1,5 , and 10 percent levels, respectively. Probability of exposure within the sample: .03 (conception 0 to 1 year after hurricane), .024 (in utero), .014 (age 0 to 6 months), .015 (age 7 to 12 months), and .029 (age 1 to 2 years). 
Table 5: The Role of Storm Categories and Pregnancy Trimesters

\begin{tabular}{|c|c|c|c|c|c|c|}
\hline & $\begin{array}{c}\text { (1) } \\
\text { Years of } \\
\text { education }\end{array}$ & $\begin{array}{c}(2) \\
\text { Middle school } \\
\text { graduation }\end{array}$ & $\begin{array}{c}(3) \\
\text { Log income } \\
\text { (1939 USD) }\end{array}$ & $\begin{array}{c}(4) \\
\text { Worked } \\
50+\text { weeks }\end{array}$ & $\begin{array}{c}(5) \\
\text { Log income } \\
\text { (1939 USD) }\end{array}$ & $\begin{array}{c}(6) \\
\text { Worked } \\
50+\text { weeks }\end{array}$ \\
\hline \multicolumn{7}{|c|}{ Panel A: Effects of in utero hurricane exposure by trimester } \\
\hline Hurricane 1 st trimester & $\begin{array}{c}-0.413^{* *} \\
(0.167)\end{array}$ & $\begin{array}{r}-0.044^{*} \\
(0.023)\end{array}$ & $\begin{array}{c}-0.104^{* *} \\
(0.041)\end{array}$ & $\begin{array}{c}0.005 \\
(0.023)\end{array}$ & $\begin{array}{r}-0.062^{*} \\
(0.037)\end{array}$ & $\begin{array}{c}0.012 \\
(0.023)\end{array}$ \\
\hline Hurricane 2nd trimester & $\begin{array}{c}-0.059 \\
(0.175)\end{array}$ & $\begin{array}{c}-0.014 \\
(0.023)\end{array}$ & $\begin{array}{c}-0.053 \\
(0.042)\end{array}$ & $\begin{array}{c}-0.012 \\
(0.022)\end{array}$ & $\begin{array}{c}-0.047 \\
(0.039)\end{array}$ & $\begin{array}{c}-0.011 \\
(0.022)\end{array}$ \\
\hline Hurricane 3rd trimester & $\begin{array}{c}0.058 \\
(0.170)\end{array}$ & $\begin{array}{l}-0.010 \\
(0.022)\end{array}$ & $\begin{array}{r}-0.068^{*} \\
(0.040)\end{array}$ & $\begin{array}{c}-0.044^{* *} \\
(0.022)\end{array}$ & $\begin{array}{c}-0.074^{* *} \\
(0.034)\end{array}$ & $\begin{array}{c}-0.045^{* *} \\
(0.021)\end{array}$ \\
\hline \multicolumn{7}{|c|}{ Panel B: Effects of in utero exposure to hurricanes and interaction with Category 2 or 3 hurricanes } \\
\hline Hurricane in utero & $\begin{array}{c}-0.157 \\
(0.123)\end{array}$ & $\begin{array}{r}-0.028^{*} \\
(0.016)\end{array}$ & $\begin{array}{c}-0.080^{* * *} \\
(0.025)\end{array}$ & $\begin{array}{c}-0.020 \\
(0.014)\end{array}$ & $\begin{array}{c}-0.065^{* * *} \\
(0.022)\end{array}$ & $\begin{array}{c}-0.017 \\
(0.013)\end{array}$ \\
\hline In utero $\times$ Category 2 or 3 & $\begin{array}{c}0.141 \\
(0.246) \\
\end{array}$ & $\begin{array}{c}0.035 \\
(0.039) \\
\end{array}$ & $\begin{array}{c}0.032 \\
(0.052) \\
\end{array}$ & $\begin{array}{c}0.011 \\
(0.045) \\
\end{array}$ & $\begin{array}{c}0.022 \\
(0.043) \\
\end{array}$ & $\begin{array}{c}0.012 \\
(0.044) \\
\end{array}$ \\
\hline Education controls & No & No & No & No & Yes & Yes \\
\hline Mean of $Y$ & 8.001 & 0.374 & 6.907 & 0.729 & 6.907 & 0.729 \\
\hline P-value (Equality of trimesters) & 0.101 & 0.468 & 0.693 & 0.310 & 0.884 & 0.205 \\
\hline $\mathrm{N}$ & \multicolumn{6}{|c|}{58851} \\
\hline
\end{tabular}

Notes: See Table 4 for details on sample and controls. Panel A shows separate coefficients for exposure during each trimester of pregnancy, but is otherwise identical to Panel B of Table 4. In Panel B, the variable of interest is an interaction of an indicator for in utero exposure to a hurricane with indicators for whether a Category 1 or a Category 2 to 3 hurricane were experienced in the location of birth while in utero. The regression also includes interactions of the storm category indicators with each of the remaining indicators for hurricane exposure by age. Standard errors are clustered by county of birth. Point estimates marked $* * * *$, and $*$ are statistically significant at the 1,5 , and 10 percent levels, respectively. Probability of exposure within sample: .008 (1st trimester), .008 (2nd trimester), and .008 (3rd trimester). Probability of storms by category: .019 (Category 1) and .004 (Category 2 or 3 ). 
Table 6: Effects on Gender Ratio in 1900, By Race

\begin{tabular}{|c|c|c|c|c|c|c|}
\hline & \multicolumn{2}{|c|}{ Pooled } & \multicolumn{2}{|c|}{ Whites } & \multicolumn{2}{|c|}{ Blacks } \\
\hline & $\begin{array}{c}(1) \\
1886-1896\end{array}$ & $\begin{array}{c}(2) \\
1892-1896\end{array}$ & $\begin{array}{c}(3) \\
1886-1896\end{array}$ & $\begin{array}{c}(4) \\
1892-1896\end{array}$ & $\begin{array}{c}(5) \\
1886-1896\end{array}$ & $\begin{array}{c}(6) \\
1892-1896\end{array}$ \\
\hline \multicolumn{7}{|c|}{ Panel A: Effects of in utero exposure to hurricanes } \\
\hline Hurricane in utero & $\begin{array}{c}-0.024^{* *} \\
(0.011)\end{array}$ & $\begin{array}{r}-0.023^{*} \\
(0.012)\end{array}$ & $\begin{array}{c}0.008 \\
(0.020)\end{array}$ & $\begin{array}{c}0.010 \\
(0.026)\end{array}$ & $\begin{array}{c}-0.044^{* *} \\
(0.017)\end{array}$ & $\begin{array}{c}-0.051^{* * *} \\
(0.017)\end{array}$ \\
\hline \multicolumn{7}{|c|}{ Panel B: Post-storm conception, in utero, or age 0 to 2 exposure to hurricanes } \\
\hline Post-storm conception & $\begin{array}{c}-0.011 \\
(0.009)\end{array}$ & $\begin{array}{c}-0.019 \\
(0.012)\end{array}$ & $\begin{array}{c}-0.024 \\
(0.017)\end{array}$ & $\begin{array}{r}-0.047^{*} \\
(0.024)\end{array}$ & $\begin{array}{c}0.008 \\
(0.018)\end{array}$ & $\begin{array}{c}0.015 \\
(0.022)\end{array}$ \\
\hline Hurricane in utero & $\begin{array}{c}-0.027^{* *} \\
(0.012)\end{array}$ & $\begin{array}{c}-0.032^{* *} \\
(0.014)\end{array}$ & $\begin{array}{c}0.008 \\
(0.021)\end{array}$ & $\begin{array}{c}-0.003 \\
(0.027)\end{array}$ & $\begin{array}{c}-0.048^{* *} \\
(0.018)\end{array}$ & $\begin{array}{c}-0.055^{* * *} \\
(0.021)\end{array}$ \\
\hline Hurricane age $[0,6]$ months & $\begin{array}{r}-0.026^{*} \\
(0.014)\end{array}$ & $\begin{array}{c}-0.036^{* *} \\
(0.015)\end{array}$ & $\begin{array}{c}-0.002 \\
(0.025)\end{array}$ & $\begin{array}{c}-0.030 \\
(0.027)\end{array}$ & $\begin{array}{c}-0.052^{* * *} \\
(0.020)\end{array}$ & $\begin{array}{c}-0.051^{* *} \\
(0.022)\end{array}$ \\
\hline Hurricane age $[7,12]$ months & $\begin{array}{c}0.022 \\
(0.015)\end{array}$ & $\begin{array}{c}0.006 \\
(0.017)\end{array}$ & $\begin{array}{c}0.041^{*} \\
(0.025)\end{array}$ & $\begin{array}{c}0.012 \\
(0.028)\end{array}$ & $\begin{array}{c}-0.012 \\
(0.020)\end{array}$ & $\begin{array}{c}-0.015 \\
(0.023)\end{array}$ \\
\hline Hurricane age $[1,2]$ years & $\begin{array}{c}-0.002 \\
(0.011) \\
\end{array}$ & $\begin{array}{c}-0.001 \\
(0.017)\end{array}$ & $\begin{array}{c}0.005 \\
(0.019)\end{array}$ & $\begin{array}{c}0.017 \\
(0.037)\end{array}$ & $\begin{array}{c}0.004 \\
(0.015)\end{array}$ & $\begin{array}{c}0.017 \\
(0.022) \\
\end{array}$ \\
\hline Mean of Y & 1.074 & 1.063 & 1.129 & 1.130 & 1.087 & 1.077 \\
\hline $\mathrm{N}$ & 43392 & 17110 & 32128 & 14160 & 25088 & 11446 \\
\hline
\end{tabular}

Note: This table presents results from models where the dependent variable is the (male/female) gender ratio in the 1900 U.S. Census. An observation is a county of residence-by-month of conception cell. Dade and Monroe counties, at the southern tip of Florida, are dropped from the sample. Each specification also excludes counties with no births, and counties with no male or female births, in at least one month during the sample period. All specification also excludes counties with no births, and counties with no male or female births, in at least one month during the sample period. All
regressions weight observations by the number of births in the county of residence. All columns include as controls state-specific linear trends, 1900 county of residence fixed effects, and conception year and month fixed effects. Standard errors (in parentheses) are clustered at the residence (birth) county level. Point estimates marked $* * * * *$ and $*$ are statistically significant at the 1,5 , and 10 percent levels, respectively. 
Table 7: Effects on Migration by 1900 and 1940

\begin{tabular}{|c|c|c|c|c|c|c|}
\hline & \multicolumn{3}{|c|}{ Migration by 1900} & \multicolumn{3}{|c|}{ Migration by 1940} \\
\hline & $\begin{array}{c}\text { (1) } \\
\text { Inter- } \\
\text { County }\end{array}$ & $\begin{array}{l}(2) \\
\text { Inter- } \\
\text { State }\end{array}$ & $\begin{array}{l}\text { (3) } \\
\text { Outside } \\
\text { South }\end{array}$ & $\begin{array}{c}(4) \\
\text { Inter- } \\
\text { County }\end{array}$ & $\begin{array}{l}\text { (5) } \\
\text { Inter- } \\
\text { State }\end{array}$ & $\begin{array}{l}\text { (6) } \\
\text { Outside } \\
\text { South }\end{array}$ \\
\hline \multicolumn{7}{|c|}{ Panel A: Effects of in utero exposure to hurricanes } \\
\hline Hurricane in utero & $\begin{array}{c}0.005 \\
(0.010)\end{array}$ & $\begin{array}{c}0.003 \\
(0.006)\end{array}$ & $\begin{array}{c}-0.001 \\
(0.003)\end{array}$ & $\begin{array}{c}0.012 \\
(0.015)\end{array}$ & $\begin{array}{c}-0.027^{* *} \\
(0.012)\end{array}$ & $\begin{array}{c}-0.001 \\
(0.007)\end{array}$ \\
\hline \multicolumn{7}{|c|}{ Panel B: Post-storm conception, in utero, or age 0 to 2 exposure to hurricanes } \\
\hline Post-storm conception & $\begin{array}{c}0.008 \\
(0.009)\end{array}$ & $\begin{array}{c}-0.004 \\
(0.005)\end{array}$ & $\begin{array}{c}-0.004 \\
(0.003)\end{array}$ & $\begin{array}{c}-0.002 \\
(0.012)\end{array}$ & $\begin{array}{c}-0.011 \\
(0.011)\end{array}$ & $\begin{array}{c}-0.007 \\
(0.008)\end{array}$ \\
\hline Hurricane in utero & $\begin{array}{c}0.008 \\
(0.011)\end{array}$ & $\begin{array}{c}0.001 \\
(0.006)\end{array}$ & $\begin{array}{c}-0.001 \\
(0.003)\end{array}$ & $\begin{array}{c}0.010 \\
(0.015)\end{array}$ & $\begin{array}{c}-0.028^{* *} \\
(0.012)\end{array}$ & $\begin{array}{c}-0.001 \\
(0.007)\end{array}$ \\
\hline Hurricane age $[0,6]$ months & $\begin{array}{c}-0.002 \\
(0.014)\end{array}$ & $\begin{array}{c}-0.007 \\
(0.006)\end{array}$ & $\begin{array}{c}0.000 \\
(0.003)\end{array}$ & $\begin{array}{c}0.002 \\
(0.018)\end{array}$ & $\begin{array}{c}-0.018 \\
(0.018)\end{array}$ & $\begin{array}{c}-0.012 \\
(0.009)\end{array}$ \\
\hline Hurricane age $[7,12]$ months & $\begin{array}{c}0.004 \\
(0.012)\end{array}$ & $\begin{array}{c}-0.004 \\
(0.008)\end{array}$ & $\begin{array}{c}-0.002 \\
(0.004)\end{array}$ & $\begin{array}{c}-0.019 \\
(0.017)\end{array}$ & $\begin{array}{c}0.012 \\
(0.014)\end{array}$ & $\begin{array}{c}-0.001 \\
(0.009)\end{array}$ \\
\hline Hurricane age $[1,2]$ & $\begin{array}{c}0.015 \\
(0.013)\end{array}$ & $\begin{array}{c}-0.007 \\
(0.006)\end{array}$ & $\begin{array}{c}0.001 \\
(0.003)\end{array}$ & $\begin{array}{c}-0.007 \\
(0.013)\end{array}$ & $\begin{array}{c}0.006 \\
(0.012)\end{array}$ & $\begin{array}{r}0.015^{*} \\
(0.008)\end{array}$ \\
\hline Mean of Y & 0.218 & 0.046 & 0.013 & 0.386 & 0.260 & 0.097 \\
\hline P-value (Equality of coefficients) & 0.907 & 0.776 & 0.563 & 0.726 & 0.056 & 0.017 \\
\hline $\mathrm{N}$ & & 79549 & & & 58851 & \\
\hline
\end{tabular}

Note: This table presents results from models where the dependent variables are indicators for migrating to different destinations by 1900 (columns 1 to 3) or 1940 (columns 4 to 6). The dependent variables are indicators for: county of residence different from county of birth, but living in the same state; state of residence different from state of birth; and residing outside the South. In addition to the nine hurricane states, the "South" includes Arkansas, Delaware, Kentucky, Maryland, Oklahoma, Tennessee, and West Virginia. Estimation is based on samples of individuals uniquely linked from the WWI draft records to the 1900 U.S. Census (columns 1 to 3) or the 1940 U.S. Census (columns 4 to 6). See Table 4 for details on the sample and controls. In columns 1 to 3 , the sample also restricts attention to individuals with mothers aged 15 to 49 at the time of birth, and the regressions include as controls indicators for mother's age at birth (age 20 to 24, 25 to 34,35 to 39 , and 40 and up). Standard errors are clustered at the birth county level. Point estimates marked ***, **, and *are statistically significant at the 1,5 , and 10 percent levels, respectively. 


\section{Figures}

Figure 1: Birth Locations and Hurricane Exposure

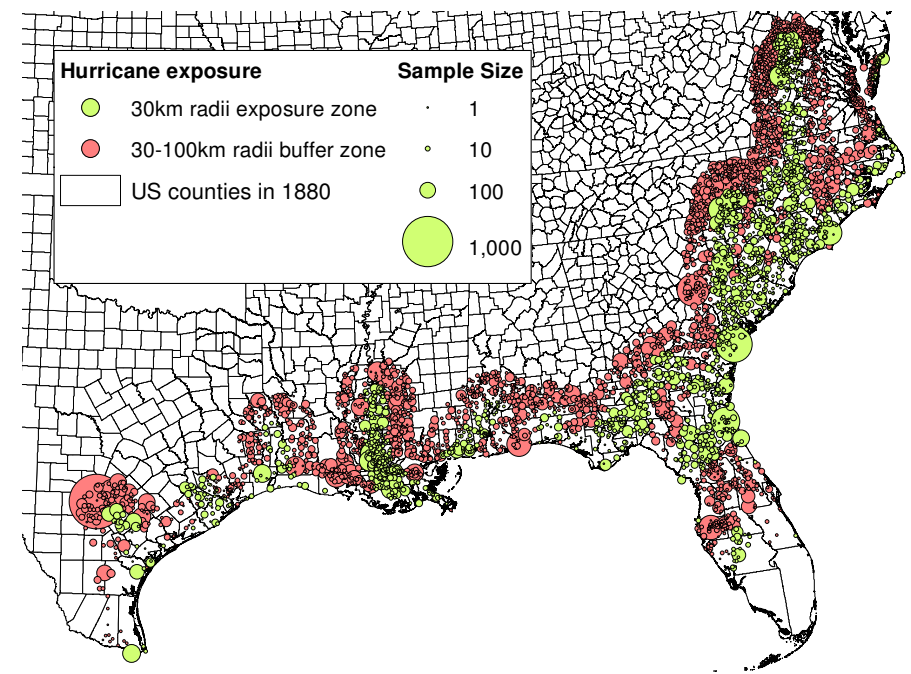

Note: This figure plots the latitude and longitude coordinates of the city or town of birth for locations within 100 kilometers of the path of a hurricane that hit the continental U.S. between 1885 and 1899. The coordinates are overlayed on a map of U.S. county boundaries for 1880 . Green circles indicate birth locations within 30 kilometers of a hurricane path during the sample period, while red circles denote locations 30 to 100 kilometers away. The diameter of the circles is proportional to the number of observations at each location. The sample consists of all U.S.-born white males satisfying the sample restrictions described in Table 4. Sources: Minnesota Population Center (2011) for boundary file; authors' calculations based on WWI Draft Registration Cards (n.d.) and U.S. Geological Survey (2014) for coordinates.

Figure 2: Estimated Completeness of WWI Draft Registration

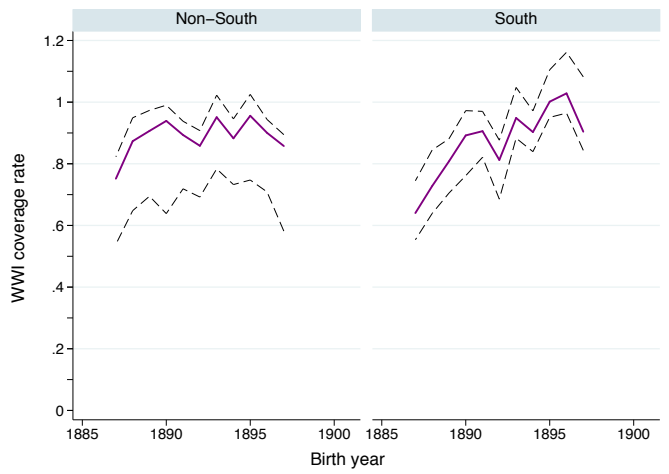

Note: This figure plots the completeness rate of the WWI draft against year of birth, by birth region: the "hurricane zone" Southern states ("South", right panel) and the rest of the county ("Non-South", left panel). The solid purple lines denote the average completeness rate by birth cohort and the dashed lines indicate the states with the highest and lowest coverage in each region. The non-South excludes Alaska, Hawaii, and the District of Columbia. The rate of completeness is calculated as the ratio of the number of individuals in a birth cohort who registered for the draft, to the number of individuals from the same birth cohort who were enumerated in the 1910 U.S. Census. Since the census only reports age in years on the day of the census, the birth cohort from the WWI records for year $t$ includes individuals born between 16 April in year $t-1$ and 15 April (census day) in year $t$. 


\section{Appendix Tables}

Table A1: Robustness - Selection of Birth Locations

\begin{tabular}{|c|c|c|c|c|}
\hline & \multicolumn{2}{|c|}{ Coordinates + centroids } & \multicolumn{2}{|c|}{ County centroids only } \\
\hline & $\begin{array}{c}(1) \\
\text { Log income }\end{array}$ & $\begin{array}{c}(2) \\
50+\text { weeks }\end{array}$ & $\begin{array}{c}(3) \\
\log \text { income }\end{array}$ & $\begin{array}{c}\text { (4) } \\
50+\text { weeks }\end{array}$ \\
\hline \multicolumn{5}{|c|}{ Panel A: Effects of in utero exposure to hurricanes } \\
\hline Hurricane in utero & $\begin{array}{c}-0.058^{* * *} \\
(0.021)\end{array}$ & $\begin{array}{c}-0.014 \\
(0.013)\end{array}$ & $\begin{array}{r}-0.036^{*} \\
(0.020)\end{array}$ & $\begin{array}{c}-0.015 \\
(0.013)\end{array}$ \\
\hline \multicolumn{5}{|c|}{ Panel B: Post-storm conception, in utero, or age 0 to 2 exposure to hurricanes } \\
\hline Post-storm conception & $\begin{array}{c}0.017 \\
(0.019)\end{array}$ & $\begin{array}{c}-0.006 \\
(0.010)\end{array}$ & $\begin{array}{r}-0.014 \\
(0.016)\end{array}$ & $\begin{array}{c}-0.011 \\
(0.010)\end{array}$ \\
\hline Hurricane in utero & $\begin{array}{c}-0.059^{* * *} \\
(0.021)\end{array}$ & $\begin{array}{c}-0.017 \\
(0.013)\end{array}$ & $\begin{array}{c}-0.044^{* *} \\
(0.021)\end{array}$ & $\begin{array}{c}-0.019 \\
(0.013)\end{array}$ \\
\hline Hurricane age $[0,6]$ months & $\begin{array}{r}-0.045^{*} \\
(0.026)\end{array}$ & $\begin{array}{c}-0.012 \\
(0.014)\end{array}$ & $\begin{array}{c}-0.066^{* *} \\
(0.026)\end{array}$ & $\begin{array}{c}-0.010 \\
(0.015)\end{array}$ \\
\hline Hurricane age $[7,12]$ months & $\begin{array}{c}-0.018 \\
(0.025)\end{array}$ & $\begin{array}{c}-0.013 \\
(0.014)\end{array}$ & $\begin{array}{c}-0.012 \\
(0.026)\end{array}$ & $\begin{array}{c}-0.015 \\
(0.014)\end{array}$ \\
\hline Hurricane age $[1,2]$ & $\begin{array}{c}-0.005 \\
(0.020)\end{array}$ & $\begin{array}{c}-0.008 \\
(0.011)\end{array}$ & $\begin{array}{c}-0.007 \\
(0.021)\end{array}$ & $\begin{array}{c}-0.003 \\
(0.012)\end{array}$ \\
\hline Mean of Y & 6.891 & 0.727 & 6.890 & 0.727 \\
\hline P-value (Equality of coefficients) & 0.027 & 0.960 & 0.237 & 0.914 \\
\hline $\mathrm{N}$ & 65781 & 65781 & 67001 & 67001 \\
\hline
\end{tabular}

Note: The table presents results based on different restrictions on the assignment of coordinates to the birth location, which determine exposure to a hurricane. Columns 1 and 2 identify exposure to hurricanes based on the coordinates of the reported birth location and add exposure based on birth county centroid when the exact location is missing, while columns 3 and 4 define exposure based only on the coordinates of the birth county centroid. In columns 1 and 3, the dependent variable is log income (1939 USD), and in columns 2 and 4 it is an indicator for working at least 50 weeks in a year. Aside from including observations with birth location known only at the county level, the regressions impose the same restrictions as the main estimation sample. See Table 4 for details on the sample and controls. Standard errors are clustered by county of birth. Point estimates marked $* *$, **, and * are statistically significant at the 1,5 , and 10 percent levels, respectively. 
Table A2: Probability of Matching WWI Records to the 1900 and 1940 U.S. Censuses

\begin{tabular}{|c|c|c|c|c|c|c|}
\hline & \multicolumn{3}{|c|}{ Match to 1900} & \multicolumn{3}{|c|}{ Match to 1940} \\
\hline & $\begin{array}{c}\text { (1) } \\
\text { Unique match }\end{array}$ & $\begin{array}{c}\text { (2) } \\
\text { Multiple matches }\end{array}$ & $\begin{array}{c}\text { (3) } \\
\text { Final sample }\end{array}$ & $\begin{array}{c}\text { (4) } \\
\text { Unique match }\end{array}$ & $\begin{array}{l}\text { (5) } \\
\text { Multiple matches }\end{array}$ & $\begin{array}{c}\text { (6) } \\
\text { Final sample }\end{array}$ \\
\hline \multicolumn{7}{|c|}{ Panel A: Effects of in-utero exposure to hurricanes } \\
\hline Hurricane in utero & $\begin{array}{c}0.004 \\
(0.005)\end{array}$ & $\begin{array}{c}0.002 \\
(0.002)\end{array}$ & $\begin{array}{c}0.005 \\
(0.004)\end{array}$ & $\begin{array}{c}0.006 \\
(0.004)\end{array}$ & $\begin{array}{c}0.006 \\
(0.004) \\
\end{array}$ & $\begin{array}{c}0.004 \\
(0.003) \\
\end{array}$ \\
\hline \multicolumn{7}{|c|}{ Panel B: Post-storm conception, in utero, or age 0 to 2 exposure to hurricanes } \\
\hline Post-storm conception & $\begin{array}{c}0.005 \\
(0.004)\end{array}$ & $\begin{array}{c}-0.002 \\
(0.002)\end{array}$ & $\begin{array}{l}0.005 \\
(0.003)\end{array}$ & $\begin{array}{c}0.001 \\
(0.004)\end{array}$ & $\begin{array}{c}0.001 \\
(0.003)\end{array}$ & $\begin{array}{l}0.001 \\
(0.003)\end{array}$ \\
\hline Hurricane in utero & $\begin{array}{c}0.006 \\
(0.005)\end{array}$ & $\begin{array}{c}0.002 \\
(0.002)\end{array}$ & $\begin{array}{l}0.007 \\
(0.004)\end{array}$ & $\begin{array}{c}0.006 \\
(0.005)\end{array}$ & $\begin{array}{c}0.007 \\
(0.005)\end{array}$ & $\begin{array}{c}0.004 \\
(0.003)\end{array}$ \\
\hline Hurricane age $[0,6]$ months & $\begin{array}{c}0.002 \\
(0.005)\end{array}$ & $\begin{array}{l}0.005^{* *} \\
(0.002)\end{array}$ & $\begin{array}{c}0.002 \\
(0.004)\end{array}$ & $\begin{array}{c}-0.007 \\
(0.005)\end{array}$ & $\begin{array}{c}0.008 \\
(0.005)\end{array}$ & $\begin{array}{c}-0.002 \\
(0.004)\end{array}$ \\
\hline Hurricane age $[7,12]$ months & $\begin{array}{c}0.003 \\
(0.004)\end{array}$ & $\begin{array}{c}-0.003 \\
(0.002)\end{array}$ & $\begin{array}{c}0.004 \\
(0.004)\end{array}$ & $\begin{array}{c}-0.004 \\
(0.005)\end{array}$ & $\begin{array}{c}0.003 \\
(0.005)\end{array}$ & $\begin{array}{c}-0.003 \\
(0.004)\end{array}$ \\
\hline Hurricane age $[1,2]$ & $\begin{array}{l}0.006 \\
(0.004)\end{array}$ & $\begin{array}{c}-0.002 \\
(0.002)\end{array}$ & $\begin{array}{l}0.007^{* *} \\
(0.003)\end{array}$ & $\begin{array}{c}0.001 \\
(0.004)\end{array}$ & $\begin{array}{l}0.001 \\
(0.004)\end{array}$ & $\begin{array}{c}0.003 \\
(0.003)\end{array}$ \\
\hline Mean of Y & 0.243 & 0.041 & 0.174 & 0.257 & 0.184 & 0.129 \\
\hline P-value (Equality of coefficients) & 0.968 & 0.020 & 0.791 & 0.332 & 0.531 & 0.550 \\
\hline $\mathrm{N}$ & \multicolumn{6}{|c|}{455888} \\
\hline
\end{tabular}

Note: This table reports the results of models where the dependent variables are indicators that equal one if an individual is matched from the WWI Draft Registration Cards database to a unique record (column 1) or more than one record (column 2) in the 1900 U.S. Census, or the same outcomes for matches to the 1940 U.S. Census (columns 4 and 5). In columns 3 and 6, the dependent variables are indicators for the subset of unique matches to the 1900 census that appear in the migration regression sample in Table 7, and the subset of unique matches to the 1940 census that are part of the main estimation sample (Table 4), respectively. In addition to the restrictions on the baseline sample described in Table 1, this table drops individuals for whom the coordinates of the birth location are unknown, and individuals whose birth state is not uniquely identified. All specifications include an indicator for birth locations within 30 kilometers of a hurricane path during the sample period, state-specific trends, and county of birth, conception year, and conception week fixed effects as controls. Standard errors (in parentheses) are clustered at the birth county level. Point estimates marked $\% * \%, *$, and * are statistically significant at the 1,5 , and 10 percent levels, respectively. 
Table A3: Interaction with Urbanization Rate and Farm Value in 1880

\begin{tabular}{|c|c|c|c|c|c|c|}
\hline & $\begin{array}{c}\text { (1) } \\
\text { Years of } \\
\text { education }\end{array}$ & $\begin{array}{l}\text { (2) } \\
\text { Middle school } \\
\text { graduation }\end{array}$ & $\begin{array}{c}(3) \\
\text { Log income } \\
\text { (1939 USD) }\end{array}$ & $\begin{array}{c}(4) \\
\text { Worked } \\
50+\text { weeks }\end{array}$ & $\begin{array}{c}(5) \\
\text { Log income } \\
(1939 \text { USD) }\end{array}$ & $\begin{array}{c}(6) \\
\text { Worked } \\
50+\text { weeks }\end{array}$ \\
\hline \multicolumn{7}{|c|}{ Panel A: Effects of in utero exposure and interaction with county urbanization rate } \\
\hline Hurricane in utero & $\begin{array}{r}-0.171 \\
(0.108)\end{array}$ & $\begin{array}{c}-0.033^{* *} \\
(0.015)\end{array}$ & $\begin{array}{c}-0.082^{* * *} \\
(0.025)\end{array}$ & $\begin{array}{c}-0.030^{* *} \\
(0.015)\end{array}$ & $\begin{array}{c}-0.066^{* * *} \\
(0.022)\end{array}$ & $\begin{array}{r}-0.027^{*} \\
(0.014)\end{array}$ \\
\hline In utero $\times$ Urbanization rate & $\begin{array}{c}0.004 \\
(0.004)\end{array}$ & $\begin{array}{c}0.001^{*} \\
(0.001)\end{array}$ & $\begin{array}{c}0.001 \\
(0.001)\end{array}$ & $\begin{array}{l}0.001^{* * *} \\
(0.000)\end{array}$ & $\begin{array}{c}0.001 \\
(0.001)\end{array}$ & $\begin{array}{l}0.001^{* * *} \\
(0.000)\end{array}$ \\
\hline $\begin{array}{l}\text { Mean of } \mathrm{Y} \\
\mathrm{N}\end{array}$ & \multicolumn{6}{|c|}{58851} \\
\hline \multicolumn{7}{|c|}{ Panel B: Effects of in utero exposure and interaction with below median farm value indicator } \\
\hline Hurricane in utero & $\begin{array}{r}-0.180 \\
(0.143)\end{array}$ & $\begin{array}{c}-0.024 \\
(0.020)\end{array}$ & $\begin{array}{c}-0.066^{* *} \\
(0.027)\end{array}$ & $\begin{array}{c}-0.029 \\
(0.018)\end{array}$ & $\begin{array}{r}-0.048^{*} \\
(0.025)\end{array}$ & $\begin{array}{c}-0.026 \\
(0.017)\end{array}$ \\
\hline In utero $\times($ Farm value $<\mathrm{p}(50))$ & $\begin{array}{c}0.107 \\
(0.211)\end{array}$ & $\begin{array}{c}0.004 \\
(0.029)\end{array}$ & $\begin{array}{c}-0.021 \\
(0.044)\end{array}$ & $\begin{array}{c}0.024 \\
(0.027)\end{array}$ & $\begin{array}{r}-0.032 \\
(0.038)\end{array}$ & $\begin{array}{c}0.023 \\
(0.026)\end{array}$ \\
\hline Education controls & No & No & No & No & Yes & Yes \\
\hline Mean of Y & 8.001 & 0.374 & 6.907 & 0.729 & 6.907 & 0.729 \\
\hline $\mathrm{N}$ & \multicolumn{6}{|c|}{58808} \\
\hline
\end{tabular}

Note: This table reports results from estimating the specifications in panel B of Table 4, with each of the hurricane exposure indicators interacted with the urbanization rate of the birth county in 1880 (Panel A), and an indicator for whether the average farm value of the birth county in 1880 was below the median among counties in the estimation sample (Panel B). The urbanization rate is defined as the percentage of county residents ( 0 to 100) living in an urban area with at least 2,500 residents. Farm value measures the per acre fair market value of farms, including land, fences, and buildings, and is obtained from the 1880 Agricultural Census. Since urbanization rate and farm value are defined at the county level, the main effects of each variable are subsumed in the county fixed effects. See Table 4 for details on the sample and controls. Standard errors are clustered at the birth county level. Point estimates marked $* * * * *$, and $*$ are statistically significant at the 1,5 , and 10 percent levels, respectively. 
Table A4: Robustness - Logarithm of Wage and Salary Income

\begin{tabular}{|c|c|c|c|c|c|c|}
\hline & \multicolumn{2}{|c|}{ Restricted Sample } & \multicolumn{2}{|c|}{ Relaxed Sample } & \multicolumn{2}{|c|}{ Full Sample } \\
\hline & (1) & (2) & (3) & (4) & (5) & (6) \\
\hline \multicolumn{7}{|c|}{ Panel A: Effects of in utero exposure to hurricanes } \\
\hline Hurricane in utero & $\begin{array}{c}-0.061^{* *} \\
(0.029)\end{array}$ & $\begin{array}{c}-0.060^{* *} \\
(0.027)\end{array}$ & $\begin{array}{c}-0.056^{* *} \\
(0.028)\end{array}$ & $\begin{array}{c}-0.055^{* *} \\
(0.025)\end{array}$ & $\begin{array}{c}-0.072 \\
(0.087)\end{array}$ & $\begin{array}{c}-0.068 \\
(0.084)\end{array}$ \\
\hline \multicolumn{7}{|c|}{ Panel B: Post-storm conception, in utero, or age 0 to 2 exposure to hurricanes } \\
\hline Post-storm conception & $\begin{array}{c}0.019 \\
(0.027)\end{array}$ & $\begin{array}{c}0.022 \\
(0.023)\end{array}$ & $\begin{array}{c}0.028 \\
(0.026)\end{array}$ & $\begin{array}{c}0.027 \\
(0.022)\end{array}$ & $\begin{array}{c}-0.019 \\
(0.075)\end{array}$ & $\begin{array}{c}-0.034 \\
(0.076)\end{array}$ \\
\hline Hurricane in utero & $\begin{array}{c}-0.067^{* *} \\
(0.030)\end{array}$ & $\begin{array}{c}-0.065^{* *} \\
(0.027)\end{array}$ & $\begin{array}{r}-0.057^{*} \\
(0.029)\end{array}$ & $\begin{array}{c}-0.056^{* *} \\
(0.025)\end{array}$ & $\begin{array}{c}-0.096 \\
(0.094)\end{array}$ & $\begin{array}{c}-0.096 \\
(0.089)\end{array}$ \\
\hline Hurricane age $[0,6]$ months & $\begin{array}{c}-0.054 \\
(0.035)\end{array}$ & $\begin{array}{r}-0.060^{*} \\
(0.032)\end{array}$ & $\begin{array}{c}-0.057 \\
(0.037)\end{array}$ & $\begin{array}{c}-0.056 \\
(0.035)\end{array}$ & $\begin{array}{c}-0.061 \\
(0.108)\end{array}$ & $\begin{array}{r}-0.073 \\
(0.107)\end{array}$ \\
\hline Hurricane age $[7,12]$ months & $\begin{array}{c}-0.026 \\
(0.041)\end{array}$ & $\begin{array}{c}-0.012 \\
(0.038)\end{array}$ & $\begin{array}{c}-0.009 \\
(0.038)\end{array}$ & $\begin{array}{l}0.006 \\
(0.037)\end{array}$ & $\begin{array}{c}-0.134 \\
(0.105)\end{array}$ & $\begin{array}{c}-0.126 \\
(0.104)\end{array}$ \\
\hline Hurricane age $[1,2]$ & $\begin{array}{c}-0.033 \\
(0.031)\end{array}$ & $\begin{array}{c}-0.032 \\
(0.028)\end{array}$ & $\begin{array}{c}-0.006 \\
(0.028)\end{array}$ & $\begin{array}{c}-0.007 \\
(0.026)\end{array}$ & $\begin{array}{c}-0.094 \\
(0.077) \\
\end{array}$ & $\begin{array}{c}-0.107 \\
(0.078)\end{array}$ \\
\hline Education controls & No & Yes & No & Yes & No & Yes \\
\hline Mean of $Y$ & 6.908 & 6.908 & 6.878 & 6.878 & 4.779 & 4.779 \\
\hline P-value (Equality of coefficients) & 0.268 & 0.145 & 0.167 & 0.098 & 0.878 & 0.937 \\
\hline $\mathrm{N}$ & \multicolumn{2}{|c|}{37110} & \multicolumn{2}{|c|}{47368} & \multicolumn{2}{|c|}{68172} \\
\hline
\end{tabular}

Note: This table presents results from models with the natural logarithm of wage and salary income as the dependent variable, with varying restrictions on the sample. Individuals who report zero wages or salary are assigned $\$ 1$ of income. In columns 1 and 2 , the sample restricts attention to individuals reporting no more than $\$ 50$ in business and farm income, and only includes individuals not reporting any wage and salary income if they are out of the labor force, and have no reported industry or occupation. Columns 3 and 4 report results from a relaxed sample that adds individuals with more than $\$ 50$ in business and farm income, while columns 5 and 6 present results from a sample that also adds all individuals not reporting any wage and salary income. All regressions include the same controls as the main specifications in column 3 of Table 4 . Standard errors are clustered by county of birth. Point estimates marked $* *, *$, and * are statistically significant at the 1,5 , and 10 percent levels, respectively. 
Table A5: Measurement Error in Gestational Age

\begin{tabular}{|c|c|c|c|c|c|c|c|c|}
\hline & \multicolumn{4}{|c|}{ Dep var: Log income } & \multicolumn{4}{|c|}{ Dep var: Worked $50+$ weeks } \\
\hline & (1) & (2) & (3) & (4) & $(5)$ & (6) & (7) & (8) \\
\hline & 37 & 38 & 40 & 41 & 37 & 38 & 40 & 41 \\
\hline \multicolumn{9}{|c|}{ Panel A: Effects of in utero exposure to hurricanes } \\
\hline Hurricane in utero & $\begin{array}{c}-0.073^{* * *} \\
(0.022)\end{array}$ & $\begin{array}{c}-0.068^{* * *} \\
(0.021)\end{array}$ & $\begin{array}{c}-0.070^{* * *} \\
(0.021)\end{array}$ & $\begin{array}{c}-0.067^{* * *} \\
(0.021)\end{array}$ & $\begin{array}{c}-0.016 \\
(0.014)\end{array}$ & $\begin{array}{c}-0.017 \\
(0.014)\end{array}$ & $\begin{array}{c}-0.016 \\
(0.014)\end{array}$ & $\begin{array}{c}-0.018 \\
(0.014)\end{array}$ \\
\hline \multicolumn{9}{|c|}{ Panel B: Post-storm conception, in utero, or age 0 to 2 exposure to hurricanes } \\
\hline Post-storm conception & $\begin{array}{c}0.014 \\
(0.019)\end{array}$ & $\begin{array}{c}0.013 \\
(0.020)\end{array}$ & $\begin{array}{c}0.020 \\
(0.020)\end{array}$ & $\begin{array}{c}0.023 \\
(0.020)\end{array}$ & $\begin{array}{c}-0.010 \\
(0.012)\end{array}$ & $\begin{array}{c}-0.007 \\
(0.012)\end{array}$ & $\begin{array}{c}-0.004 \\
(0.012)\end{array}$ & $\begin{array}{c}0.000 \\
(0.012)\end{array}$ \\
\hline Hurricane in utero & $\begin{array}{c}-0.076^{* * *} \\
(0.023)\end{array}$ & $\begin{array}{c}-0.072^{* * *} \\
(0.022)\end{array}$ & $\begin{array}{c}-0.073^{* * *} \\
(0.022)\end{array}$ & $\begin{array}{c}-0.070^{* * *} \\
(0.021)\end{array}$ & $\begin{array}{c}-0.019 \\
(0.014)\end{array}$ & $\begin{array}{c}-0.020 \\
(0.014)\end{array}$ & $\begin{array}{c}-0.018 \\
(0.014)\end{array}$ & $\begin{array}{r}-0.020 \\
(0.013)\end{array}$ \\
\hline Hurricane age $[0,6]$ months & $\begin{array}{r}-0.049^{*} \\
(0.027)\end{array}$ & $\begin{array}{r}-0.051^{*} \\
(0.027)\end{array}$ & $\begin{array}{r}-0.053^{*} \\
(0.027)\end{array}$ & $\begin{array}{c}-0.055^{* *} \\
(0.027)\end{array}$ & $\begin{array}{r}-0.012 \\
(0.015)\end{array}$ & $\begin{array}{r}-0.012 \\
(0.015)\end{array}$ & $\begin{array}{r}-0.012 \\
(0.015)\end{array}$ & $\begin{array}{r}-0.013 \\
(0.015)\end{array}$ \\
\hline Hurricane age $[7,12]$ months & $\begin{array}{c}-0.010 \\
(0.028)\end{array}$ & $\begin{array}{c}-0.011 \\
(0.028)\end{array}$ & $\begin{array}{c}-0.010 \\
(0.028)\end{array}$ & $\begin{array}{c}-0.009 \\
(0.028)\end{array}$ & $\begin{array}{c}-0.009 \\
(0.015)\end{array}$ & $\begin{array}{c}-0.009 \\
(0.015)\end{array}$ & $\begin{array}{c}-0.009 \\
(0.015)\end{array}$ & $\begin{array}{r}-0.009 \\
(0.015)\end{array}$ \\
\hline Hurricane age $[1,2]$ & $\begin{array}{r}-0.016 \\
(0.021)\end{array}$ & $\begin{array}{r}-0.016 \\
(0.021)\end{array}$ & $\begin{array}{r}-0.014 \\
(0.021)\end{array}$ & $\begin{array}{r}-0.017 \\
(0.021)\end{array}$ & $\begin{array}{r}-0.008 \\
(0.013)\end{array}$ & $\begin{array}{r}-0.008 \\
(0.013)\end{array}$ & $\begin{array}{r}-0.008 \\
(0.013)\end{array}$ & $\begin{array}{r}-0.007 \\
(0.013)\end{array}$ \\
\hline P-value (Equality of coefficients) & 0.015 & 0.022 & 0.011 & 0.010 & 0.972 & 0.962 & 0.949 & 0.860 \\
\hline Prob. in utero exposure & 0.022 & 0.023 & 0.024 & 0.025 & 0.022 & 0.023 & 0.024 & 0.025 \\
\hline $\mathrm{N}$ & & & & 58851 & & & & \\
\hline
\end{tabular}

Note: The table shows the robustness of the main results to different assumptions about the gestational age. In the main specification, we assume that the gestational age is 39 weeks, while in this table, it ranges from 37 to 41 weeks. In columns 1 to 4 , the dependent variable is the $\log$ of total income (1939 USD), and in columns 5 to 8 it is an indicator for having worked at least 50 weeks in 1939. See Table 4 for details on sample and controls. Standard errors are clustered by county of birth. The dependent variable means are: 6.91 (log income) and .73 (worked $50+$ weeks). 
Table A6: Robustness - Definition of Treatment

\begin{tabular}{|c|c|c|c|c|c|c|}
\hline & \multicolumn{3}{|c|}{ No donut hole } & \multicolumn{3}{|c|}{ Exclude $[\mathrm{d}, \mathrm{d}+20] \mathrm{km}$ donut hole } \\
\hline & $\begin{array}{c}(1) \\
20 \mathrm{~km}\end{array}$ & $\begin{array}{c}(2) \\
40 \mathrm{~km}\end{array}$ & $\begin{array}{c}(3) \\
50 \mathrm{~km}\end{array}$ & $\begin{array}{c}(4) \\
20 \mathrm{~km}\end{array}$ & $\begin{array}{c}(5) \\
40 \mathrm{~km}\end{array}$ & $\begin{array}{c}(6) \\
50 \mathrm{~km}\end{array}$ \\
\hline \multicolumn{7}{|c|}{ Panel A: Effects of in utero exposure to hurricanes } \\
\hline Hurricane in utero & $\begin{array}{c}-0.064^{* * *} \\
(0.025)\end{array}$ & $\begin{array}{c}-0.067^{* * *} \\
(0.019)\end{array}$ & $\begin{array}{c}-0.034^{* *} \\
(0.016)\end{array}$ & $\begin{array}{c}-0.081^{* * *} \\
(0.031)\end{array}$ & $\begin{array}{c}-0.052^{* *} \\
(0.022)\end{array}$ & $\begin{array}{c}-0.034 \\
(0.023)\end{array}$ \\
\hline \multicolumn{7}{|c|}{ Panel B: Post-storm conception, in utero, or age 0 to 2 exposure to hurricanes } \\
\hline Post-storm conception & $\begin{array}{c}0.032 \\
(0.023)\end{array}$ & $\begin{array}{c}0.007 \\
(0.018)\end{array}$ & $\begin{array}{c}-0.002 \\
(0.013)\end{array}$ & $\begin{array}{c}0.034 \\
(0.029)\end{array}$ & $\begin{array}{c}-0.003 \\
(0.021)\end{array}$ & $\begin{array}{c}0.001 \\
(0.018)\end{array}$ \\
\hline Hurricane in utero & $\begin{array}{c}-0.059^{* *} \\
(0.027)\end{array}$ & $\begin{array}{c}-0.073^{* * *} \\
(0.020)\end{array}$ & $\begin{array}{c}-0.037^{* *} \\
(0.017)\end{array}$ & $\begin{array}{c}-0.076^{* *} \\
(0.032)\end{array}$ & $\begin{array}{c}-0.058^{* * *} \\
(0.022)\end{array}$ & $\begin{array}{c}-0.037 \\
(0.023)\end{array}$ \\
\hline Hurricane age $[0,6]$ months & $\begin{array}{c}-0.033 \\
(0.038)\end{array}$ & $\begin{array}{c}-0.074^{* * *} \\
(0.023)\end{array}$ & $\begin{array}{r}-0.039^{*} \\
(0.020)\end{array}$ & $\begin{array}{c}-0.024 \\
(0.041)\end{array}$ & $\begin{array}{c}-0.058^{* *} \\
(0.027)\end{array}$ & $\begin{array}{c}-0.026 \\
(0.028)\end{array}$ \\
\hline Hurricane age $[7,12]$ months & $\begin{array}{c}0.010 \\
(0.034)\end{array}$ & $\begin{array}{c}-0.018 \\
(0.030)\end{array}$ & $\begin{array}{c}0.002 \\
(0.021)\end{array}$ & $\begin{array}{c}-0.006 \\
(0.041)\end{array}$ & $\begin{array}{c}-0.003 \\
(0.034)\end{array}$ & $\begin{array}{c}-0.005 \\
(0.027)\end{array}$ \\
\hline Hurricane age $[1,2]$ years & $\begin{array}{c}0.024 \\
(0.026)\end{array}$ & $\begin{array}{c}-0.022 \\
(0.020)\end{array}$ & $\begin{array}{c}-0.002 \\
(0.018)\end{array}$ & $\begin{array}{c}0.035 \\
(0.030)\end{array}$ & $\begin{array}{c}-0.027 \\
(0.025)\end{array}$ & $\begin{array}{c}-0.011 \\
(0.023)\end{array}$ \\
\hline Mean of Y & 6.907 & 6.907 & 6.907 & 6.923 & 6.885 & 6.863 \\
\hline P-value (Equality of coefficients) & 0.030 & 0.009 & 0.193 & 0.030 & 0.240 & 0.704 \\
\hline Prob. in utero exposure & 0.015 & 0.032 & 0.049 & 0.014 & 0.038 & 0.050 \\
\hline $\mathrm{N}$ & 58851 & 58851 & 58851 & 44164 & 36093 & 32397 \\
\hline
\end{tabular}

Note: See Table 4 for details on sample and controls. Columns 1 and 4 restrict the exposure region to a 20 kilometer-radii bandwidth around the storm track, while columns 2 and 5 extend it to 40 kilometers, and columns 3 and 6 extend it to 50 kilometers. Columns 4 to 6 also exclude a 20 kilometer-radii bandwidth ("donut hole" region) immediately beyond the exposure zone. Standard errors are clustered by county of birth. Point estimates marked $* * * ; *$, and $*$ are statistically significant at the 1,5 , and 10 percent levels, respectively. 
Table A7: Robustness - Aggregated Data

\begin{tabular}{|c|c|c|c|c|c|c|}
\hline & $\begin{array}{c}\text { (1) } \\
\text { Years of } \\
\text { education }\end{array}$ & $\begin{array}{c}(2) \\
\text { Middle school } \\
\text { graduation }\end{array}$ & $\begin{array}{c}(3) \\
\text { Log income } \\
\text { (1939 USD) }\end{array}$ & $\begin{array}{c}(4) \\
\text { Worked } \\
50+\text { weeks }\end{array}$ & $\begin{array}{c}(5) \\
\text { Log income } \\
\text { (1939 USD) }\end{array}$ & $\begin{array}{c}(6) \\
\text { Worked } \\
50+\text { weeks }\end{array}$ \\
\hline \multicolumn{7}{|c|}{ Panel A: Effects of in utero exposure to hurricanes } \\
\hline Hurricane in utero & $\begin{array}{c}-0.265^{* *} \\
(0.110)\end{array}$ & $\begin{array}{c}-0.036^{* *} \\
(0.015) \\
\end{array}$ & $\begin{array}{c}-0.081^{* * *} \\
(0.026)\end{array}$ & $\begin{array}{c}-0.027^{*} \\
(0.015)\end{array}$ & $\begin{array}{c}-0.053^{* *} \\
(0.022)\end{array}$ & $\begin{array}{c}-0.022 \\
(0.015) \\
\end{array}$ \\
\hline \multicolumn{7}{|c|}{ Panel B: Post-storm conception, in utero, or age 0 to 2 exposure to hurricanes } \\
\hline Post-storm conception & $\begin{array}{c}-0.010 \\
(0.104)\end{array}$ & $\begin{array}{c}0.005 \\
(0.013)\end{array}$ & $\begin{array}{c}-0.012 \\
(0.021)\end{array}$ & $\begin{array}{c}-0.015 \\
(0.012)\end{array}$ & $\begin{array}{c}-0.011 \\
(0.017)\end{array}$ & $\begin{array}{c}-0.015 \\
(0.012)\end{array}$ \\
\hline Hurricane in utero & $\begin{array}{c}-0.258^{* *} \\
(0.114)\end{array}$ & $\begin{array}{c}-0.033^{* *} \\
(0.016)\end{array}$ & $\begin{array}{c}-0.081^{* * *} \\
(0.027)\end{array}$ & $\begin{array}{r}-0.028^{*} \\
(0.015)\end{array}$ & $\begin{array}{c}-0.054^{* *} \\
(0.022)\end{array}$ & $\begin{array}{c}-0.023 \\
(0.015)\end{array}$ \\
\hline Hurricane age $[0,6]$ months & $\begin{array}{c}0.159 \\
(0.146)\end{array}$ & $\begin{array}{c}0.018 \\
(0.019)\end{array}$ & $\begin{array}{c}-0.068^{* *} \\
(0.033)\end{array}$ & $\begin{array}{c}-0.010 \\
(0.016)\end{array}$ & $\begin{array}{c}-0.084^{* * *} \\
(0.028)\end{array}$ & $\begin{array}{c}-0.013 \\
(0.015)\end{array}$ \\
\hline Hurricane age $[7,12]$ months & $\begin{array}{c}-0.175 \\
(0.134)\end{array}$ & $\begin{array}{c}-0.006 \\
(0.018)\end{array}$ & $\begin{array}{c}0.003 \\
(0.031)\end{array}$ & $\begin{array}{c}0.005 \\
(0.017)\end{array}$ & $\begin{array}{c}0.021 \\
(0.028)\end{array}$ & $\begin{array}{c}0.009 \\
(0.017)\end{array}$ \\
\hline Hurricane age $[1,2]$ & $\begin{array}{c}0.151 \\
(0.101)\end{array}$ & $\begin{array}{c}0.021 \\
(0.013)\end{array}$ & $\begin{array}{c}0.031 \\
(0.024)\end{array}$ & $\begin{array}{c}0.013 \\
(0.013)\end{array}$ & $\begin{array}{c}0.015 \\
(0.021)\end{array}$ & $\begin{array}{c}0.010 \\
(0.012)\end{array}$ \\
\hline Education controls & No & No & No & No & Yes & Yes \\
\hline Mean of Y & 8.045 & 0.385 & 6.868 & 0.724 & 6.868 & 0.724 \\
\hline P-value (Equality of coefficients) & 0.027 & 0.057 & 0.006 & 0.157 & 0.005 & 0.217 \\
\hline $\mathrm{N}$ & \multicolumn{6}{|c|}{26924} \\
\hline
\end{tabular}

Note: This table presents results from models analogous to those presented in Table 4, with the exception that the data have been collapsed at the county of birth-by-conception month level. The dependent variables are county of birth-by-conception month means of the highest grade completed (column 1), the probability of middle school graduation (column 2), the natural logarithm of total income in 1939 USD (columns 3 and 5), and the probability of working at least 50 weeks in 1939 (columns 4 and 6). In panel A, the coefficient on in utero exposure takes the value of one if at least one individual was exposed in utero to a hurricane in a given county and conception month cell (the coefficients in panel B are similarly defined). Each column controls for the percentage of individuals with exactly matching first and last names, the average absolute deviation in ages between the WWI records and the 1940 census, state-specific linear trends, as well as county of birth, conception year, and conception month fixed effects. Columns 5 and 6 also include a control for the birth county-by-conception month average for years of completed education rounded to the nearest integer. Standard errors are clustered at the county level. Point estimates marked $* * * ; *$, and $*$ are statistically significant at the 1,5 , and 10 percent levels, respectively. 


\section{Appendix Figures}

Figure A1: Linkage Rates from the WWI Draft Registration Cards to U.S. Population Censuses (a) Birth year and month (matching to 1940 census)

(b) Birth year and month (matching to 1900 census)
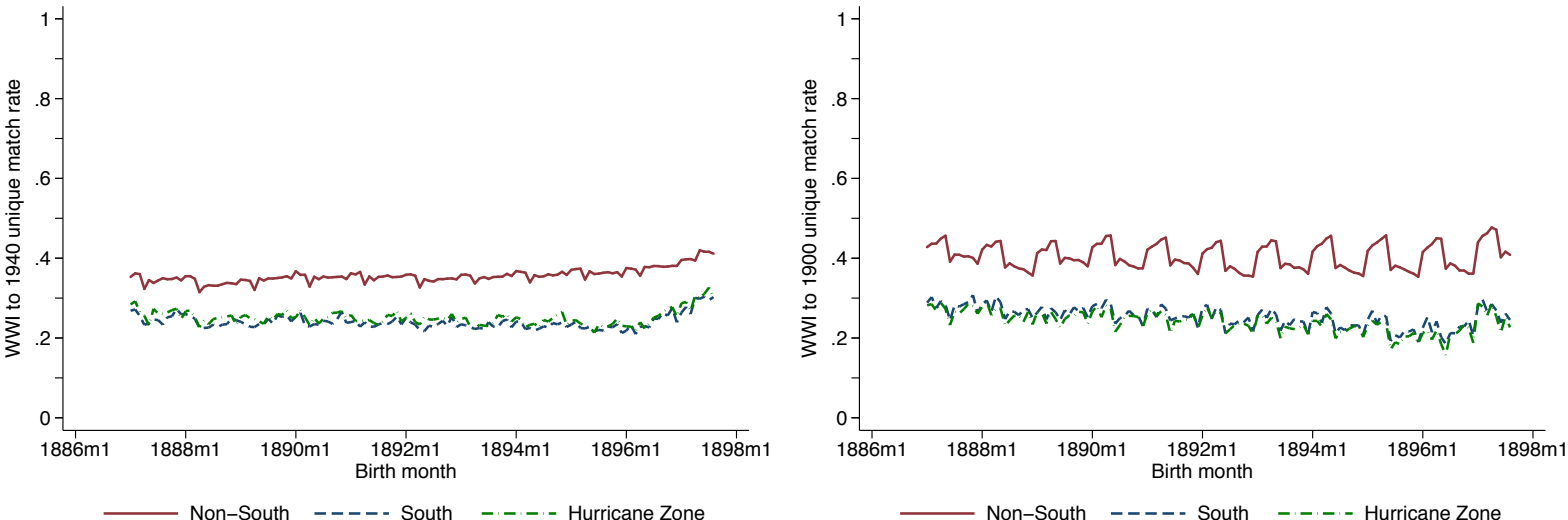

(c) Commonness of name (matching to 1940 census)

(d) Commonness of name (matching to 1900 census)
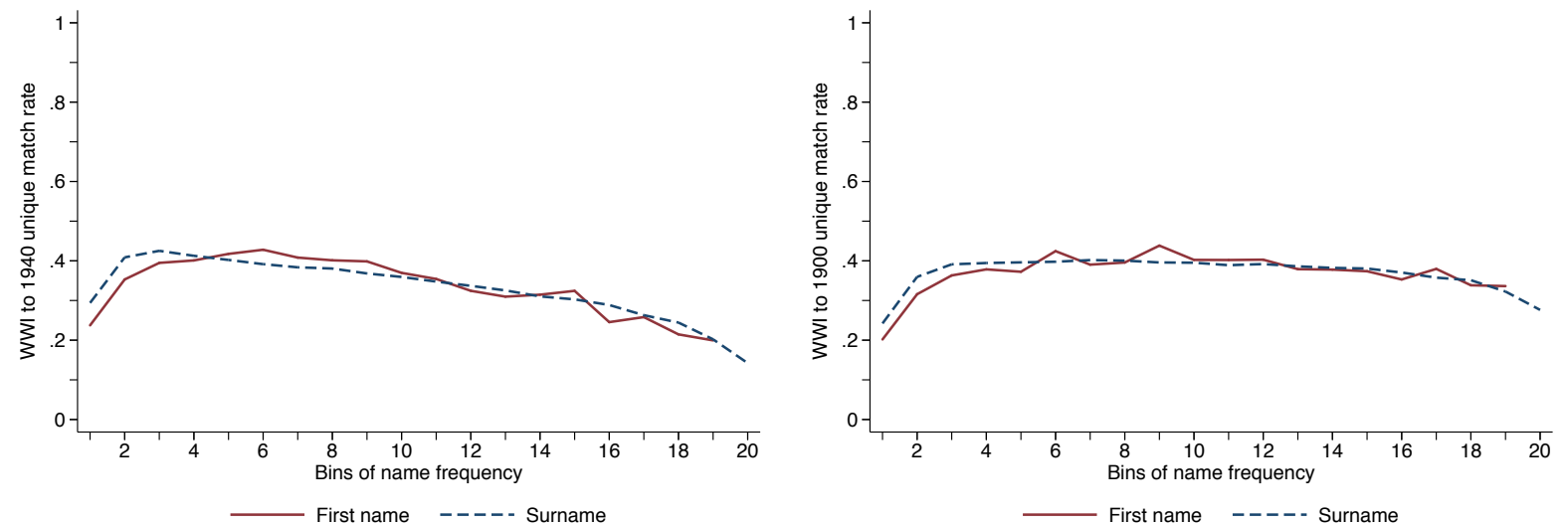

Note: In panels (a) and (b), this figure plots the rate of unique matches from the WWI Draft Registration Cards to the 1940 and 1900 U.S. Population Censuses, respectively, against the month and year of birth, by U.S. geographic regions: Non-South, South, and locations ever within 100 kilometers of a hurricane during the sample period from 1885 to 1899 ("Hurricane Zone"). The latter is contained within the nine states comprising the South: Alabama, Florida, Georgia, Louisiana, Mississippi, North Carolina, South Carolina, Texas and Virginia. Panels (c) and (d) plot the rate of unique matches to the 1940 and 1900 censuses, respectively, against ventiles of name frequency within the population of WWI Draft records, by first name and surname. 
Figure A2: Effects of In Utero Exposure on Log of Total Income, Dropping States One-by-one

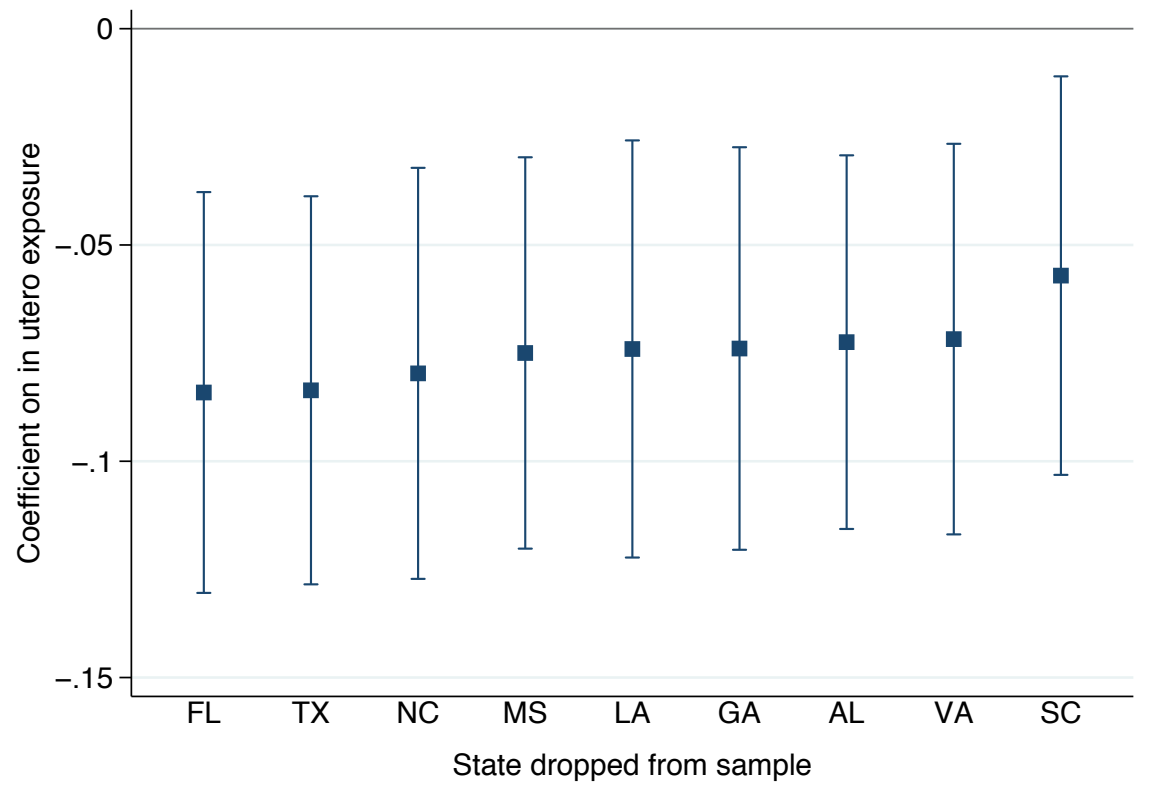

Note: Each line in the figure represents a 95-percent confidence interval, while the square marker denotes the point estimate, for the effect of in utero exposure to hurricanes on the log of total income, from estimating Equation 2 using a sample that deviates from the main specification by dropping all observations from a particular state. The lines are ordered by the size of the in utero exposure coefficients. Each specification includes the same controls as panel B of Table 4. Standard errors are clustered by county of birth. 
Figure A3: Effects of In Utero Exposure on Log of Total Income, Dropping Storms One-by-one

(a) Ignoring Exposure from Dropped Storm

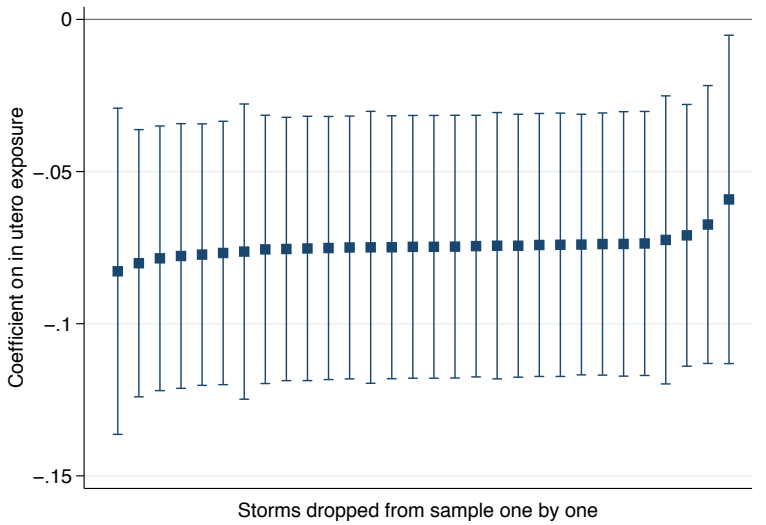

(b) Keeping Exposure from Dropped Storm

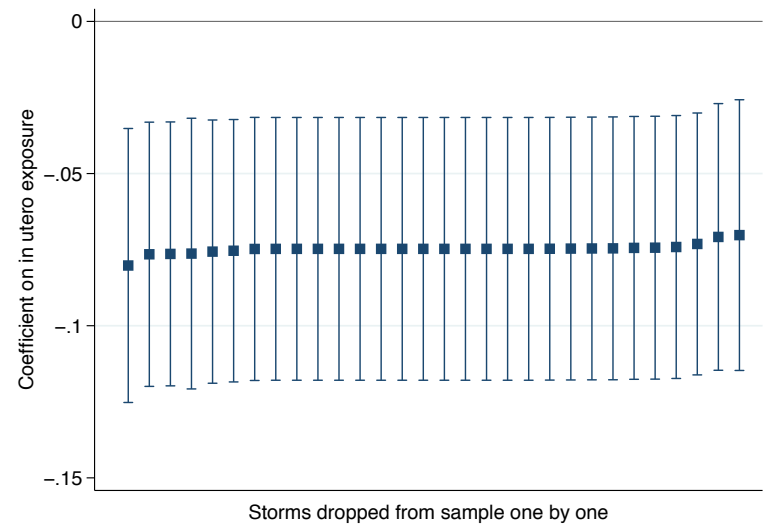

Note: Each line in the figure represents a 95-percent confidence interval, while the square marker denotes the point estimate, for the effect of in utero exposure to hurricanes on the log of total income, from estimating Equation 2 by dropping one storm at a time from the sample. The lines are ordered by the size of the in utero exposure coefficients. We follow two procedures for dropping storms to deal with individuals exposed to multiple storms: ignoring exposure to the dropped storms (Figure A3a) and accounting for exposure to dropped storms when individuals were exposed to multiple storms (Figure A3b). In either case, individuals born in locations within 100 kilometers of multiple hurricanes remain in the sample. Twelve of the estimates in Figure A3b are identical to the main estimates in column 3 and Panel B of Table 4, given that the set of birth locations within 100 kilometers of some hurricane paths are a subset of birth locations within 100 kilometers of other storms, and thus no observations are dropped from the sample. Each specification includes the same controls as panel B of Table 4. Standard errors are clustered by county of birth. 
Figure A4: Effects of In Utero Hurricane Exposure on Log of Total Income, by Distance Bands around Hurricane Path

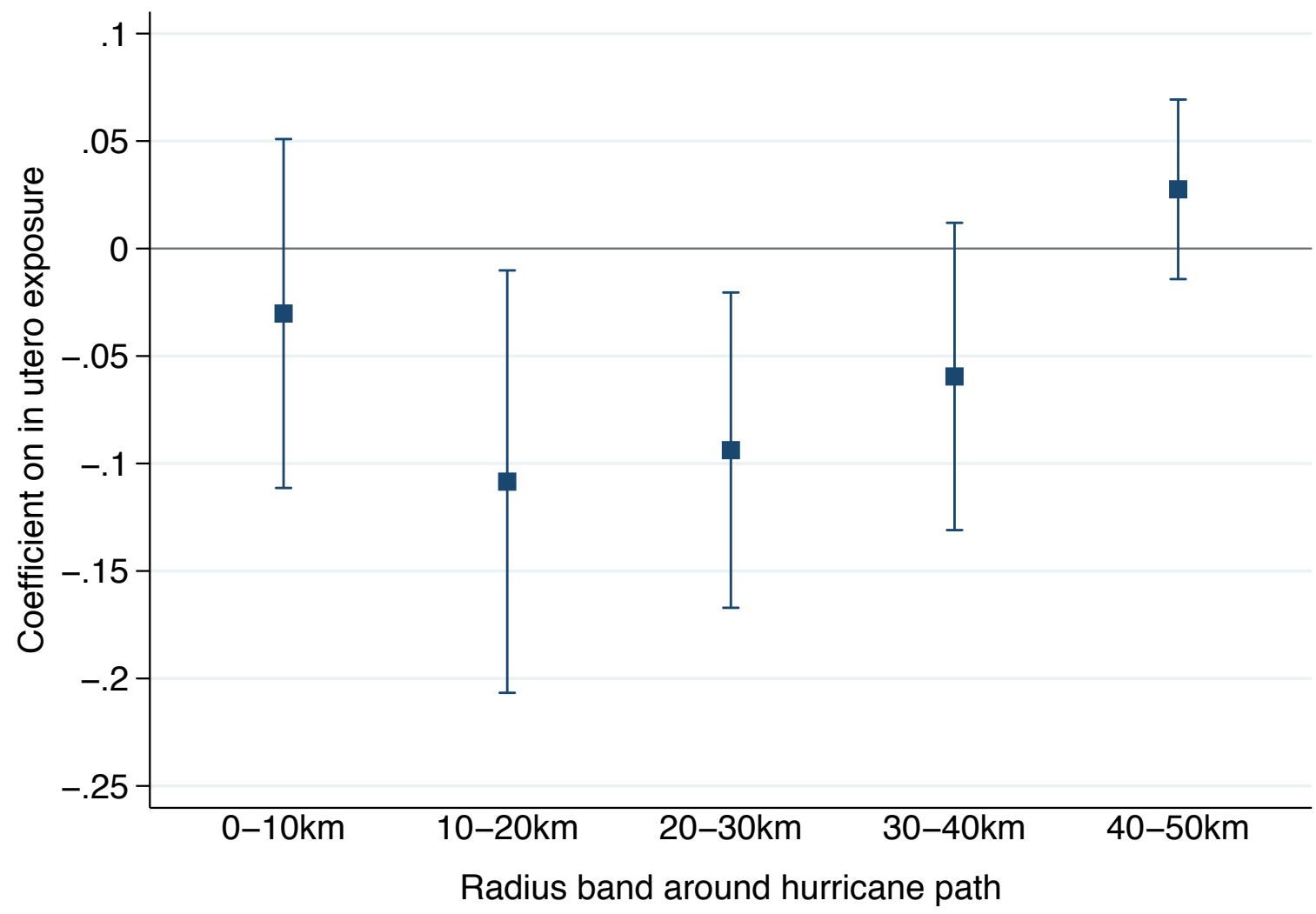

Note: This figure plots the coefficients on in utero exposure, interacted with indicators for distance bands around the hurricane path $(0$ to 10 , 10 to 20,20 to 30,30 to 40 , and 40 to 50 kilometers), all estimated from a regression with the log of total income as the dependent variable. Each line in the figure represents a 95-percent confidence interval, while the square marker denotes the point estimate. The specification extends Equation 2 to include indicators for whether a birth location overlapped each of the five distance bands around a hurricane that occurred during the sample period, as well as interactions of the distance band dummies with each of the exposure indicators: conception up to one year post-storm, in utero, age 0 to 6 months, age 6 to 12 months, and age 1 to 2 years old. See Table 4 for details on the sample and controls. 
Figure A5: Robustness to Tolerance for Mismatched Names

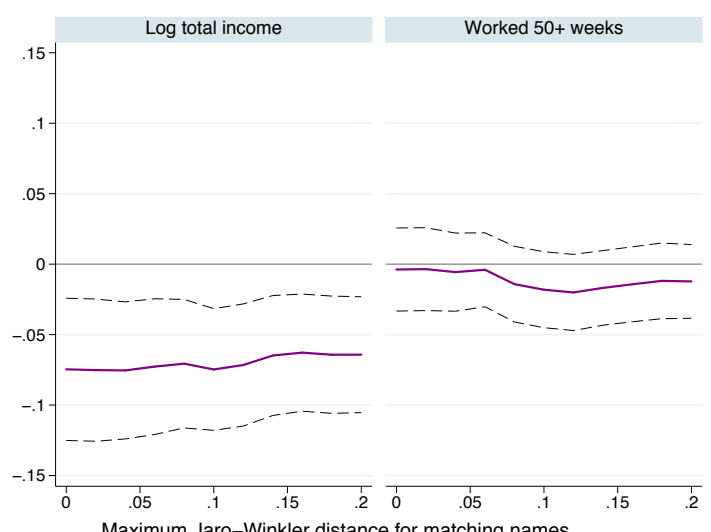

Note: This figure plots coefficients on in utero exposure and 95 percent confidence intervals against the maximum Jaro-Winkler string distance tolerated for an observation to be considered matched, by the dependent variable in the regression: the natural log of total annual income (reported wage and salary income in addition to estimated business and farm income) in 1939, and an indicator for working at least 50 weeks in 1939. Aside from the changes to the Jaro-Winkler threshold, each regression is identical to the specification presented in panel B of Table 4.

Figure A6: Measurement Error Due to Matching - Similarity of Names

(a) Log income

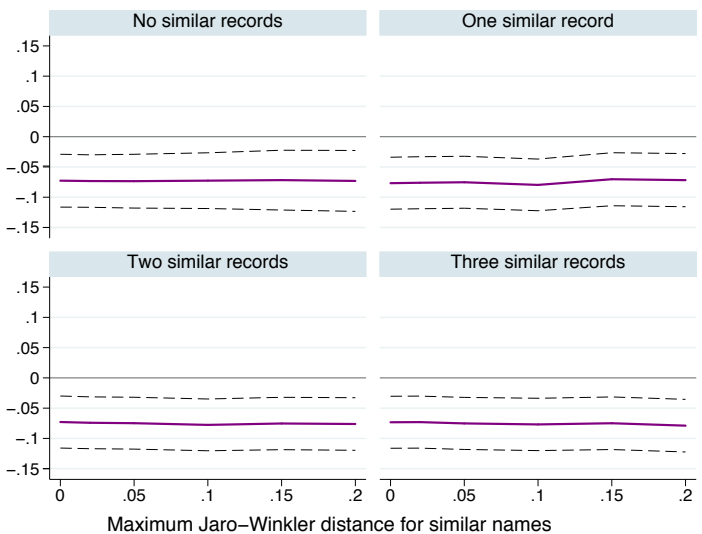

(b) Weeks worked

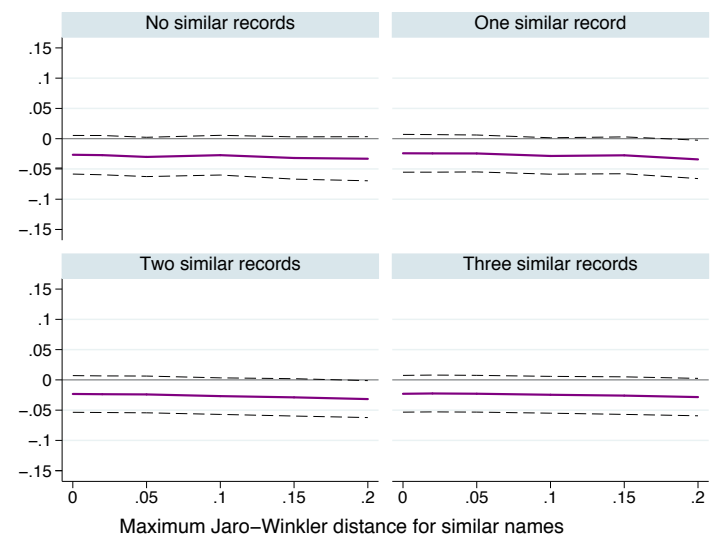

Note: This figure plots coefficients on in utero exposure and 95 percent confidence intervals, from regressions with the natural log of total income (panel a), or an indicator for working at least 50 weeks in 1939 (panel b), as the dependent variable, against a range of Jaro-Winkler string distance thresholds for a record to be considered similar to the best match $(\rho)$, by the maximum number of similar records in the 1940 census allowed for an observation to be included in the sample (ranging from 0 to 3 similar records). A similar record is defined as having a birth year within one year of the matched record, and a Jaro-Winkler similarity score averaged over the first and last name satisfying $(1+\rho) J_{s}>\bar{J}$ where $\bar{J}$ is the Jaro-Winkler score of the matched record, $J_{s}$ is the Jaro-Winkler score of a similar record, and $\rho \epsilon[0,0.1]$. Aside from the changes to the Jaro-Winkler threshold and the restrictions on the number of similar records, each regression is identical to the specification presented in panel B of Table 4. 


\section{For Online Publication: Online Appendix}

\section{A Data Appendix}

\section{A.1 Hurricane tracks}

We reconstruct hurricane paths using the HURDAT2 database of best-track estimates for Atlantic hurricanes produced by the National Hurricane Center (NHC) at the National Oceanic and Atmospheric Administration (NOAA). ${ }^{42}$ The HURDAT2 database contains all storms that occurred between 1851 and 2015 in the North Atlantic basin, and matched or exceeded the intensity of a tropical depression. It contains a standardized set of latitude and longitude coordinates for the location of a storm every six hours, which are estimated from storm observations in historical sources. ${ }^{43}$ We use GIS software to join the coordinates for a storm into a line segment. When the duration of a storm extends across multiple weeks, we split the storm track into multiple segments while extending each segment by one data point (equivalent to the movement of the storm over 6 hours) at each week-to-week transition to avoid missing the area between two coordinates when computing exposure to the storm.

\section{Saffir-Simpson Hurricane Wind Scale}

The Saffir-Simpson Hurricane Wind Scale classifies hurricanes into five categories according to wind speed: 119-153 kilometers per hour (kph) (Category 1), 154-177 kph (Category 2), 178-208 kph (Category 3), 209-251 kph (Category 4), and $252 \mathrm{kph}$ or higher (Category 5). We exclude observations of tropical depressions (up to $64 \mathrm{kph}$ ) and tropical storms (65-118 kph) that appear in the database. Each category of hurricane is associated with an expected severity of damage to property and infrastructure that is based on a modern setting, but should still be relevant to the historical period of study. Category 1: homes can have minor damage to the roof and vinyl sidings, while large branches of trees will snap. Category 2: homes can sustain major roof and siding damage and shallow rooted trees may snap. Category 3: homes may incur major damage or removal of roof decking, trees will snap, and water will be unavailable for extended period of time. Category 4: homes can sustain severe damage with loss of most of the roof structure and some exterior walls. Most trees will snap, and most of the area will be uninhabitable for an extended period of time. Category 5: a high percentage of homes will be destroyed and most of the area will be uninhabitable for an extended period of time. ${ }^{44}$

\footnotetext{
${ }^{42}$ The data was originally accessed on March 29, 2013 (http://www.aoml.noaa.gov/hrd/hurdat/easyread2012.html). The database has since been updated to include storms up to 2015 and is currently located at http://www.aoml.noaa.gov/hrd/hurdat/hurdat2-1851-2015-021716.txt. For more details on the re-analysis project that updated the original HURDATA database in 2012, see http://www.aoml.noaa.gov/hrd/hurdat/Data_Storm.html.

${ }^{43}$ For documentation on each storm in the database, see http://www.aoml.noaa.gov/hrd/hurdat/metadata_dec12.html

${ }^{44}$ See http://www.nhc.noaa.gov/aboutsshws.php for more information.
} 


\section{A.2 World War I Draft Registration Cards}

\section{Historical Background}

On 18 May 1917, six weeks after the U.S. declared war on Germany, the U.S. government passed the Selective Service Act, which required all males living in the U.S between the ages of 18 and 45, regardless of citizenship status, to register for the draft. Anyone already in active military service by June 1917 was not required to register. Three separate registrations were held for the World War I draft. The first registration took place on 5 June 1917, and covered men born between 6 June 1886 and 5 June 1896 (those aged 21 to 31 at the time). The Second Registration took place on 5 June 1918, and covered males born between 6 June 1896 and 5 June 1897 (those who had turned 21 since the previous registration), as well as those covered by the First Registration who had not already registered. The Third Registration was held on 12 September 1918 and covered males born between 11 September 1897 and 12 September 1900 as well as those born between 11 September 1872 and 5 June 1886, and anyone else who was not in active military service and had failed to register on the previous occasions (Ancestry.com 2005). The Selective Service System (SSS) was established under the Provost Marshal General Office (PMGO) to oversee the registration and drafting of men into military service. A local board was responsible for about 30,000 residents in a city or county. On average, a district board had authority over 30 local boards, each of which registered approximately 5,000 men (Nudd 2005).

The WWI Draft Registration Cards include an individual's name, exact date of birth, and place of birth at either the county, city, or township level. The database contains nearly 24 million records, which represents about 23 percent of the estimated U.S. population in 1918 and about 93 to 98 percent of all men residing in the U.S. who were born between 1872 and 1900, and enumerated in the 1910 census. ${ }^{45}$ The Provost Marshal General, Enoch Crowder, estimated that between 2.4 and 3.6 million men avoided military service by not registering for the draft (Chambers 1987), which would account for 10 to 15 percent of the eligible population and would be consistent with Figure 2 showing evidence of under-registration among cohorts born in the second half of 1880 s. ${ }^{46}$

The decision to evade the draft registration was likely influenced by the risk of conscription. The military established a five-tier classification system, with most drafted men coming from Class 1. Federal and state officials, ministers, and pilots were among those assigned to a fifth group (Class 5) that was not subject to induction into military service. Registrants could be placed in Classes 2 through 4 if they were granted a deferment, which depended upon income, occupational and social status, and the presence of dependents (Nudd 2005). The military established recruitment quotas as a function of a state's draft-age population and the number of volunteer servicemen from the state. Given that fewer volunteers from the South had joined the military, Southern counties were subject to higher quotas for the draft, and thus faced stronger incentives to avoid registration (Keith 2001).

\footnotetext{
${ }^{45}$ There is some uncertainty in the share of the population due to records with missing gender or multiple transcribed values for age in the 1910 census.

${ }^{46}$ Under-registration for the WWI draft would only be a concern for the empirical analysis if it was related to hurricane exposure, which is unlikely to have been the case.
} 


\section{Geocoding Birth Locations}

We geocode the birth locations in the World War I Draft Registration Cards database by matching birth place strings to place names in the Geographic Names Information System (GNIS) database (U.S. Geological Survey 2014). The GNIS file contains the universe of U.S. physical and cultural geographic features, and assigns latitude and longitude coordinates to each location. We also match the birth place strings in the WWI records against place names and counties listed in the 1900, 1910, and 1920 U.S. Censuses. We begin by extracting and cleaning place name strings in each file, then separately match the list of place names in each historical census and the GNIS file to the place names in the WWI records, allowing for phonetic differences in the place name strings.

In some cases, the GNIS file will contain multiple locations with the same name in different counties of a particular state. To identify the correct match, we make use of the WWI records linked to the 1900 census. For each unique birth place string in the WWI records, we identify the modal county of residence in 1900. Next, we use GIS software to overlay the coordinates of locations in the GNIS file on 1900 county boundaries, and prioritize GNIS locations in 1900 counties that match the modal county of residence for a WWI birth place string. ${ }^{47}$ We can also identify the correct location when the WWI record provides both the location (city or town) and county of birth. When the matches to the place names in the historical censuses and the contemporary GNIS file are in conflict, we prioritize matches based on the quality of the linkage.

Although the instructions for the WWI Draft Registration Cards asked respondents to record their city and state of birth, some respondents only reported the county and state of birth. In either case, without knowing both the city and county, it is not always possible to uniquely identify a location. In some cases, a city in one county will have the same name as a different county in the same state. Such ambiguity can introduce significant measurement error to the determination of hurricane exposure status, and thus we exclude these conflicting cases from the main estimation sample, in addition to ambiguous cases where a city has the same name as the county in which it is located.

To account for changes in county boundaries over time, we assign all latitude and longitude coordinates to 1880 counties, the most recent census year prior to the start of our sample period. In specifications where exposure to hurricanes is defined at the county level we also include WWI records that only contain the county of birth, which we identify by linking the birth place strings to lists of county names from the 1900 to 1920 censuses. In all situations, we do not assign a birth location to a WWI record that has potential matches in multiple counties.

\section{A.3 U.S. Census of Population}

The 1940 Census of Population data are extracted from the restricted-use complete count file created by IPUMS-USA in conjunction with Ancestry.com, and accessed at the National Bureau of Economic Research. A drawback of the 1940 census is that information on income is limited to wage and salary earnings. When it comes to business, farm, or self-employment income, enumerators only asked for

\footnotetext{
${ }^{47}$ We require at least 50 percent of WWI records with a given birth place string to reside in the modal county of residence in 1900, and exclude birth place strings that appear fewer than ten times in the WWI records.
} 
a "yes" or "no" response to the question of whether the individual had more than $\$ 50$ in non-wage income. In our final sample, 38 percent of individuals report having at least $\$ 50$ in non-wage, non-salary income. We use the IPUMS 1\% sample of the 1950 census (Ruggles et al., 2015), which reported business income in addition to wage earnings, to impute business, farm, and self-employment income following the procedure used by Feigenbaum (2015b).

We restrict attention to white males aged 39 to 57 with non-missing business earnings, years of education, occupation codes, and industry codes in the 1950 census, and convert reported business earnings into 1939 dollars using the CPI. ${ }^{48}$ We estimate business earnings as a function of age and years of education fixed effects, state of residence, as well as industry code and occupation code for the 1950 census sample, and use the estimated coefficients to predict business earnings for the 1940 sample. Among individuals in the 1940 census who reported having at least $\$ 50$ in business earnings, we assign total income consisting of reported wage and salary income plus imputed business earnings, or only the latter in cases where zero wage and salary income was reported. ${ }^{49}$

\section{IPUMS Occupational Status Variables}

Here we reproduce explanations of the occupational status variables constructed and described by IPUMS (Ruggles et al. 2015):

OCCSCORE Occupational income score: Assigns each occupation a value representing the median total income (in hundreds of 1950 dollars) of all persons with that particular occupation in 1950.

ERSCOR50 Occupational earnings score, 1950 basis: Reports the percentage of persons in occupations having lower standardized median earnings than the respondent's occupation. The scores were based on the earnings levels of the employed civilian labor force aged 16 and above, excluding persons who did not work in the past one year.

EDSCOR50 Occupational education score, 1950 basis: Indicates the percentage of people in the respondent's occupational category who had completed one or more years of college.

NPBOSS50 Nam-Powers-Boyd occupational status score, 1950 basis: A measure of occupational status that gives equal weights to the median earnings and educational attainment associated with each category in the OCC1950 variable. It can be interpreted as the percentage of persons in the civilian labor force employed in occupations with combined levels of education and earnings below that occupation. The scores can vary from 0 to 100 .

\footnotetext{
${ }^{48}$ Specifically, we use a chained CPI with 1982-84 base year. We perform the same analysis for black males when we report results for the black population.

${ }^{49}$ Following Feigenbaum (2015b), we use a multi-level model which produces estimated fixed effects that are closer to the mean in cells with smaller sample sizes (Hill and Gelman, 2007).
} 
Online Appendix Tables

Table O1: Hurricanes Making Landfall, 1885 to 1899

\begin{tabular}{ccccc}
\hline Year & Date & Category & Strength (kph) & States Exposed \\
\hline \multicolumn{5}{c}{ Panel A: Hurricanes making continental } \\
1885 & Aug 25 & 2 & 170 & FL, landfall \\
1886 & Jun 14 & 2 & 160 & TX SC \\
1886 & Jun 21 & 1 & 150 & FL, GA \\
1886 & Jul 01 & 1 & 130 & FL \\
1886 & Aug 20 & 2 & 160 & TX \\
1886 & Sep 23 & 1 & 140 & TX \\
1886 & Oct 13 & 1 & 140 & LA, TX \\
1887 & Jul 27 & 1 & 120 & AL, FL \\
1887 & Sep 21 & 1 & 140 & TX \\
1887 & Oct 19 & 1 & 120 & LA \\
1888 & Aug 17 & 2 & 160 & FL, LA, MS \\
1889 & Sep 23 & 1 & 120 & LA \\
1891 & Jul 06 & 1 & 130 & TX \\
1893 & Aug 28 & 2 & 165 & GA, NC, SC \\
1893 & Sep 07 & 1 & 130 & LA \\
1893 & Oct 13 & 1 & 150 & NC, SC, VA \\
1893 & Oct 02 & 2 & 175 & AL, LA, MS \\
1894 & Sep 26 & 1 & 140 & FL, GA, SC \\
1894 & Oct 09 & 2 & 160 & FL, GA, VA \\
1896 & Jul 07 & 2 & 160 & FL \\
1896 & Sep 29 & 3 & 185 & FL, GA, NC, SC \\
1897 & Sep 13 & 1 & 140 & FL, LA, TX \\
1898 & Aug 03 & 1 & 130 & FL \\
1898 & Oct 02 & 2 & 165 & FL, GA \\
1899 & Aug 01 & 2 & 160 & FL \\
1899 & Aug 18 & 2 & 165 & NC \\
\hline & Pan & & & \\
\hline
\end{tabular}

Panel B: Hurricanes within $30 \mathrm{~km}$ of continental U.S. landfall

\begin{tabular}{llll}
1886 & Jul 17 & 1 & 140 \\
1888 & Jun 16 & 1 & 130 \\
1888 & Oct 09 & 2 & 175 \\
1898 & Aug 30 & 1 & 140 \\
\hline
\end{tabular}

Panel A presents a list of Category 1 to 5 hurricanes making continental U.S. landfall between 1885 and 1899 . The category and wind speed associated with each storm represent the maximum values recorded after the storm made landfall. Panel B lists hurricanes that pass within $30 \mathrm{~km}$ of continental U.S. landfall. The category and wind speed associated with each storm represent the maximum values recorded at any point during the storm's path. In Panel A, the date refers to the first landfall date of the hurricane, while in Panel B, it refers to the first day on which a storm reaches hurricane strength. 
Table O2: Match Rates of Birth Locations in the WWI Draft Registration Cards

\begin{tabular}{|c|c|c|c|c|c|c|c|c|c|c|c|c|}
\hline & \multicolumn{4}{|c|}{ All WWI Records } & \multicolumn{4}{|c|}{ Matched to 1940} & \multicolumn{4}{|c|}{ Final sample } \\
\hline & (1) & (2) & (3) & (4) & (5) & (6) & (7) & (8) & (9) & (10) & (11) & (12) \\
\hline & All & $30-100 \mathrm{~km}$ & $0-30 \mathrm{~km}$ & In utero & All & $30-100 \mathrm{~km}$ & $0-30 \mathrm{~km}$ & In utero & All & $30-100 \mathrm{~km}$ & $0-30 \mathrm{~km}$ & In utero \\
\hline Birth county unknown & 0.042 & 0.000 & 0.000 & 0.000 & 0.036 & 0.000 & 0.000 & 0.000 & 0.000 & 0.000 & 0.000 & 0.000 \\
\hline Birth county known & 0.067 & 0.064 & 0.109 & 0.109 & 0.066 & 0.064 & 0.109 & 0.109 & 0.000 & 0.000 & 0.000 & 0.000 \\
\hline City-(different)-county conflict & 0.136 & 0.176 & 0.086 & 0.072 & 0.130 & 0.176 & 0.086 & 0.072 & 0.066 & 0.092 & 0.008 & 0.007 \\
\hline City-(same)-county conflict & 0.122 & 0.132 & 0.148 & 0.139 & 0.117 & 0.132 & 0.148 & 0.139 & 0.162 & 0.154 & 0.180 & 0.169 \\
\hline Birth location known & 0.633 & 0.627 & 0.657 & 0.680 & 0.652 & 0.627 & 0.657 & 0.680 & 0.772 & 0.754 & 0.812 & 0.824 \\
\hline $\mathrm{N}$ & 1887988 & 87462 & 41359 & 2874 & 328455 & 87462 & 41359 & 2874 & 76196 & 52523 & 23673 & 1690 \\
\hline
\end{tabular}

Notes: The table presents match rates of birth locations for individuals registered in the WWI draft and born in one of the nine Southern states exposed to hurricanes (columns 1 to 4). In subsequent columns, we restrict attention to white males matched to the 1940 U.S. Census (columns 5 to 8 ), and records satisfying the restrictions imposed on our final analysis sample (columns 9 to 12). Within each group of columns, we present match rates for four samples: individuals born in one of nine hurricane states, in locations 30 to 100 kilometers

away from hurricane tracks during the sample period, in locations 0 to 30 kilometers away, and individuals exposed in utero to hurricanes. In each column we first show the share of

WWI observations with an unknown birth location, or with only birth county known. City-(different)-county conflict refers to individuals born in a city or town in a county with the same name as another county in the same state, while City-(same)-county conflict referes to individuals born in a city or town with the same name as the county in which it is located. 
Table O3: Robustness - Results for the Black Population

\begin{tabular}{|c|c|c|c|c|c|c|}
\hline & $\begin{array}{c}\text { (1) } \\
\text { Years of } \\
\text { education }\end{array}$ & $\begin{array}{c}(2) \\
\text { Middle school } \\
\text { graduation }\end{array}$ & $\begin{array}{c}(3) \\
\text { Log income } \\
\text { (1939 USD) }\end{array}$ & $\begin{array}{c}(4) \\
\text { Worked } \\
50+\text { weeks }\end{array}$ & $\begin{array}{c}(5) \\
\text { Log income } \\
\text { (1939 USD) }\end{array}$ & $\begin{array}{c}(6) \\
\text { Worked } \\
50+\text { weeks }\end{array}$ \\
\hline \multicolumn{7}{|c|}{ Panel A: Effects of in utero exposure to hurricanes } \\
\hline Hurricane in utero & $\begin{array}{c}0.057 \\
(0.126)\end{array}$ & $\begin{array}{c}-0.002 \\
(0.013)\end{array}$ & $\begin{array}{c}0.003 \\
(0.032)\end{array}$ & $\begin{array}{c}-0.045^{* *} \\
(0.019)\end{array}$ & $\begin{array}{c}-0.001 \\
(0.030)\end{array}$ & $\begin{array}{c}-0.046^{* *} \\
(0.019)\end{array}$ \\
\hline \multicolumn{7}{|c|}{ Panel B: Post-storm conception, in utero, or age 0 to 2 exposure to hurricanes } \\
\hline Post-storm conception & $\begin{array}{c}0.037 \\
(0.124)\end{array}$ & $\begin{array}{c}-0.001 \\
(0.011)\end{array}$ & $\begin{array}{c}0.023 \\
(0.024)\end{array}$ & $\begin{array}{c}0.023 \\
(0.018)\end{array}$ & $\begin{array}{c}0.019 \\
(0.023)\end{array}$ & $\begin{array}{c}0.022 \\
(0.017)\end{array}$ \\
\hline Hurricane in utero & $\begin{array}{c}0.077 \\
(0.129)\end{array}$ & $\begin{array}{c}0.002 \\
(0.013)\end{array}$ & $\begin{array}{c}0.007 \\
(0.033)\end{array}$ & $\begin{array}{c}-0.040^{* *} \\
(0.020)\end{array}$ & $\begin{array}{c}0.001 \\
(0.032)\end{array}$ & $\begin{array}{c}-0.041^{* *} \\
(0.020)\end{array}$ \\
\hline Hurricane age $[0,6]$ months & $\begin{array}{c}0.136 \\
(0.160)\end{array}$ & $\begin{array}{c}0.021 \\
(0.014)\end{array}$ & $\begin{array}{c}-0.010 \\
(0.041)\end{array}$ & $\begin{array}{c}-0.018 \\
(0.027)\end{array}$ & $\begin{array}{c}-0.018 \\
(0.039)\end{array}$ & $\begin{array}{c}-0.021 \\
(0.027)\end{array}$ \\
\hline Hurricane age $[7,12]$ months & $\begin{array}{c}-0.001 \\
(0.172)\end{array}$ & $\begin{array}{c}0.014 \\
(0.017)\end{array}$ & $\begin{array}{c}0.020 \\
(0.037)\end{array}$ & $\begin{array}{c}0.041^{*} \\
(0.022)\end{array}$ & $\begin{array}{c}0.023 \\
(0.035)\end{array}$ & $\begin{array}{c}0.040^{*} \\
(0.022)\end{array}$ \\
\hline Hurricane age $[1,2]$ & $\begin{array}{c}0.064 \\
(0.138)\end{array}$ & $\begin{array}{c}0.017 \\
(0.011)\end{array}$ & $\begin{array}{c}-0.004 \\
(0.028)\end{array}$ & $\begin{array}{c}-0.001 \\
(0.016)\end{array}$ & $\begin{array}{c}-0.009 \\
(0.027)\end{array}$ & $\begin{array}{c}-0.003 \\
(0.016)\end{array}$ \\
\hline Education controls & $\mathrm{No}$ & No & No & No & Yes & Yes \\
\hline Mean of $Y$ & 4.954 & 0.105 & 6.121 & 0.583 & 6.121 & 0.583 \\
\hline P-value (Equality of coefficients) & 0.950 & 0.625 & 0.892 & 0.007 & 0.823 & 0.007 \\
\hline $\mathrm{N}$ & \multicolumn{6}{|c|}{24107} \\
\hline
\end{tabular}

Note: This table reports results from specifications that are identical to those presented in Table 4, with the exception that the models are estimated on a sample of blacks instead of whites. See the notes to Table 4 for more details on the sample restrictions and controls. Standard errors are clustered at the county level. Point estimates marked $* * * *$, and * are statistically significant at the 1,5 , and 10 percent levels, respectively. 
Table O4: Effects of Hurricane Exposure on Farm Values

Pre- and post-exposure years

(1)

(2)

$[1880,1890]$

$[1890,1900]$

\begin{tabular}{lcc}
\hline Hurricane exposure & 0.175 & -0.773 \\
& $(2.731)$ & $(1.320)$ \\
\hline Mean of $\mathrm{Y}$ & 11.17 & 8.57 \\
$\mathrm{~N}$ & 184 & 210 \\
\hline
\end{tabular}

Note: This table reports estimates for the effects of hurricane exposure on average county-level farm values. Farm values are defined as per acre fair market values of farms, including land, fences, and buildings, and are obtained from the 1880, 1890 and 1900 Agricultural Censuses. The pre and post periods are 1880 and 1890 in column 1 , and 1890 and 1900 in column 2. The window of exposure to hurricanes is 1 to 2 years prior to the post period and the area of exposure is a 0 to 30 kilometer-radii band around the storm path. Each sample contains the set of counties within 100 kilometers of a hurricane path during the treatment period, while each specification includes an indicator for the post period and county fixed effects. We exclude counties with missing farm values in any of the census years. 
Table O5: Robustness - Restricting the Control Group to Pre-storm Births

\section{Control: Pre-storm births}

(1) (2)

Panel A: Effects of in utero exposure to hurricanes

\begin{tabular}{lcc} 
Hurricane in utero & $\begin{array}{c}-0.067^{* * *} \\
\text { Panel B: In utero or age } 0 \text { to } 2 \text { exposure to hurricanes }\end{array}$ & \begin{tabular}{c}
$-0.054^{* *}$ \\
\multicolumn{1}{c}{}
\end{tabular} \\
& $-0.078^{* * *}$ & $-0.064^{* * *}$ \\
Hurricane in utero & $(0.026)$ & $(0.024)$ \\
& -0.043 & $-0.047^{*}$ \\
Hurricane age [0,6] months & $(0.030)$ & $(0.025)$ \\
& -0.007 & 0.011 \\
Hurricane age [7,12] months & $(0.031)$ & $(0.028)$ \\
& -0.021 & -0.024 \\
Hurricane age [1,2] & $(0.024)$ & $(0.021)$ \\
& No & Yes \\
\hline Education controls & 6.909 & 6.909 \\
Mean of Y & & 36004 \\
$\mathrm{~N}$ & &
\end{tabular}

Note: This table presents results based on a sample which restricts attention to individuals born before a sample period hurricane and those exposed in utero. In comparison to the main specification, the indicator for post-storm conception is excluded from the estimation model given that it is always equal to zero in the restricted sample. All regressions include the same controls as the main specifications in column 3 of Table 4. Standard errors are clustered by county of birth. Point estimates marked $* * * \%$, and $*$ are statistically significant at the 1,5 , and 10 percent levels, respectively. 
Table O6: Robustness - Occupational Scores as Dependent Variable

\begin{tabular}{|c|c|c|c|c|c|}
\hline & $\begin{array}{c}\text { (1) } \\
\text { Occupational } \\
\text { income score }\end{array}$ & $\begin{array}{c}(2) \\
\text { Occupational } \\
\text { education score }\end{array}$ & $\begin{array}{c}\text { (3) } \\
\text { Occupational } \\
\text { earnings score }\end{array}$ & $\begin{array}{c}\text { (4) } \\
\text { Nam-Powers- } \\
\text {-Boyd score }\end{array}$ & $\begin{array}{c}(5) \\
\text { Occupational } \\
\text { log income }\end{array}$ \\
\hline \multicolumn{6}{|c|}{ Panel A: Effects of in utero exposure to hurricanes } \\
\hline Hurricane in utero & $\begin{array}{c}-0.463 \\
(0.320)\end{array}$ & $\begin{array}{r}-0.898^{*} \\
(0.484)\end{array}$ & $\begin{array}{r}-1.530^{*} \\
(0.830)\end{array}$ & $\begin{array}{r}-1.299^{*} \\
(0.778)\end{array}$ & $\begin{array}{c}-0.025^{* *} \\
(0.012)\end{array}$ \\
\hline \multicolumn{6}{|c|}{ Panel B: Post-storm conception, in utero, or age 0 to 2 exposure to hurricanes } \\
\hline Post-storm conception & $\begin{array}{c}0.392 \\
(0.296)\end{array}$ & $\begin{array}{c}0.278 \\
(0.379)\end{array}$ & $\begin{array}{c}1.014 \\
(0.763)\end{array}$ & $\begin{array}{c}0.841 \\
(0.658)\end{array}$ & $\begin{array}{c}0.003 \\
(0.012)\end{array}$ \\
\hline Hurricane in utero & $\begin{array}{c}-0.418 \\
(0.345)\end{array}$ & $\begin{array}{r}-0.949^{*} \\
(0.500)\end{array}$ & $\begin{array}{c}-1.443 \\
(0.893)\end{array}$ & $\begin{array}{c}-1.255 \\
(0.822)\end{array}$ & $\begin{array}{c}-0.027^{* *} \\
(0.013)\end{array}$ \\
\hline Hurricane age $[0,6]$ months & $\begin{array}{c}-0.629 \\
(0.432)\end{array}$ & $\begin{array}{c}-1.381^{* *} \\
(0.652)\end{array}$ & $\begin{array}{c}-1.483 \\
(1.106)\end{array}$ & $\begin{array}{c}-1.265 \\
(1.095)\end{array}$ & $\begin{array}{c}-0.027 \\
(0.019)\end{array}$ \\
\hline Hurricane age $[7,12]$ months & $\begin{array}{c}-0.149 \\
(0.458)\end{array}$ & $\begin{array}{c}-0.954 \\
(0.631)\end{array}$ & $\begin{array}{c}-0.285 \\
(1.240)\end{array}$ & $\begin{array}{c}-0.410 \\
(1.070)\end{array}$ & $\begin{array}{c}0.002 \\
(0.017)\end{array}$ \\
\hline Hurricane age $[1,2]$ years & $\begin{array}{c}0.403 \\
(0.321)\end{array}$ & $\begin{array}{c}0.584 \\
(0.468)\end{array}$ & $\begin{array}{c}0.608 \\
(0.753)\end{array}$ & $\begin{array}{c}0.364 \\
(0.686)\end{array}$ & $\begin{array}{c}-0.011 \\
(0.010)\end{array}$ \\
\hline Mean of $Y$ & 26.1 & 13.8 & 51.9 & 49.8 & 7.6 \\
\hline P-value (Equality of coefficients) & 0.070 & 0.016 & 0.061 & 0.139 & 0.289 \\
\hline $\mathrm{N}$ & \multicolumn{4}{|c|}{58593} & 56723 \\
\hline
\end{tabular}

Note: In columns 1 to 4, the dependent variables are measures of occupational status created by IPUMS (Ruggles et al. 2015). See Table 4 for details on the sample and controls, and the Online Appendix for a description of the dependent variables. In column 5, the dependent variable is an occupational income score computed by the authors based on average $1950 \mathrm{log}$ income by three-digit occupation code, for white males aged 42 to 53 in the 1 percent sample of the 1950 census (Ruggles et al. 2015). 1950 income includes wage and salary income, in addition to business, farm, and self-employment income. Standard errors are clustered at the birth county level. Point estimates marked $* * * ; *$, and $*$ are statistically significant at the 1,5 , and 10 percent levels, respectively. 
Table O7: Robustness to Trimming Tails of Income Distribution

\begin{tabular}{|c|c|c|c|c|c|c|}
\hline & $\begin{array}{l}(1) \\
\text { Bot } \\
5 \%\end{array}$ & $\begin{array}{l}(2) \\
\text { Bot } \\
10 \%\end{array}$ & $\begin{array}{l}(3) \\
\text { Top } \\
5 \%\end{array}$ & $\begin{array}{l}(4) \\
\text { Top } \\
10 \%\end{array}$ & $\begin{array}{c}(5) \\
\text { Bot/Top } \\
5 \%\end{array}$ & $\begin{array}{c}(6) \\
\text { Bot/Top } \\
10 \%\end{array}$ \\
\hline \multicolumn{7}{|c|}{ Panel A: Effects of in utero exposure to hurricanes } \\
\hline Hurricane in utero & $\begin{array}{c}-0.048^{* *} \\
(0.022)\end{array}$ & $\begin{array}{c}-0.054^{* * *} \\
(0.019)\end{array}$ & $\begin{array}{c}-0.059^{* * *} \\
(0.022)\end{array}$ & $\begin{array}{c}-0.064^{* * *} \\
(0.020)\end{array}$ & $\begin{array}{c}-0.033 \\
(0.022)\end{array}$ & $\begin{array}{c}-0.041^{* *} \\
(0.017)\end{array}$ \\
\hline \multicolumn{7}{|c|}{ Panel B: Post-storm conception, in utero, or age 0 to 2 exposure to hurricanes } \\
\hline Post-storm conception & $\begin{array}{c}0.023 \\
(0.016)\end{array}$ & $\begin{array}{c}0.021 \\
(0.015)\end{array}$ & $\begin{array}{c}0.019 \\
(0.019)\end{array}$ & $\begin{array}{c}0.022 \\
(0.019)\end{array}$ & $\begin{array}{c}0.019 \\
(0.016)\end{array}$ & $\begin{array}{c}0.020 \\
(0.014)\end{array}$ \\
\hline Hurricane in utero & $\begin{array}{c}-0.049^{* *} \\
(0.023)\end{array}$ & $\begin{array}{c}-0.054^{* * *} \\
(0.020)\end{array}$ & $\begin{array}{c}-0.061^{* * *} \\
(0.022)\end{array}$ & $\begin{array}{c}-0.065^{* * *} \\
(0.021)\end{array}$ & $\begin{array}{c}-0.033 \\
(0.023)\end{array}$ & $\begin{array}{c}-0.040^{* *} \\
(0.017)\end{array}$ \\
\hline Hurricane age $[0,6]$ months & $\begin{array}{r}-0.047 \\
(0.029)\end{array}$ & $\begin{array}{r}-0.041^{*} \\
(0.023)\end{array}$ & $\begin{array}{c}-0.055^{* *} \\
(0.026)\end{array}$ & $\begin{array}{c}-0.032 \\
(0.024)\end{array}$ & $\begin{array}{c}-0.051^{* *} \\
(0.024)\end{array}$ & $\begin{array}{c}-0.022 \\
(0.019)\end{array}$ \\
\hline Hurricane age $[7,12]$ months & $\begin{array}{r}-0.005 \\
(0.023)\end{array}$ & $\begin{array}{r}-0.004 \\
(0.022)\end{array}$ & $\begin{array}{r}-0.006 \\
(0.028)\end{array}$ & $\begin{array}{r}-0.008 \\
(0.027)\end{array}$ & $\begin{array}{c}-0.000 \\
(0.022)\end{array}$ & $\begin{array}{c}0.000 \\
(0.018)\end{array}$ \\
\hline Hurricane age $[1,2]$ & $\begin{array}{r}-0.003 \\
(0.018)\end{array}$ & $\begin{array}{r}-0.002 \\
(0.016)\end{array}$ & $\begin{array}{r}-0.010 \\
(0.021)\end{array}$ & $\begin{array}{r}-0.014 \\
(0.019)\end{array}$ & $\begin{array}{c}0.003 \\
(0.018)\end{array}$ & $\begin{array}{c}0.003 \\
(0.016)\end{array}$ \\
\hline Education controls & No & No & No & No & No & No \\
\hline Mean of Y & 7.010 & 7.079 & 6.829 & 6.764 & 6.933 & 6.940 \\
\hline P-value (Equality of coefficients) & 0.028 & 0.007 & 0.040 & 0.023 & 0.046 & 0.016 \\
\hline $\mathrm{N}$ & 55871 & 52947 & 55909 & 52967 & 52929 & 47063 \\
\hline
\end{tabular}

Note: This table reports results from estimating the specification shown in column 3 of Table 4, with different sample restrictions. Each column excludes a group of observation in the tails of the sample income distribution: the bottom 5 percent (column 1), the bottom 10 percent (column 2), the top 5 percent (column 3), the top 10 percent (column 4), the top and bottom 5 percent (column 5), and the top and bottom 10 percent (column 6). See Table 4 for details on the sample and controls. Standard errors are clustered at the birth county level. Point estimates marked $* *, * *$, and $*$ are statistically significant at the 1,5 , and 10 percent levels, respectively. 
Table O8: Robustness to Restrictions on Range of Conception Years

\begin{tabular}{|c|c|c|c|c|c|c|}
\hline & \multicolumn{3}{|c|}{ Range of conception years in sample } & \multicolumn{3}{|c|}{ Birth (b) or conception (c) years dropped } \\
\hline & $\begin{array}{c}(1) \\
1886-1888\end{array}$ & $\begin{array}{c}(2) \\
1889-1891\end{array}$ & $\begin{array}{c}(3) \\
1892-1896\end{array}$ & $\begin{array}{c}(4) \\
\mathrm{c} 1889-1891\end{array}$ & $\begin{array}{c}(5) \\
\text { b1891-1892 }\end{array}$ & $\begin{array}{c}(6) \\
\text { b1896-1897 }\end{array}$ \\
\hline \multicolumn{7}{|c|}{ Panel A: Effects of in utero exposure to hurricanes } \\
\hline Hurricane in utero & $\begin{array}{c}-0.027 \\
(0.040)\end{array}$ & $\begin{array}{c}-0.087 \\
(0.111)\end{array}$ & $\begin{array}{c}-0.073^{* * *} \\
(0.027)\end{array}$ & $\begin{array}{c}-0.071^{* * *} \\
(0.022)\end{array}$ & $\begin{array}{c}-0.072^{* * *} \\
(0.021)\end{array}$ & $\begin{array}{c}-0.053^{* *} \\
(0.026)\end{array}$ \\
\hline \multicolumn{7}{|c|}{ Panel B: Post-storm conception, in utero, or age 0 to 2 exposure to hurricanes } \\
\hline Post-storm conception & $\begin{array}{c}-0.043 \\
(0.054)\end{array}$ & $\begin{array}{c}0.056 \\
(0.044)\end{array}$ & $\begin{array}{c}0.037 \\
(0.027)\end{array}$ & $\begin{array}{c}0.017 \\
(0.022)\end{array}$ & $\begin{array}{c}0.025 \\
(0.020)\end{array}$ & $\begin{array}{c}0.022 \\
(0.021)\end{array}$ \\
\hline Hurricane in utero & $\begin{array}{c}-0.125^{* *} \\
(0.060)\end{array}$ & $\begin{array}{c}-0.064 \\
(0.119)\end{array}$ & $\begin{array}{c}-0.067^{* *} \\
(0.030)\end{array}$ & $\begin{array}{c}-0.077^{* * *} \\
(0.023)\end{array}$ & $\begin{array}{c}-0.076^{* * *} \\
(0.022)\end{array}$ & $\begin{array}{c}-0.055^{* *} \\
(0.026)\end{array}$ \\
\hline Hurricane age $[0,6]$ months & $\begin{array}{c}-0.191^{* *} \\
(0.081)\end{array}$ & $\begin{array}{c}-0.024 \\
(0.048)\end{array}$ & $\begin{array}{c}-0.027 \\
(0.035)\end{array}$ & $\begin{array}{c}-0.055^{* *} \\
(0.027)\end{array}$ & $\begin{array}{c}-0.052^{* *} \\
(0.027)\end{array}$ & $\begin{array}{c}-0.047 \\
(0.032)\end{array}$ \\
\hline Hurricane age $[7,12]$ months & $\begin{array}{r}-0.148^{*} \\
(0.080)\end{array}$ & $\begin{array}{c}0.065 \\
(0.113)\end{array}$ & $\begin{array}{c}0.015 \\
(0.034)\end{array}$ & $\begin{array}{c}-0.015 \\
(0.031)\end{array}$ & $\begin{array}{c}-0.012 \\
(0.029)\end{array}$ & $\begin{array}{c}-0.006 \\
(0.027)\end{array}$ \\
\hline Hurricane age $[1,2]$ & $\begin{array}{r}-0.159^{*} \\
(0.083)\end{array}$ & $\begin{array}{c}0.028 \\
(0.033)\end{array}$ & $\begin{array}{c}-0.011 \\
(0.035)\end{array}$ & $\begin{array}{c}-0.038 \\
(0.030)\end{array}$ & $\begin{array}{r}-0.047^{*} \\
(0.025)\end{array}$ & $\begin{array}{c}-0.016 \\
(0.023)\end{array}$ \\
\hline Mean of $Y$ & 6.873 & 6.912 & 6.918 & 6.905 & 6.905 & 6.909 \\
\hline P-value (Equality of coefficients) & 0.380 & 0.351 & 0.033 & 0.019 & 0.004 & 0.088 \\
\hline $\mathrm{N}$ & 13029 & 15982 & 29840 & 42869 & 53546 & 51129 \\
\hline
\end{tabular}

Note: This table reports results from estimating the specification shown in column 3 of Table 4, with different sample restrictions. The first three columns split the sample into three groups based on the range of conception years: 1886 to 1888,1889 to 1891 , and 1892 to 1896 , respectively. Columns 4 to 6 drop selective cohorts from the sample: the 1889 to 1891 conception years, births between 15 April 1891 and 15 April 1892, and births after 16 April 1896, respectively. See Table 4 for details on the sample and controls. Standard errors are clustered at the birth county level. Point estimates marked $* * * *$, and $*$ are statistically significant at the 1,5 , and 10 percent levels, respectively. 
Table O9: Robustness to Dropping Individuals Employed in Agriculture

\begin{tabular}{|c|c|c|c|c|c|c|}
\hline & $\begin{array}{c}\text { (1) } \\
\text { Years of } \\
\text { education }\end{array}$ & $\begin{array}{c}(2) \\
\text { Middle school } \\
\text { graduation }\end{array}$ & $\begin{array}{c}(3) \\
\text { Log income } \\
\text { (1939 USD) }\end{array}$ & $\begin{array}{c}(4) \\
\text { Worked } \\
50+\text { weeks }\end{array}$ & $\begin{array}{c}(5) \\
\text { Log income } \\
\text { (1939 USD) }\end{array}$ & $\begin{array}{c}(6) \\
\text { Worked } \\
50+\text { weeks }\end{array}$ \\
\hline \multicolumn{7}{|c|}{ Panel A: Effects of in utero exposure to hurricanes } \\
\hline Hurricane in utero & $\begin{array}{c}-0.055 \\
(0.115)\end{array}$ & $\begin{array}{c}-0.023 \\
(0.017)\end{array}$ & $\begin{array}{c}-0.052^{* *} \\
(0.024)\end{array}$ & $\begin{array}{c}-0.015 \\
(0.017) \\
\end{array}$ & $\begin{array}{c}-0.048^{* *} \\
(0.023)\end{array}$ & $\begin{array}{c}-0.013 \\
(0.016)\end{array}$ \\
\hline \multicolumn{7}{|c|}{ Panel B: Post-storm conception, in utero, or age 0 to 2 exposure to hurricanes } \\
\hline Post-storm conception & $\begin{array}{c}0.014 \\
(0.109)\end{array}$ & $\begin{array}{c}0.011 \\
(0.013)\end{array}$ & $\begin{array}{c}0.011 \\
(0.022)\end{array}$ & $\begin{array}{c}-0.006 \\
(0.014)\end{array}$ & $\begin{array}{c}0.013 \\
(0.019)\end{array}$ & $\begin{array}{c}-0.005 \\
(0.013)\end{array}$ \\
\hline Hurricane in utero & $\begin{array}{c}-0.079 \\
(0.123)\end{array}$ & $\begin{array}{c}-0.024 \\
(0.017)\end{array}$ & $\begin{array}{c}-0.058^{* *} \\
(0.024)\end{array}$ & $\begin{array}{c}-0.019 \\
(0.017)\end{array}$ & $\begin{array}{c}-0.051^{* *} \\
(0.023)\end{array}$ & $\begin{array}{c}-0.016 \\
(0.016)\end{array}$ \\
\hline Hurricane age $[0,6]$ months & $\begin{array}{c}-0.154 \\
(0.151)\end{array}$ & $\begin{array}{c}-0.022 \\
(0.022)\end{array}$ & $\begin{array}{c}-0.067^{* *} \\
(0.031)\end{array}$ & $\begin{array}{c}-0.027 \\
(0.017)\end{array}$ & $\begin{array}{c}-0.054^{* *} \\
(0.026)\end{array}$ & $\begin{array}{c}-0.023 \\
(0.016)\end{array}$ \\
\hline Hurricane age $[7,12]$ months & $\begin{array}{r}-0.289^{*} \\
(0.171)\end{array}$ & $\begin{array}{c}-0.023 \\
(0.021)\end{array}$ & $\begin{array}{c}-0.027 \\
(0.029)\end{array}$ & $\begin{array}{c}-0.006 \\
(0.018)\end{array}$ & $\begin{array}{c}-0.002 \\
(0.028)\end{array}$ & $\begin{array}{c}0.001 \\
(0.017)\end{array}$ \\
\hline Hurricane age $[1,2]$ & $\begin{array}{c}0.033 \\
(0.112)\end{array}$ & $\begin{array}{c}0.009 \\
(0.015)\end{array}$ & $\begin{array}{c}-0.008 \\
(0.024)\end{array}$ & $\begin{array}{c}-0.008 \\
(0.015)\end{array}$ & $\begin{array}{c}-0.010 \\
(0.023)\end{array}$ & $\begin{array}{c}-0.008 \\
(0.015)\end{array}$ \\
\hline Education controls & No & No & No & No & Yes & Yes \\
\hline Mean of Y & 8.508 & 0.422 & 7.070 & 0.712 & 7.070 & 0.712 \\
\hline P-value (Equality of coefficients) & 0.344 & 0.119 & 0.134 & 0.789 & 0.165 & 0.790 \\
\hline $\mathrm{N}$ & \multicolumn{6}{|c|}{45032} \\
\hline
\end{tabular}

Note: Each specification drops individuals working in the agricultural sector, which we identify based on 1950 IPUMS occupational codes which are assigned to individuals in the 1940 census. We define individuals in the agricultural sector as having a 1950 occupational code of 100 (farmers, owners and tenants), a 1950 industry code of 105 (agriculture), or a Duncan Socioeconomic Index value of 14 (farmers, owners and tenants). See Table 4 for details on the sample and controls. Standard errors are clustered at the birth county level. Point estimates marked $* * * *$, and $*$ are statistically significant at the 1,5 , and 10 percent levels, respectively. 


\section{Online Appendix Figures}

Figure O1: Kernel Density Plot for Log of Total Income by Exposure Status

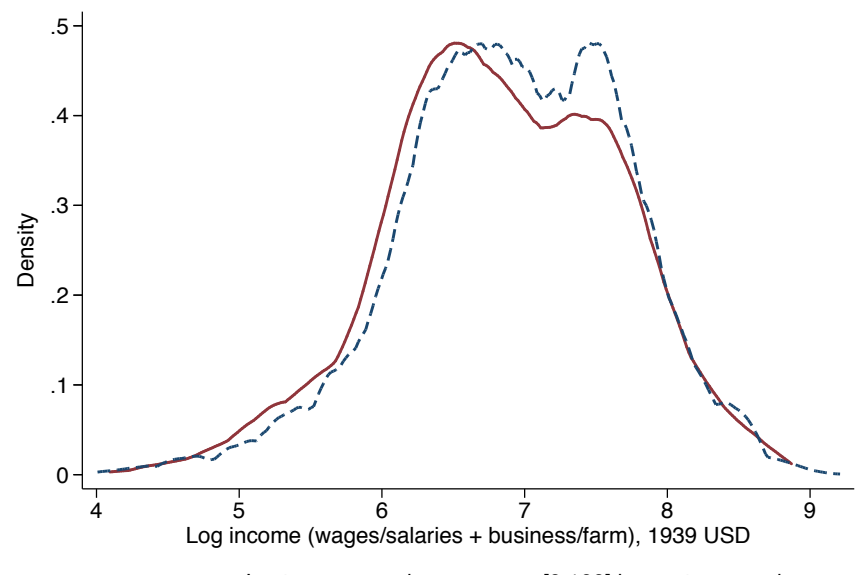

Note: This figure shows kernel density plots for the log of total income (1939 USD) produced using the Epanechnikov kernel function. The solid red line depicts the kernel density plot for individuals in the main estimation sample who were exposed in utero to a hurricane. The dashed blue line represents the kernel density plot for individuals born within 100 kilometers of a hurricane that hit the birth location during the sample period who were not exposed to a storm. That is, the sub-sample excludes individuals born within 30 kilometers of a hurricane who were exposed to the storm in utero or between birth and age two, or were conceived up to one year after the storm. Total income combines reported wage and salary income, in addition to estimated business, farm, and self-employment income. Both measures are truncated at $\$ 5000$ (1939 USD). For clarity, the figure excludes a handful of observations with income below $\$ 50$.

Figure O2: Observations Exposed In Utero

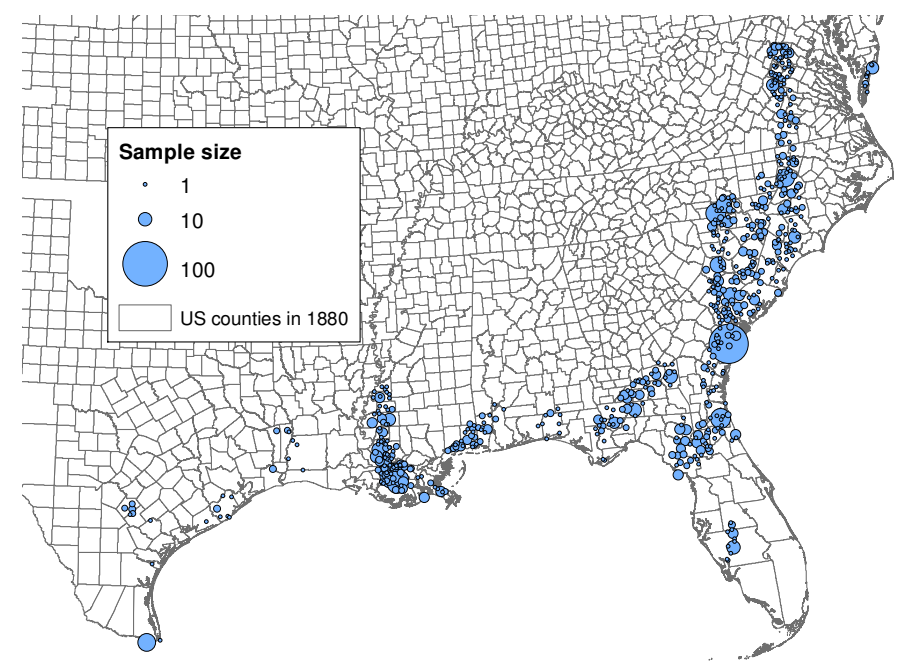

Note: This figure plots the latitude and longitude coordinates of the city or town of birth for individuals exposed in utero to hurricanes that hit the continental U.S. between 1886 and 1897, where birth locations are defined as exposed if they are within 30 kilometers of the hurricane path. The coordinates (shown in blue) are overlayed on a map of U.S. county boundaries for 1880 and the diameter of the circles is proportional to the number of observations at each location. The sample consists of all U.S.-born white males satisfying the restrictions described in Table 4. Sources: Minnesota Population Center (2011) for boundary file; authors' calculations based on WWI Draft Registration Cards (n.d.) and U.S. Geological Survey (2014) for coordinates. 
Figure O3: Effects of Age 0 to 6 Month Exposure on Income, Dropping Storms One-by-one

(a) Ignoring Exposure from Dropped Storm

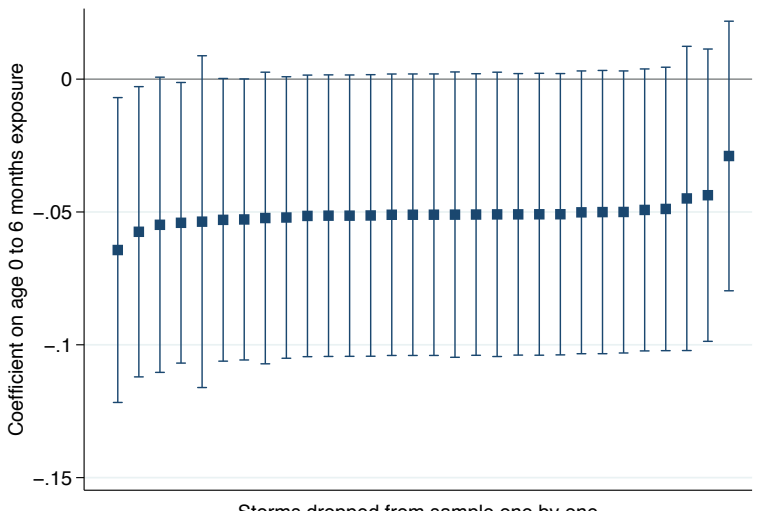

(b) Keeping Exposure from Dropped Storm

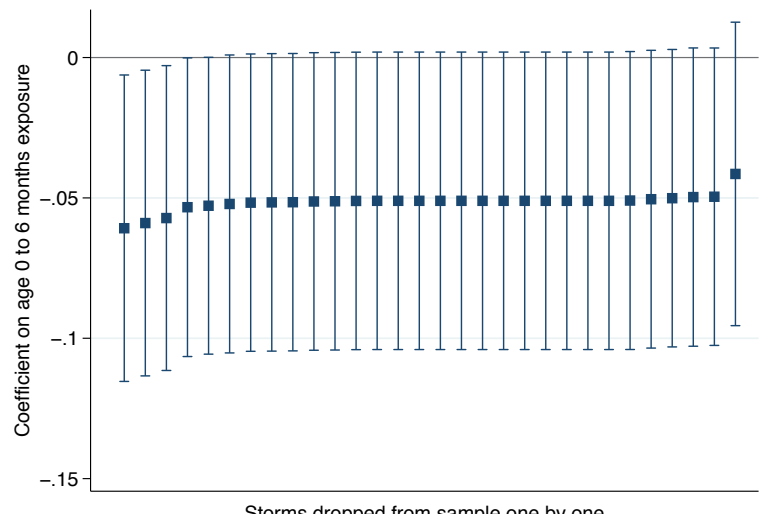

Note: Each line in the figure represents a 95-percent confidence interval, while the square marker denotes the point estimate, for the effect of age 0 to 6 exposure to hurricanes on the log of total income, from estimating Equation 2 by dropping one storm at a time from the sample. The lines are ordered by the size of the age 0 to 6 month exposure coefficients. We follow two procedures for dropping storms to deal with individuals exposed to multiple storms: ignoring exposure to the dropped storms (Figure O3a) and accounting for exposure to dropped storms when individuals were exposed to multiple storms (Figure O3b). In either case, individuals born in locations within 100 kilometers of multiple hurricanes remain in the sample. Twelve of the estimates in Figure O3b are identical to the main estimates in column 3 and Panel B of Table 4 , given that the set of birth locations within 100 kilometers of some hurricane paths are a subset of birth locations within 100 kilometers of other storms, and thus no observations are dropped from the sample. Each specification includes the same controls as panel B of Table 4. Standard errors are clustered by county of birth. 